\author{
UNIVERSIDADE DE SÃO PAULO \\ ESCOLA DE ENGENHARIA DE SÃO CARLOS \\ ÁREA DE PÓS-GRADUAÇÃO EM ENGENHARIA MECÂNICA
}

\title{
METODOLOGIA DE ANÁLISE MODAL DE FLUTTER COM SENSORES PIEZELÉTRICOS EM ESTRUTURAS AERONÁUTICAS
}

\author{
ALEXANDRE SIMÕES DE ALMEIDA
}

Dissertação apresentada à Escola de Engenharia de São Carlos, da Universidade de São Paulo, como requisito parcial para a obtenção do título de Mestre em Engenharia Mecânica.

Orientador: Prof. Assoc. Flávio Donizeti Marques

\section{SÃO CARLOS}



Dissertação apresentada à Escola de Engenharia de São Carlos, da Universidade de São Paulo, como requisito parcial para a obtenção do título de Mestre em Engenharia Mecânica.

Orientador: Prof. Assoc. Flávio Donizeti Marques

ESTE EXEMPLAR TRATA-SE
DA VERSÃO CORRIGIDA.
A VERSÃO ORIGINAL
ENCONTRA-SE DISPONIIVEL
JUNTO AO DEPARTAMETO DE
ENGENHARIA MECÂNICA DA
EESC-SP

\section{SÃO CARLOS}


AUTORIZO A REPRODUÇÃO TOTAL OU PARCIAL DESTE TRABALHO, POR QUALQUER MEIO CONVENCIONAL OU ELETRÔNICO, PARA FINS DE ESTUDO E PESQUISA, DESDE QUE CITADA A FONTE.

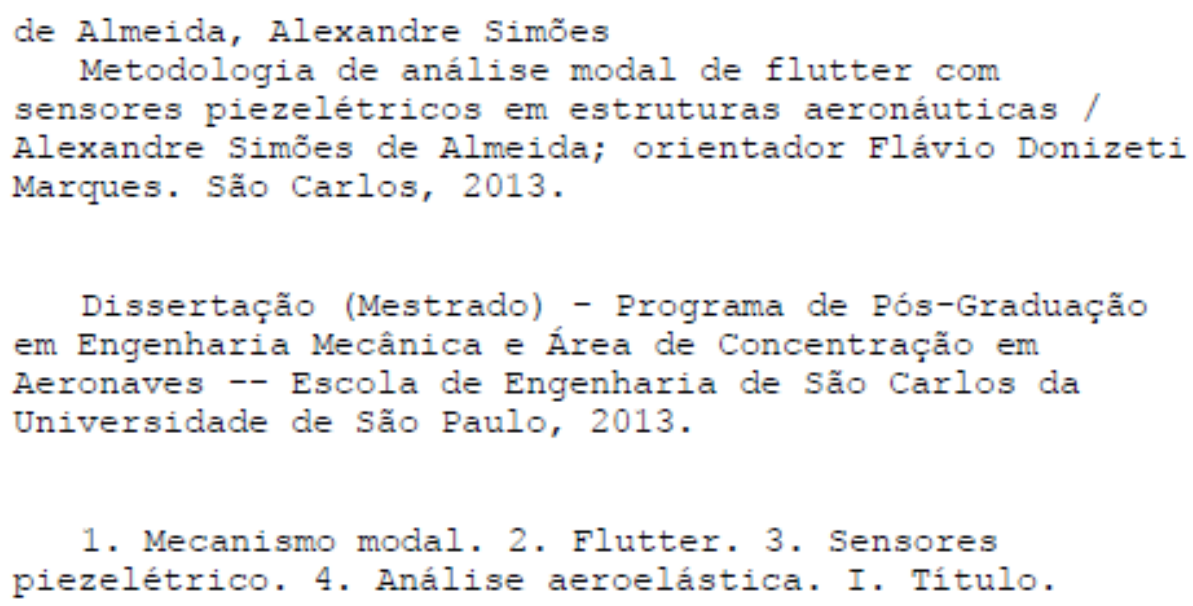

1. Mecanismo modal. 2. Flutter. 3. Sensores piezelétrico. 4. Análise aeroelástica. I. Título. 
Candidato: Engenheiro ALEXANDRE SIMÕES DE ALMEIDA.

Título da dissertação: "Metodologia e análise modal de flutter com sensores piezelétricos em estruturas aeronáuticas".

Data da defesa: 29/11/2013

\section{Comissão Julgadora:}

Prof. Associado Flávio Donizeti Marques(Orientador)

(Escola de Engenharia de São Carlos/EESC)

Prof. Associado Volnei Tita

(Escola de Engenharia de São Carlos/EESC)

Prof. Dr. Roberto Gil Annes da Silva

(Instituto Tecnológico 'de Aeronáutica/ITA)
Resultado:
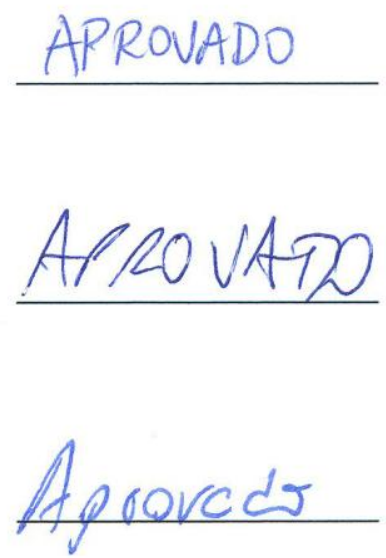

Coordenador do Programa de Pós-Graduação em Engenharia Mecânica:

Prof. Associado Marcelo Areias Trindade

Presidente da Comissão de Pós-Graduação:

Prof. Titular Denis Vinicius Coury 



\section{AGRADECIMENTOS}

Agradeço a realização desse trabalho ao meu orientador Flávio Donizeti Marques pelo apoio, aprendizado e compreensão durante meu período de mestrado. Também agradeço a ele a enorme oportunidade concedida de compor trabalhos além deste.

Agradeço a CAPES pelo apoio em forma de bolsa (processo 00011/07-0) e pelo apoio das agências brasileiras de pesquisas CNPq e INCT-EIE.

Agradeço à USP e ao Departamento de Engenharia Aeronáutica de São Carlos pelo fornecimento de infra-estrutura aos trabalhos desenvolvidos.

Agradeço aos colegas e funcionários que contribuíram com conhecimento e companheirismo em todos os momentos. Também agradeço a eles pelos diveros momentos de descontração e pela amizade desenvolvida, o que guardo para o resto da vida.

Agradeço ao professor Volnei Tita pelo apoio e aprendizado fornecido, especialmente no momento da minha chegada ao departamento.

Agradeço ao professor Hernan Dario Ceron Munhoz pelo apoio e amizade desenvolvidos ao longo do trabalho.

Agradeço a minha família pela cumplicidade e apoio em todos os momentos de dificuldade. 


\section{SUMÁRIO}

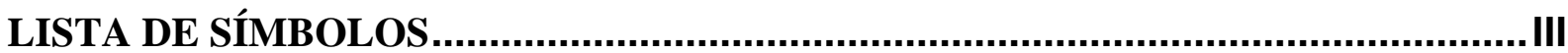

SÍMBOLOS GREGOS ............................................................................. V

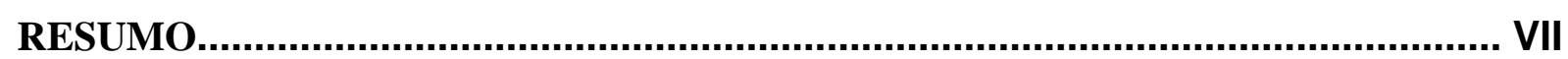

ABSTRACT ................................................................................................. VII

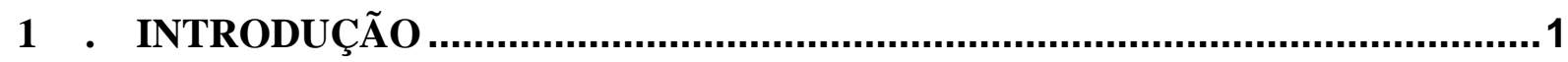

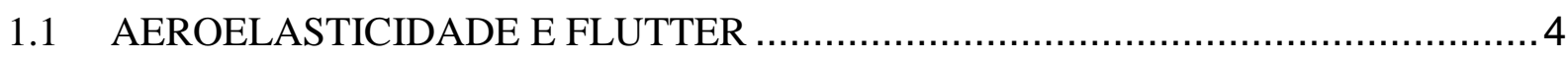

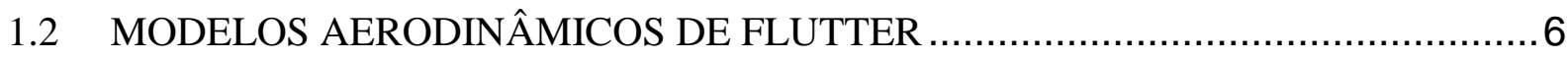

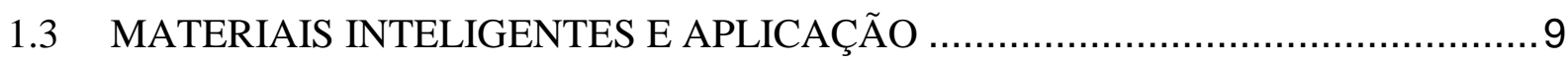

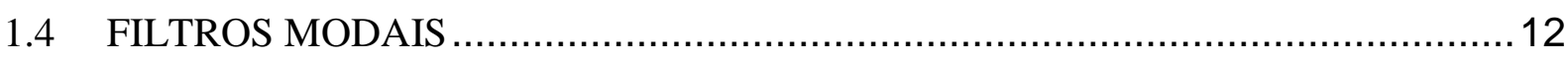

1.5 FLUTTER EM ESTRUTURAS DE MATERIAL COMPÓSITO ….........................14

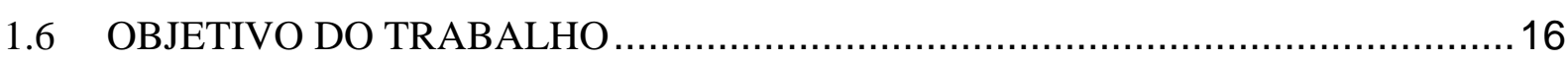

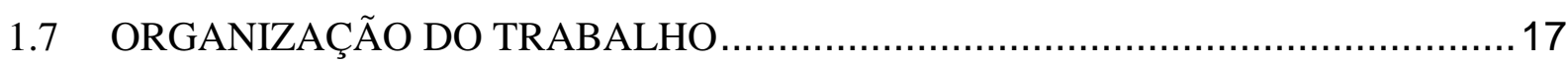

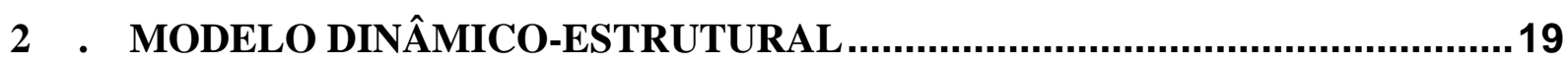

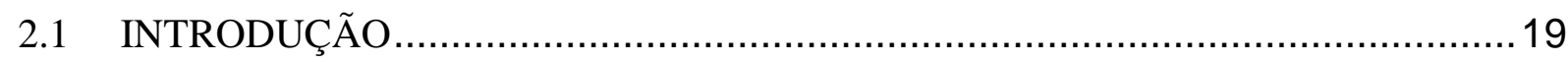

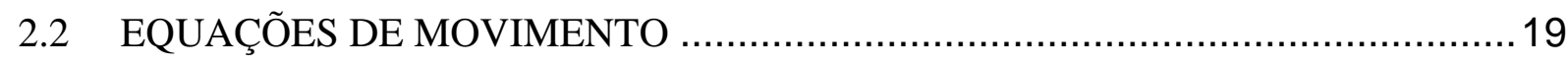

2.3 CARACTERIZAÇÃO DO MATERIAL PIEZELÉTRICO.....................................23

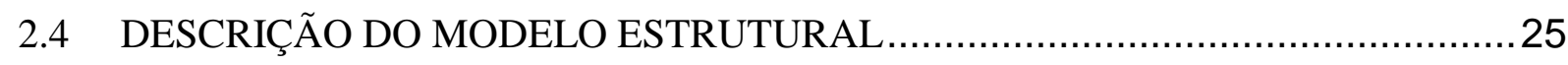

2.5 VALIDAÇÃO DO MODELO ESTRUTURAL ................................................ 32

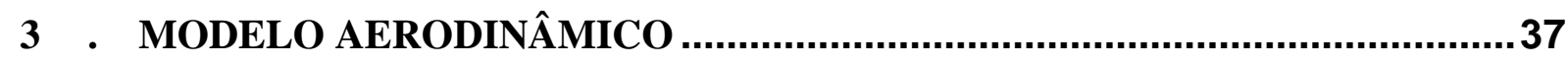

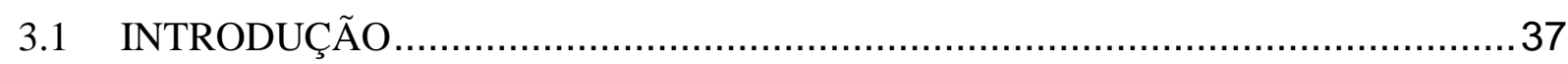

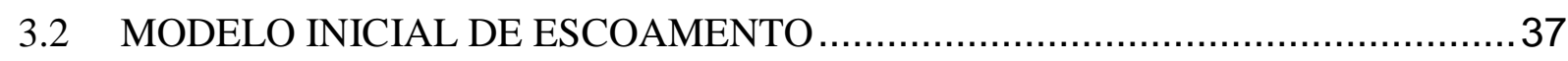

3.3 REPRESENTAÇÃO GEOMÉTRICA DO AEROFÓLIO....................................... 40

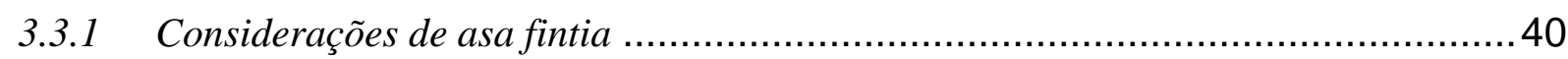

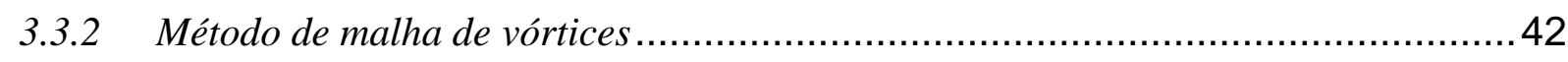

3.4 MODELO AERODINÂMICO FINAL: NÃO - ESTACIONÁRIO …...................... 44

4 . ANÁLISE AEROELÁSTICA E RESULTADOS ........................................51

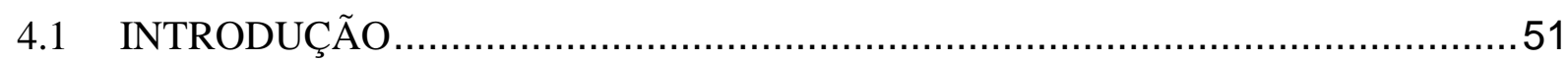

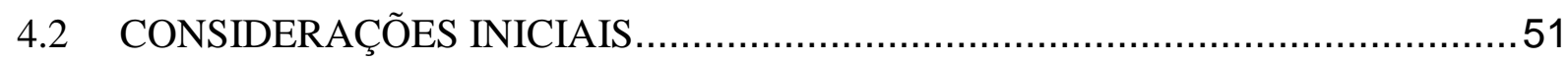

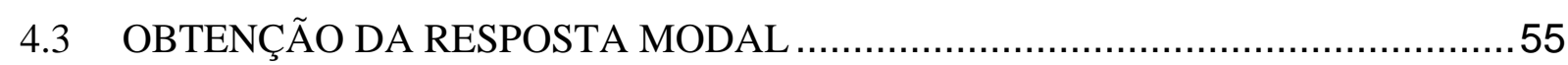

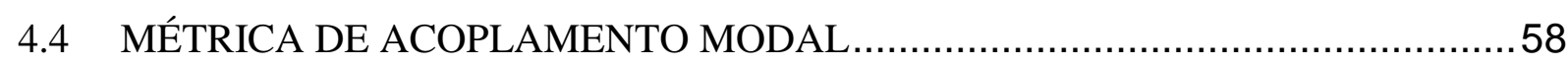

4.5 DETERMINAÇÃO DA VELOCIDADE DE FLUTTER........................................60

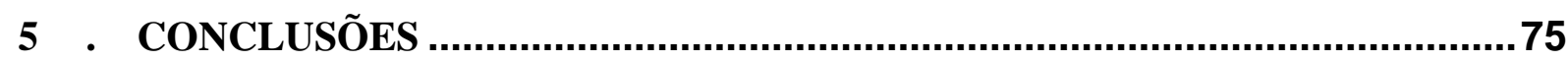




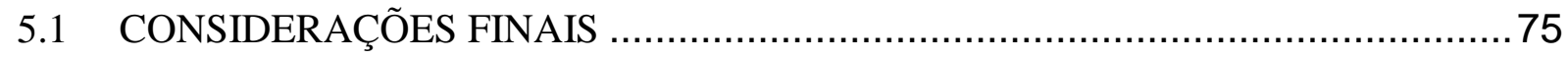

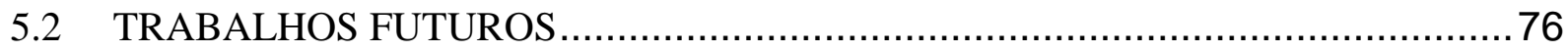

REFERÊNCIAS BIBLIOGRÁFICAS .................................................................... 78 


\section{LISTA DE SÍMBOLOS}

$a$

coeficiente de influência;

$C_{11} \quad$ coeficiente de rigidez elástica devido ao carregamento aplicado na direção 1 e deformação resultante na direção 1 ;

$C_{12} \quad$ coeficiente de rigidez elástica devido ao carregamento aplicado na direção $1 \mathrm{e}$ deformação resultante na direção 2;

$C_{13} \quad$ coeficiente de rigidez elástica devido ao carregamento aplicado na direção $1 \mathrm{e}$ deformação resultante na direção 3;

$C_{22} \quad$ coeficiente de rigidez elástica devido ao carregamento aplicado na direção 2 e deformação resultante na direção 2;

$C_{33} \quad$ coeficiente de rigidez elástica devido ao carregamento aplicado na direção 3 e deformação resultante na direção 3;

$C_{44}, C_{55}, C_{66} \quad$ coeficientes de rigidez elástica transversal;

$D_{i} \quad$ fluxo elétrico na direção principal “i”;

$e \quad$ número de Euler;

$e_{i j} \quad$ coeficiente de acoplamento eletromecânico devido a tensão elétrica aplicada na direção “i” e deformção mecânica resultante na direção “j” ;

E campo elétrico;

$E_{i} \quad$ campo elétrico na direção principal “i”;

$E_{i j} \quad$ módulo de Young devido a tensão mecânica aplicada na direção “i” e deformação na direção “j”;

$g_{i}(\omega)$ amplitude do modo de vibrar "i”" em função da freqüência;

$G_{i j} \quad$ módulo de elasticidade transversal;

$[G]$ matriz de mudança de sistema de coordenadas;

j constante do domínio complexo $(\sqrt{-1})$; 
$[K] \quad$ matriz de rigidez estrutural;

$[\bar{K}] \quad$ matriz de rigidez modal;

L força de sustentação aerodinâmica;

$\vec{L} \quad$ vetor do carregamento aerodinâmico;

$\{L\}_{a} \quad$ carregamento aerodinâmico no sistema de coordenadas da malha aerodinâmica;

$\{L\}_{e} \quad$ carregamento aerodinâmico no sistema de coordenadas da malha estrutural;

[M] matriz de massa;

$[\bar{M}] \quad$ matriz de massa modal;

$\vec{n}_{1}, \vec{n}_{j} \quad$ vetor normal na direção 1, ou direção “j””;

$p_{1}, p_{2}$ pressão estática no ponto 1 ou 2 da linha de corrente considerada;

$\vec{r} \quad$ vetor que define a posição de um ponto em relação a determinado ponto do segmento de vórtice;

$\vec{r}_{1}, \vec{r}_{2} \quad$ vetor ligando a extremidade 1 ou 2 de um segmento de vórtice reto a um ponto considerado;

$\vec{R}_{0} \quad$ vetor que descreve a posição de origem do sistema de coordenadas fixo no corpo em relação ao sistema inercial;

s constante de flexibilidade;

S deformação mecânica;

$S_{i j} \quad$ deformação mecânica;

$S_{p} \quad$ área de um painel da asa;

t tempo;

$\mathrm{T}$ tensão mecância;

$T_{i j} \quad$ tensão mecânica;

$u \quad$ componente da velocidade do escoamento na direção " $\mathrm{x}$ ";

$v \quad$ componente da velocidade do escoamento na direção " $\mathrm{y}$ ";

$\vec{v} \quad$ velocidade devido ao movimento da asa;

$\vec{v}_{k} \quad$ velocidade na esteira da asa; 
$\vec{v}_{r e l} \quad$ velocidade da asa em relação ao sistema de coordenadas fixo no corpo;

$V_{1}, V_{2}$ velocidade do escoamento nos pontos 1 ou 2 da linha de corrente considerada;

$\vec{V} \quad$ velocidade local induzida;

$\vec{V}_{0} \quad$ velocidade da origem do sistema de coordenadas fixo ao corpo;

$\vec{V}_{n} \quad$ velocidade normal ao escoamento;

$\vec{V}_{\infty} \quad$ velocidade do fluxo livre de perturbação;

$x \quad$ deslocamento sofrido pela estrutura;

$\dot{x} \quad$ velocidade sofrida pela estrutura;

$\ddot{x} \quad$ aceleração sofrida pela estrutura;

$\vec{w} \quad$ vetor velocidade induzida pelos vórtices;

\section{SÍMBOLOS GREGOS}

$\alpha \quad$ ângulo de atque;

$\varepsilon \quad$ constante dielétrica do meterial;

$\varepsilon_{i} \quad$ deformação elástica na direção "i”;

$\varepsilon_{i j} \quad$ constante dielétrica devido ao fluxo elétrico na direção "i" e campo elétrico na direção “j”;

$\phi \quad$ potencial de velocidades;

$[\phi] \quad$ matriz modal da estrutura;

$[\phi]_{e} \quad$ matriz modal no sistema de coordenadas da malha estrutural;

$\gamma_{i} \quad$ deformação angular;

$\eta \quad$ deslocamento no domínio modal da estrutura;

$\ddot{\eta} \quad$ aceleração no domínio modal da estrutura;

$v_{i j} \quad$ coeficiente de Poisson cuja deformação na direção "i” gera deformação na direção “j”; 


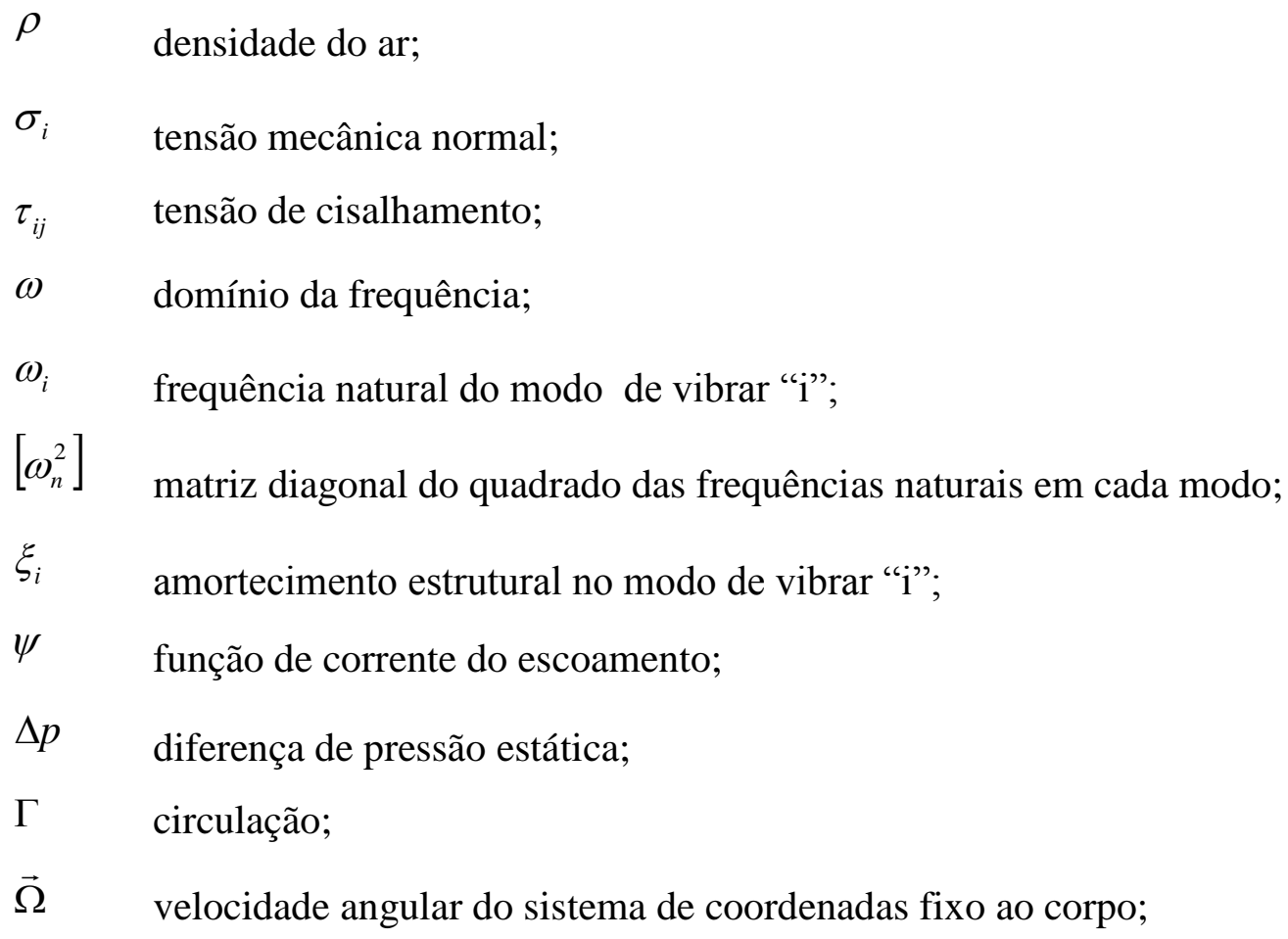




\section{RESUMO}

ALMEIDA, A.S. (2013). Metodologia de análise modal de flutter com sensores piezelétricos em estruturas aeronáuticas. São Carlos. 88p. Dissertação (Mestrado) - Escola de Engenharia de São Carlos, Universidade de São Paulo.

A identificação de mecanismos modais é uma tarefa que requer um grande esforço ao se considerar geometrias complexas. O uso de materiais inteligentes como tecnologia nesse tipo de identificação vem sendo bastante difundido, principalmente o uso de sensores piezelétricos, como o piezo-fiber composite (PFC). Esse tipo de aplicação pode se tornar uma ferramenta bastante prática no estudo de instabilidades aeroelásticas, em especial o mecanismo modal de flutter. A proposta desse trabalho é criar uma metodologia de análise de flutter simulando o desempenho de materiais piezelétricos, aderidos em laminados compóstios, como sensores modais. Inicialmente, é realizada uma análise aeroelástica da estrutura para se identificar o mecanismo e os modos dominantes para o surgimento do flutter. Em seguida, os modos identificados são detectados pelos sensores com uma determinada potência de sinal. A sensibilidade desse sinal é avaliada de acordo com a posição e configuração do laminado embebido no sensor. Para realizar essa simulação, um modelo de asa é gerado e suas freqüências naturais e modos são determinados pelo método dos elementos finitos (MEF). Com esses dados, é possível caracterizar o modelo nas equações de movimento aeroelásticas. O carregamento aerodinâmico dessas equações é obtido utilizando o método dos anéis de vórtice, do inglês: vortex lattice method (VLM). A simulação é realizada em cada velocidade de fluxo e a resposta dos sensores piezelétricos é obtida no domínio do tempo e domínio da freqüência para se analisar a potência do sinal. Foi realizada uma prévia análise de um modelo de asa representado por uma placa e as configurações de maior potência de sinal são identificadas. A posição dos sensores se demonstrou mais sensível do que a configuração do laminado e a utilização de apenas um sensor foi suficiente para identificação do mecanismo modal, o que pode tornar essa tecnologia viável em ensaios de flutter em estruturas de material compósito.

Palavras-chave: Mecanismo modal, flutter, sensores piezelétricos, análise aeroelástica. 


\begin{abstract}
ALMEIDA, A.S. (2013). Modal flutter analysis methodology using piezoelectric sensor in aeronautical structures. São Carlos. 88p. Dissertação (Mestrado) - Escola de Engenharia de São Carlos, Universidade de São Paulo (In Portuguese).

For complex aeronautical structures, modal mechanism identification requires a great deal of effort. The use of smart materials has been developed in this application, mainly the sensor application with piezo-fiber composites (PFC). It can become a useful tool in aeroelastic instabilities studies, especially on flutter modal mechanism. This work intends to develop a methodology of flutter analysis evaluating the piezoelectric materials performance, using composites impregnation effects, and working as a modal sensor. First, one aeroelastic analysis is done to identify the flutter mechanism and its dominant modes. Then, it modes is detected by sensors with some specific power of electric signal, whose sensitivity is evaluated according with position and embeeded laminate configuration. This simulation uses a plate model representing a wing, whose natural frequencies and modes are determined by finite element method (FEM). So, given this data, is possible to define the wing model using an equation of motion, whose aerodynamic load is obtained by vortex lattice method (VLM). That equation is solved step by step, for each airspeed considered, then, the PFC response is obtained both in the frequency and time domain. The analysis was done using a metric that qualifies the best configuration according with the power of signal. The sensor position was more significant than the laminate configuration; however, the use of only one sensor is sufficient to identify the modal mechanism, which becomes this technology feasible in flutter test of composite structures.
\end{abstract}

Key words: flutter mechanism, modal coupling, piezoelectric sensor, aeroelastic analysis. 


\section{INTRODUÇÃO}

A necessidade de aeronaves que voem em maiores velocidades e com mais eficiência de operação criam grandes desafios aos projetistas, como o exemplo da redução de peso das aeronaves e o aumento da resistência aos esforços em vôo. Para isso, o emprego de novos materiais e novas tecnologias é fundamental para atender essas necessidades. O emprego dos materiais compósitos é um exemplo de preocupação com essa melhora no desempenho, pois, se comparado com os metais comumente usados nas estruturas aeronáuticas, oferece alta resistência mecânica, elevada rigidez, boa resistência a fadiga e baixa densidade. Daniel e Ishai (1994) apresentam o conceito de resistência mecânica e rigidez específicos, que incluem o efeito da densidade dos materiais, o que torna ainda mais visível a vantagem de se usar materiais compósitos nas estruturas de aeronaves.

Com essa aplicação, as estruturas se tornam mais flexíveis, e problemas de vibrações e instabilidades estruturais merecem cuidado e análise ao se considerar os esforços de vôo. Essa preocupação pode ser estudada pelo escopo da aeroelasticidade, que estuda a interação entre as forças aerodinâmicas e as forças elásticas e de inércia da estrutura. Essa interação caracteriza os fenômenos de instabilidade e de resposta da estrutura, e deve ser presente nas considerações de dimensionamento de um projeto aeronáutico.
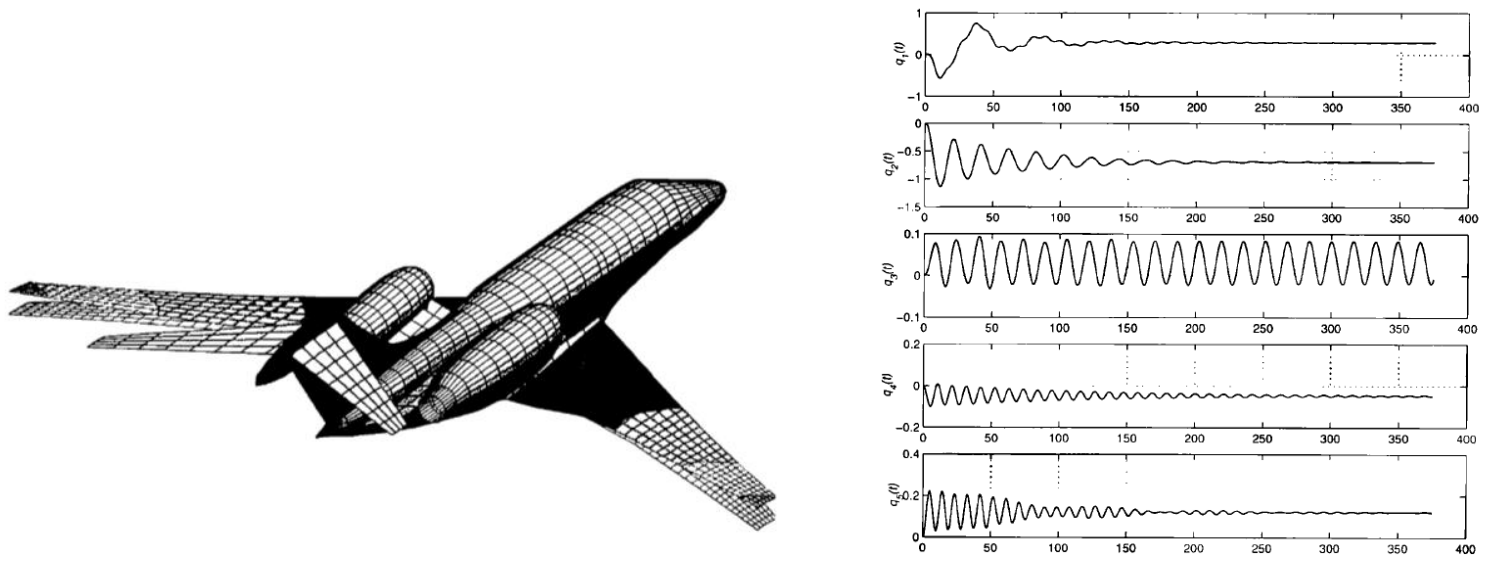

FIGURA 1.1 - Análise modal aeroelástica na fase preliminar de projeto (PREIDIKMAN; MOOK, 2000).

Os primeiros casos registrados de fenômenos aeroelásticos aconteceram no início da primeira guerra mundial. O primeiro caso foi em um avião biplano bombardeiro, o Handley 
Page 0/400, que apresentou uma vibração na região entre a cauda e a fuselagem. Esse fenômeno foi investigado e foi constatado que, o tipo de transmissão de comando do manche para os profundores, bem como sua rigidez, causavam um acoplamento entre os modos da cauda e da fuselagem, o que acarretava violentas oscilações nessa região (BISPLINGHOFF; ASHLEY; HALFMAN, 1955).

Os fenômenos aeroelásticos se destacaram quando se manifestaram na asa das aeronaves. Isso ocorreu na passagem do biplano para o monoplano, ainda nesse período da primeira grande guerra, no momento em que os projetistas se preocupavam em criar uma aeronave de combate mais veloz. Além de velocidade, essas aeronaves precisariam suportar os consequentes carregamentos aerodinâmicos e fatores de carga em manobras. Para isso, era desejada a configuração de monoplano cantilever, como foi o exemplo do Fokker D-8. Essa aeronave possuia uma asa que era resistente aos ensaios estruturais estáticos, no entanto, apresentava falhas catastróficas da asa, quando na recuperação de mergulhos. Esse paradoxo só pôde ser resolvido quando os projetistas decidiram medir o ângulo de ataque na ponta de asa durante o ensaio estático, e foi possível concluir que esse ângulo era maior que no resto da envergadura, o que poderia caracterizar um carregamento diferente do estático. Ao se carregar a asa, essa, devido a sua insuficiente rigidez, se torcia e alterava o ângulo de ataque a ponto de aumentar a intensidade do carregamento aerodinâmico. Isso caracterizava o primeiro caso de aeroelasticidade estática registrado. Desde então, com a preocupação do monoplano cantilever, os cientistas iniciaram pesquisas mais completas no campo da aeroelasticidade.

Além das pesquisas, os ensaios aeroelásticos começaram a se tornar uma preocupação importante, ainda mais no período entre guerras, em que o conceito das aeronaves caminhava para o monoplano e o regime de vôo em velocidades cada vez maiores. Um exemplo dessa preocupação foi o primeiro ensaio do fenômeno de flutter, proposto pelo alemão Von Schlippe em 1935 (SCHLIPPE, 1936). O ensaio era feito em vôo, levando a aeronave à velocidade máxima e medindo a amplitude da vibração de acordo com a velocidade, e com essa curva estimar uma previsão de flutter. O ensaio proposto falhou em futuras aplicações, devido à inadequada instrumentação e excitação empregada (KEHOE, 1995). A evolução dos projetos aeronáuticos estava diretamente ligada à necessidade de melhoramento da previsão dos fenômenos aeroelásticos. Para isso, tanto as análises quanto os ensaios deveriam ser aperfeiçoados.

Seguindo o exemplo do flutter, as previsões partiram de métodos analíticos, como o proposto por Theodorsen em 1934, descrevendo escoamentos simplificados, até os métodos 
numéricos capazes de representar escoamentos mais complexos e com maior precisão conforme a evolução dos computadores. As metodologias atuais conseguem juntar análises de dinâmica dos fluídos computacional (CFD), com análises estruturais usando o método dos elementos finitos (MEF), de maneira cada vez mais completa, no que se diz respeito à realidade do modelo aeroelástico.

Os ensaios aeroelásticos, em especial o ensaio de flutter, evoluiu de maneira a aprimorar o método empregado na excitação, na instrumentação e na análise dos resultados, a qual passou a monitorar o amortecimento global em função da velocidade, ao invés da amplitude. Os ensaios evoluíram de maneira a serem indispensáveis no processo de certificação da aeronave, conforme assegurado pelas normas MIL-A-8870C, FAR 25 e JAR 25. Além da padronização do ensaio, melhorias no custo do ensaio podem ser obtidas com o uso de técnicas de monitoramento de flutter em tempo real, que alteram o tratamento dos dados de forma a reduzir o tempo de ensaio (VERBOVEN et al., 2004; MEVEL; BASSEVILLE; BENVENISTE, 2005).

A previsão do flutter pode ser melhorada com a utilização de materiais inteligentes como sensores, o que pode aumentar a sensibilidade do sinal (KEHOE, 1995). Além do potencial do material piezelétrico como sensor, estes podem ser inseridos nos laminados, de maneira a fazerem parte das camadas do laminado (NJUGUNA, 2007), o que possibilita a instalação de sensores em qualquer região da estrutura de material compósito.
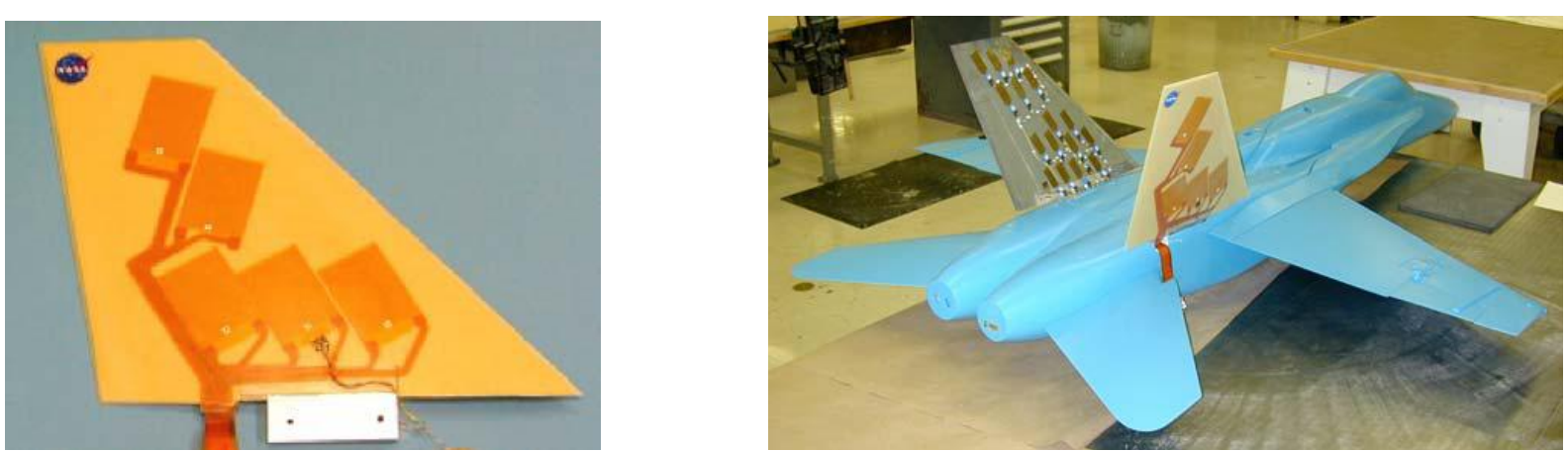

FIGURA 1.2 - Estruturas em fibra de vidro de modelos em escala com sensores piezelétricos instalados (SODANO, 2003).

Além da função de sensor, os materiais piezelétricos também podem ser usados como atuadores, de forma a controlar a velocidade de flutter. Heeg (1993), realizou a primeira verificação experimental no uso de atuadores piezelétricos em um modelo bidimensional em 
túnel de vento, chegando a aumentar a velocidade de flutter em 15\%, de maneira controlada. Apartir de então, estudos foram realizados para a utilização de sensores e atuadores em materiais compósitos. Song e Li (2012) aplicaram técnicas de controle para supressão de flutter em materiais compósitos, na condição de vôo supersônico. Eles utilizaram sensores e atuadores piezelétricos em uma placa de material compósito, obtendo bons resultados e importantes conclusões sobre a influência dos ângulos das camadas.

Sendo assim, o desenvolvimento de análises aeroelásticas envolvendo a utilização de sensores piezelétricos, bem como a exploração das diversas possibilidades de aplicação em conjunto com os materiais compósitos, pode trazer muitas melhorias nas aplicações de previsão e controle dos fenômenos aeroelásticos desse tipo de estrutura, que é uma tendência nos projetos aeronáuticos. De acordo com as possibilidades apontadas, o trabalho explora a possibilidade do material piezelétrico como sensor na estrutura de material compósito, de forma que os tópicos a seguir fazem uma revisão da literatura relacionada com os princiapais assuntos e conceitos a serem utilizados nessa proposta.

\subsection{AEROELASTICIDADE E FLUTTER}

A aeroelasticidade é dividida em duas partes: aeroelasticidade estática e dinâmica.

Os fenômenos podem se caracterizar como uma instabilidade, na qual se pode obter uma falha estrutural, ou podem ser caracterizados como um tipo de resposta, que apesar de não caracterizar uma falha, podem contribuir para a fadiga da estrutura.

A parte estática estuda o efeito do carregamento estático na estrutura. Esse tipo de simplificação associa a inércia e a aerodinâmica com termos constantes. Os fenômenos estudados mais significativos desse escopo são a divergência, a perda de efetividade de comando e a condição de comando reverso. A divergência se caracteriza por uma velocidade na qual o momento restaurador da rigidez do aerofólio é menor que o efeito do carregamento aerodinâmico, o que causa uma falha catastrófica nesse dado carregamento (instabilidade). A perda de efetividade de comando acontece na condição em que, o efeito na sustentação, do momento restaurador da superfície de comando, anula o efeito da sustentação gerado pelo perfil. Se essa condição for extrapolada, tem-se a reversão de comando. 
O escopo da aeroelasticidade dinâmica considera os efeitos de inércia e aerodinâmicos como sendo dependetes do tempo, tornando os balanços de força e momento como equações diferenciais de movimento. Os fenômenos mais comuns desse escopo, associados à estabilidade são as oscilações de ciclo limite e o flutter, enquanto que o buffeting está associado a um fenômeno de resposta. O buffeting é provocado por impulsos do carregamento aerodinâmico devido à esteira de turbulência formada entre a asa e outros componentes, o que cria vibrações transientes na estrutura podendo degradar o comportamento das superfícies de comando. A oscilação de ciclo limite é um fenômeno de estabilidade que considera as não linearidades do modelo, e é caracterizado pela vibração em amplitude e frequência constante. Uma revisão mais completa sobre os campos que compõem a aeroelasticidade pode ser visto em Bisplighoff; Ashley e Halfman (1955).

O flutter é um fenômeno auto-excitado de instabilidade. Nesse caso a deformarção da estrutura realimenta o carregemento aerodinâmico, sendo que, em uma determinada velocidade, a resposta da estrutura passa a ser divergente. O flutter pode estar associado a uma questão de balanceamento e rigidez da estrutura, sendo que todo projeto aeronáutico deve considerar essa condição de maneira à previnir sua ocorrência dentro do envelope de voo. $\mathrm{O}$ mesmo pode ocorrer em qualquer parte da estrutura da aeronave e vem sendo uma preocupação cada vez mais importante conforme as estruturas se tornam complexas e mais flexíveis.

Devido à condição de instabilidade e perigo que o flutter pode acarretar no vôo, foram desenvolvidos métodos analíticos e numéricos para o seu cálculo, bem como ensaios em túnel de vento e ensaios em vôo. Em uma análise de previsão de flutter é comum se fazer o levantamento da curva do amortecimento total (fluído-estrutura) em função da velocidade, porque essa análise que é comparada com os ensaios de flutter, conforme as normas MIL-A8870C, FAR 25 e JAR 25. Essa abordagem explica o fenômeno quando o amortecimento total decresce para zero, o que pode ser acompanhado de maneira gradual durante o aumento de velocidade e conferindo a segurança da aeronave de ensaio, no qual a condição de flutter não é alcançada, sendo esta determinada por uma extrapolação. Uma revisão sobre esses ensaios pode ser vista em Kehoe (1995) e Kayran (2007).

Além da obtenção da curva de amortecimento total, o flutter pode ser estudado com a determinação do mecanismo modal, que é a relação entre determinados modos, chamados de modos de flutter, em que se observa um aumento de energia no sistema. Geralmente, essa relação envolve o acoplamento entre os modos de flexão e torção, o que é deteminado pelo 
fato de que, na maioria das asas, o eixo elástico não coincide com a linha do centro de gravidade ao longo da envergadura (SCANLAN, 1951). Essa relação entre os modos é uma informação que pode ser usada na previsão de flutter, de maneira que, com o aumento da velocidade, as frequiências desses modos se aproximam e o amortecimento destes tende a ser nulo. Essa característica modal do flutter pode ser contemplada em uma análise $V$ - $g-f$ (velocidade, amortecimento e frquência) usando o método $K$ e $P$ - $K$ (HODGES; PIERCE, 2002), ou pelos modelos de ordem reduzida para múltiplos graus de liberdade.

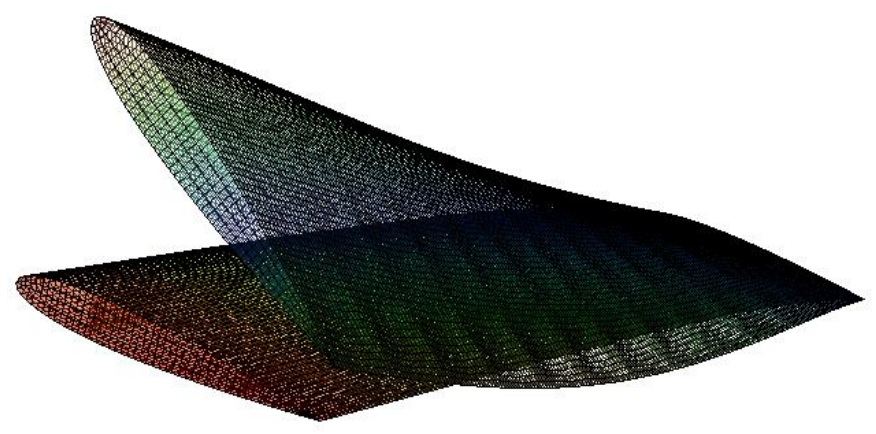

FIGURA 1.3 - Acoplamento entre os modos de flexão e torção.

\subsection{MODELOS AERODINÂMICOS DE FLUTTER}

Em uma análise aeroelástica, o uso de um modelo aerodinâmico é de fundamental importância para a obtenção do carregamento aerodinâmico, que é a excitação da equação de movimento. Um dos fatores complicantes de modelos aeroelásticos é a condição nãoestacionária do escoamento. Essa é uma condição necessária para caracterizar a interação fluido-estrutura, na qual existe o movimento do aerofólio, e também, o atraso de fase entre as variáveis desse movimento e o carregamento aerodinâmico gerado.

O modelo clássico proposto por Theodorsen (1934), considera um escoamento bidimensional sujeito a pequenas perturbações em torno de um ponto de equilíbrio, para excitações harmônicas. Ele utiliza um carregamento harmônico no domínio complexo que é determinado por funções de Bessel, de acordo com o parâmetro de freqüência reduzida. Esse carregamento é definido no domínio da freqüência, o que dificulta a interpretação física.

Para o caso da aplicação tridimensional, os primeiros modelos surgiram da aplicação do método proposto por Theodorsen em uma asa finita, chamado Teoria das faixas. Essa 
aplicação é uma aproximação que considera a divisão de uma asa finita em diversos estágios, cada qual, modelado como um caso bidimensional em que é possível se considerar o carregamento de Theodorsen. Os efeitos de downwash também são considerados nos estágios. No entanto, modelos mais completos começaram a serem usados com o desenvolvimento da teoria da superfície de sustentação que é baseada na teoria da linha de sustentação. A teoria da superfície de sustentação considera a distribuição de dipolos singulares pela área da asa, o que possibilita a implementação de métodos numéricos para o cálculo da sustentação em cada região da asa. Essa aplicação considera um potencial de velocidades ou de acelerações associado aos dipolos que caracterizam as linhas de corrente na asa.

Djojodihardjo e Windall (1969) consideraram a distribuição do petencial de velocidades em uma asa finita, de acordo com os dipolos singularmente distribuídos. O método conhecido como doublet lattice method serviu de modelo para a criação de um método numérico que resolve a não linearidade associada a formação da esteira em um escoamento não-estacionário e tridimensional. $\mathrm{O}$ método calcula passo a passo a distribuição de circulação em cada região da asa.

De acordo com a definição da singularidade dipolo adotada no método de vorticidade, é possível criar outros métodos, como é o caso do método dos anéis de vórtice (do inglês, vortex lattice method - VLM), que é detalhado em Katz e Plotkin (1991).

Os modelos aeroelásticos são construídos pela utilização dos modelos aerodinâmicos associados a uma equação de movimento que depende do problema analisado, bem como dos graus de liberdade do mesmo. Esses modelos geram a previsão da velocidade de flutter e os modos associados. A resposta pode ser analisada no domínio da frequêencia ou no domínio do tempo, conforme o modelo aerodinâmico proposto. A resposta no domínio do tempo permite uma melhor visualização física do fenômeno, porém exige um custo computacional maior. Já as respostas no domínio da freqüência possuem maior precisão e facilidade de cálculo, mas apresenta difícil interpretação física. A diferença entre os dois tipos de resposta é ilustrada por Dowell et al. (1994).

Um dos métodos de análise de flutter mais populares é o método $V$-g-f, no domínio da freqüência, que analisa iterativamente o amortecimento do sistema, sendo que, na velocidade e freqüência em que esse amortecimento é nulo, tem-se a velocidade de flutter. $\mathrm{O}$ amortecimento proposto é considerado artificial de maneira a representar o amortecimento do fluido e da estrutura na equação de movimento. O monitoramento do amortecimento tem 
como função, melhorar o sentido físico do fenômeno no domínio da freqüência. Esses métodos podem ser revisados em Hodges e Pierce (2002).

Os métodos no domínio do tempo vêm se desenvolvendo conforme a capacidade de se computar seus resultados. Strganac e Mook (1990) criaram um modelo aeroelástico considerando escoamento não-estacionário utilizando VLM para o cálculo do carregamento. O modelo foi construído com a representação do escoamento e estrutura na equação de movimento, a qual foi integrada no domínio do tempo para obtenção da resposta. O trabalho de Preidikman e Mook (2000) partiu de uma modelagem muito similiar, no entanto, o modelo desenvolvido foi capaz de resolver as não linearidades do escoamento e pôde ser aplicado em outras partes da aeronave, até mesmo, podendo representar a modificação da esteira e da estrutura com o tempo.

O desenvolvimento dos modelos aeroelásticos seguiu as necessidades de se representar condições mais complexas, tanto do escoamento quanto da estrutura. $\mathrm{O}$ desafio de se modelar condições de escoamento transônico, supersônico, somado com as representações de estruturas com rigidez não-linear trouxe à necessidade de melhorar as ferramentas de modelagem para a representação das não-linaeridades nas equações de movimento. O efeito da não-linearidade geométrica e aerodinâmica é abordado por Patil, Hodges e Cesnik (2000). O modelo proposto sugere as equações de movimento linearizadas em espaço de estados demonstrando conclusões importantes, como o efeito da redução da velocidade de flutter, ao ser comparada com modelos lineares, e a ocorrência do ciclo limite para velocidades acima da velocidade de flutter em pequenos distúrbios do sistema.

Com o objetivo de representar melhor os problemas aeroelásticos, a modelagem se tornou uma composição de modelos em CFD, com modelos solucionados via MEF dinâmicoestruturais, permitindo a representação mais fiel e acurada do fluído e estrutura. Dessa forma, o modelo de escoamento utiliza uma representação por equações de Euler e Navier-Stokes, enquanto que a estrutura é representada por sistemas de equações de Lagrange. Além disso, a discretização das malhas de CFD usam elementos e sistemas de referência diferentes da discretização do MEF. Esse conjunto de diferenças pode trazer diversos problemas para a análise como um todo, o que exige um trabalho especial na troca de informações entre os modelos, para que não ocorra erro numérico (DOWELL; HALL, 2001).

Sendo assim, os modelos aeroelásticos usam muitos métodos de interpolação dos resultados entre os modelos de fluído e estrutura, bem como algoritmos mais elaborados e robustos como o desenvolvido por Maman e Farhat (1995). O trabalho de Benini (2002) 
realiza a troca de informações entre as malhas com interpolação por splines, o que permite uma boa representação entre fluído e estrutura. Esse tipo de representação separada entre as duas naturezas do fenômeno aeroelástico, permite uma maior fidelidade e desenvolvimento do modelo, aliado com um adequado custo computacional.

\subsection{MATERIAIS INTELIGENTES E APLICAÇÃO}

Os materiais inteligentes são aqueles que apresentam um acoplamento entre grandezas de domínios físicos diferentes (LEO, 2007). Dentro desse grupo de materiais é possível citar o exemplo das ligas de memória de forma e dos materiais piezelétricos. As ligas de memória de forma apresentam uma deformação quando aquecidas ou resfriadas, que corresponde a um acoplamento termomecânico, enquanto que os materiais piezelétricos apresentam um acoplamento eletromecânico, pois quando deformados, emitem um sinal elétrico, e o caminho inverso também é possível.

Os materiais piezelétricos, em especial, vêm ganhando espaço nas pesquisas tecnológicas devido a sua versatilidade com a eletrônica nos estudos de vibrações e controle. O efeito piezelétrico foi descoberto em 1880, pelos irmãos Pierre e Jacques Curie, que identificaram um sinal elétrico como conseqüência de uma deformação mecânica aplicada em um cristal de quartzo. Esse efeito é denominado efeito direto, sendo que, o efeito inverso foi descoberto no ano seguinte por Lippman, que constatou uma deformação mecânica induzida por um campo elétrico aplicado no material. A estrutura cristalina do quartzo possui regiões aleatoriamente orientadas contendo arranjos de dipolos, e quando essa estrutura está sob efeito de um campo elétrico, esses dipolos se orientam na direção do campo. Essa orientação faz com que a estrutura cristalina também se alinhe mecanicamente, correspondendo à deformação resultante do material, o que ilustra o fenômeno físico do acoplamento eletromecânico. Com esse raciocínio é possível entender o motivo pelo qual, ao se alterar o sentido de polarização do campo, pode-se obter uma compressão ou tração no sentido longitudinal do campo aplicado (PARTON; KUDRYAVTSEV, 1988).

A aplicação tecnológica desses materiais veio acontecer anos depois, com o desenvolvimento do sonar de submarinos na época da primeira guerra mundial. O motivo pelo qual essa aplicação não foi uma reação imediata ao descobrimento do efeito, foi o fato de que 
o acoplamento dos cristais de quartzo era fraco, o que o tornava inviável (LEO, 2007). Para suprir essa deficiência, o desenvolvimento dos transdutores piezelétricos sintéticos fez-se necessário, e em 1947, Roberts (1947) desenvolveu a cerâmica ferroelétrica de titanato de bário (BaTiO3). Em seguida, Jaffe, Berlincourt e Cmolik (1954) sintetizaram a cerâmica de Titanato Zirconato de Chumbo, popularmente conhecida como PZT, de desempenho superior aos transdutores de bário.

O maior inconveniente de se trabalhar com piezelétricos cerâmicos é a sua característica frágil e a incapacidade de se conformar em superfícies curvas. Pensando nisso que o laboratório Active Materials and Structures Lab do MIT desenvolveu o active fiber composites (AFC), e o laboratório NASA Langley Research Center desenvolveu o micro-fiber composites (MFC). Ambos consistem em fibras piezo cerâmicas embebidas em matriz polimérica (epoxy) e com eletrodos interdigitais, o que confere melhor flexibilidade, adaptação a geometrias curvas e melhor acoplamento eletromecânico. Além dessas vantagens, existe a possibilidade de se integrar os piezelétricos em materiais compósitos como é o caso da fibra de vidro e fibra de carbono (SODANO, 2003).

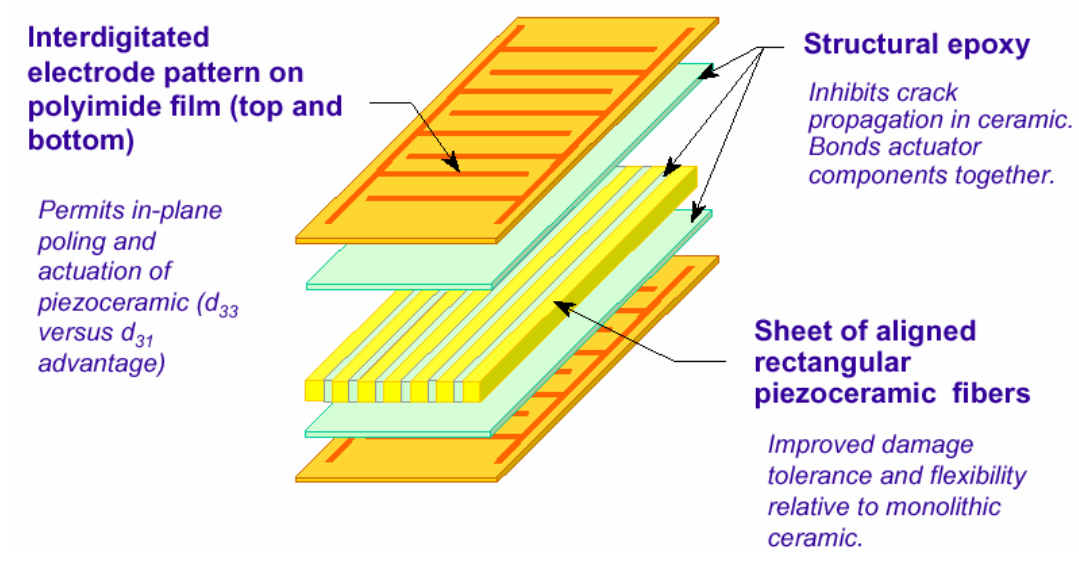

FIGURA 1.4 - Divisão das camadas de um MFC típico (SODANO, 2003).

Atualmente, os materiais piezelétricos possuem grande aplicação como elemento transdutor de acelerômetros, sensores, atuadores e células de carga.

Além das pesquisas envolvidas com o desenvolvimento dos piezelétricos sintéticos, existe a preocupação com a incorporação do fenômeno eletromecânico nas simulações. Muitos pesquisadores utilizam o método dos elementos finitos para criar simulações de estruturas incorporadas com piezelétricos na função de sensores ou atuadores. 
Allik e Hughes (1970) incorpororam o efeito piezelétrico na formulação de elementos finitos, utilizando o principio variacional descrevendo o efeito eletromecânico pelo princípio dos trabalhos virtuais. Foi proposto um elemento tetraédrico por razões de simplicidade e redução de custo computacional.

Lam et al., (1997) desenvolveram um modelo de elementos finitos para simular o controle de vibrações de uma placa de material compósito. Eles utilizaram teoria clássica de placas laminadas para descrever a dinâmica estrutural da placa, usaram o princípio de Hamilton para a formulação do efeito dos sensores e atuadores da placa e implementaram um sistema de controle de malha fechada com realimentação negativa, modelo o qual, demonstrou eficácia no projeto de sistemas de controle para esse caso.

Abreu, Ribeiro e Steffen (2004) criaram uma metodologia de análise utilizando o principio de Hamilton para a formulação do elemento piezelétrico usando MEF e adotaram o modelo de placa de Kirchhoff para representar uma placa de material compósito com sensores piezelétricos incorporados. Eles compararam a metodologia com o pacote computacional ANSYS tanto na análise estática quanto em uma análise dinâmica. Os resultados dos deslocamentos resultantes e tensões elétricas de ambos modelos foram muito próximos.

Os softwares comerciais de elementos finitos possuem recursos para a caracterização do material piezelétrico em uma análise, porém, a versatilidade de se usar as bibliotecas de elementos piezelétricos não é completa, o que exige criação de super elementos para a aplicação. Existe uma alternativa de utilização de métodos de homogenização de propriedades para utilizar os elementos piezelétricos disponíveis sem criar novos elementos.

Bravo Castillero et al., (2001) propõem um método de homogenização assintótica de simples implementação computacional e que caracteriza os materiais piezelétricos independente da geometria e oferecendo validação experimental. Com esse tipo de ferramenta, é possível usar uma configuração AFC ou MFC como sensores e atuadores em placas, e integrar essas simulações com os pacotes comerciais de MEF, como pode ser visto no trabalho de Sartorato, Medeiros e Tita (2012).

Os materiais inteligentes, em especial os piezelétricos, podem ser utilizados no controle e detecção de fenômenos aeroelásticos conforme a revisão feita por Njuguna (2007), o que exige uma caracterização adequada desse tipo de material nas análises. 


\subsection{FILTROS MODAIS}

Filtros modais, utilizados em análises de vibrações, são dispositivos que trabalham o sinal da resposta dinâmica estrutural, de forma a decompor essa resposta em termos dos modos de vibrar. Esses dispositivos são obtidos com o uso de sensores de deslocamento e atuadores, devidamente posicionados, na estrutura. Os filtros modais podem ser usados para facilitar a identificação de mecanismos de acoplamento entre os modos de vibrar, o que é muito comum nos fenômenos aeroelásticos dinâmicos.

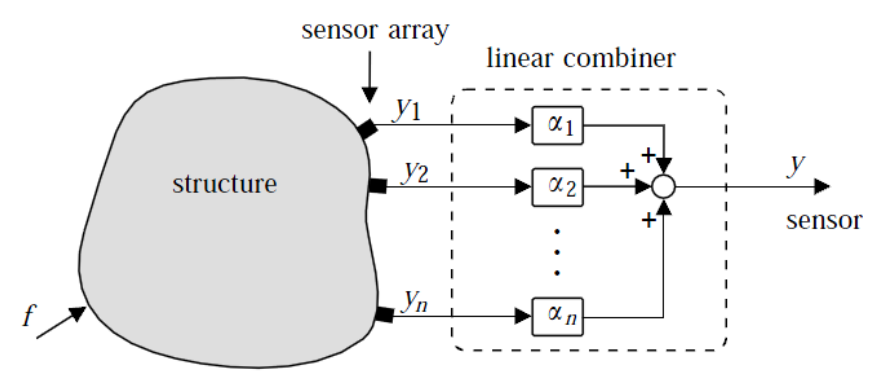

\section{FIGURA 1.5 - Esquema de arranjo de sensores compondo um filtro modal (PREUMONT et al., 2003).}

Gupta, Sharma e Thakur (2010) fazem uma revisão sobre critérios a serem levados como objetivo na otimização do posicionamento de sensores e atuadores em estruturas. Existem diversos objetivos adotados para se realizar o controle de vibrações, entre eles: maximização das forças e momentos aplicados pelos sensores, maximização da deflexão da estrutura a ser controlada, minimização do esforço de controle e maximização da energia dissipada, maximização do grau de controlabilidade e de observabilidade, e, minimização do efeito de spill-over.

Ramesh e Narayanan (2007) fizeram o estudo de otimização do posicionamento de sensores e atuadores piezelétricos, de PZT, em uma placa metálica. O modelo do conjunto da placa com atuadores foi gerado em elementos finitos usando um elemento de placa de Kirchhof. Foram analisados arranjos de PZT's distribuídos pela placa e o desempenho foi medido de acordo com a eficiência de controle, que foi determinada através do método do regulador linear quadrático (LQR). A otimização foi realizada utilizando o metodo dos algoritmos genéticos (AG). 
Deraemaker e Preumont (2005) aplicaram a filtragem modal para detecção de falhas estruturais. Baseado no fato de que, quando uma falha se inicia em um determinado ponto da estrutura, existe uma alteração local na rigidez, e consequentemente, criando singularidades nas FRF's obtidas. Para detectar a influencia local das falhas, foi utilizada uma distribuição de sensores ao longo da estrutura, e, com as FRF's obtidas em cada um, aplicou-se a filtragem modal para montar uma resposta global e assim comparar com a estrutura não danificada.

Preumont et. al (2003) fizeram um trabalho experimental de comparação entre sensores contínuos e arranjos de sensores como filtros modais para avaliar a eficiência dos arranjos. Sensores discretos piezelétricos foram utilizados em uma placa de vidro engastada, e a criação de um filtro modal baseado na determinação dos coeficientes de ponderação através do método dos mínimos quadrados. Foi possível concluir que o fenômeno de Spatial Aliasin limita os filtros a serem eficientes em uma determinada faixa de frequiência e para um pequeno número de modos alvos.

Friswell e Jian (2007) avaliaram o desempenho de sensores modais contínuos para placas. Eles utilizaram sensores de PVDF (fluoreto de polivinilideno) e através de um modelo analítico de placa, criaram parâmetros associados a esse modelo os quais descreviam o formato geométrico do sensor. A metodologia analítica proposta permitiu desenvolver uma geometria de sensor para cada modo alvo perseguido.

Han e Lee (1999) trabalharam com a otimização dos sensores e atuadores em uma placa para a redução do problema de spill-over (do inglês) no controle de vibração. Esse efeito ocorre quando o modelo estrutural é representado pelos primeiros modos, que são modos de baixa freqüência, e então, quando se aplica o controle de malha fechada no modelo, os atuadores podem excitar os modos de alta freqüência, que não são identificados pelo observador de estados, o que ocasiona um fenômeno de instabilidade. No modelo proposto por Han e Lee (1999) foi utilizada uma placa de material compósito, com filmes de PVDF como sensor e elementos PZT espalhados na placa como sensor. Um algoritmo genético foi utilizado para otimizar a controlabilidade e observabilidade do sistema, o que refletia diretamente no posicionamento dos elementos PZT. O modelo em MEF, baseado em experimentos para levantamento das FRF's, foi desenvolvido em elementos finitos e associado ao método de otimização. Foram obtidos bons resultados de identificação e controle de vibrações nos modos alvos.

Pagani e Trindade (2009) criaram uma metodologia de projeto e otimização de filtros modais utilizando arranjos de sensores piezelétricos discretos. O modelo é caracterizado por 
uma placa de metal com possibilidade de instalação de 36 sensores piezelétricos. A modelagem foi concebida em elementos finitos considerando um modelo de acoplamento eletromecânico de placas, utilizando-se o software ANSYS. O projeto busca como objetivos a ampliação da faixa de freqüência e minimização do número de sensores necessários. É utilizado um método de algoritmo genético para a otimização da topologia dos arranjos de acordo com o objetivo buscado.

Os filtros modais podem ser usados em diversas aplicações de problemas de dinâmica estrutural, sendo que o conceito dessa ferramenta também pode ser utilizado em análises aeroelásticas no sentido de identificar os modos do sistema.

\subsection{FLUTTER EM ESTRUTURAS DE MATERIAL COMPÓSITO}

Uma das vantagens de se usar materiais compósitos nas estruturas é sua versatilidade no processo de produção, que possibilita o controle da configuração do laminado de acordo com a função exercida. Isso expande a fase de seleção de materiais para um projeto do material. Dentre os parâmetros controlados no processo de fabricação, tem-se o ângulo das camadas e o número de camadas (influenciando a espessura), que podem ser selecionados de acordo com as análises estruturais da peça em concepção. Além da função estrutural, essa ligação entre análise e configuração pode ser relacionada com as características desejadas de sensoriamento modal e estabilidade dos fenômenos aeroelásticos.

Guo, Bannerjee e Cheung (2003) realizaram um estudo da influência da espessura e ângulo das camadas na velocidade de flutter. Baseado no mecanismo de acoplamento modal flexão-torção no flutter, eles sugerem o aumento da rigidez de torção para que a velocidade de flutter aumente. $\mathrm{O}$ aumento de rigidez proposto é conseguido com a otimização do ângulo das camadas do laminado, sendo que a espessura também é otimizada para que não haja redução na resistência da peça, e nem aumento do peso. Foi conseguido um aumento de $18 \%$ na velocidade de flutter e uma redução de $15 \%$ na redução do peso, ao se comparar com a configuração não otimizada. 


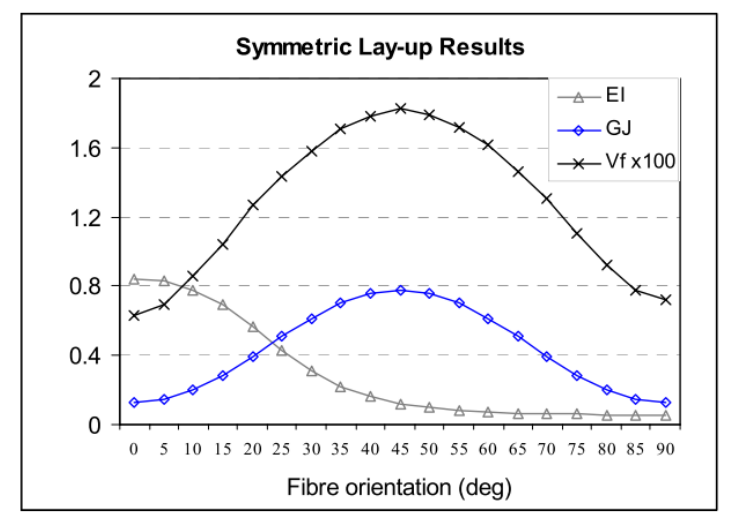

FIGURA 1.6 - Velocidade de flutter influenciada pelo ângulo das camadas de laminados simétricos (GUO; BANNERJEE; CHEUNG, 2003).

Kim e Oh (2006) fazem uma comparação entre uma asa de material compósito e uma asa de material isotrópico de mesmo peso, para avaliar o desempenho destas quanto à margem de estabilidade de flutter. Constata-se que a estrutura, com os ângulos das camadas otimizados, pode-se obter maiores velocidades de flutter, de maneira a aumentar a margem de estabilidade referente a esse fenômeno. A mesma constatação é obtida por Guo, Cheng e Cui (2006), que aplicam uma otimização usando algoritmos genéticos em uma asa de enflechamento para trás, na qual o efeito de acoplamento modal pode ser maior.

Attaran et al. (2011) abordam um modelo aeroelástico simplificado, com o objetivo de verificar a influência de parâmetros da asa nas velocidades de flutter e divergência. Os parâmetros utilizados foram a razão de aspecto, o enflechamento e o ângulo das camadas. Além da influência definida, foi proposta uma otimização desses parâmetros para aumentar as velocidades de instabilidade aeroelástica. $\mathrm{O}$ artigo ilustra a influência do fator de acoplamento de rigidez torção-flexão, na velocidade de flutter e de acordo com os ângulos das camadas.

Problemas de aeroelasticidade mais complexos também foram analisados utilizando a otimização do laminado compósito. O trabalho de Kim et al. (2013) define a metodologia para a otimização de uma longarina de asa de um tiltrotor, buscando uma maior estabilidade ao fenômeno de whirl flutter, que consiste na redução de amortecimento total do sistema, devido ao acoplamento entre os modos do rotor e nacele do motor, o qual é gerado pelo efeito giroscópico do rotor. Utilizando algoritmos genéticos chega-se nos ângulos ótimos para uma longarina de seção quadrada, obtendo-se de 13 à $18 \%$ de aumento da velocidade de whirl flutter. 
Njuguna (2007) faz uma revisão sobre o controle e sensoriamento de flutter em estruturas de material compósito, descrevendo a importância dos materiais piezelétricos nessa aplicação, e a necessidade de desenvolver algoritmos complexos e robustos para as análises propostas para essa aplicação.

Então, é possível constatar a influência da topologia dos laminados compósitos nos fenômenos aeroelásticos, sugerindo que, a associação desses laminados com materiais piezelétricos pode gerar um sensor cuja configuração poderá ser otimizada para uma função de sensoriamento. Esse tema pode ser explorado com o estudo da possibilidade de se criar filtros e sensores modais com essa combinação entre compósitos estruturais e piezelétricos.

\subsection{OBJETIVO DO TRABALHO}

Esse trabalho tem o objetivo de explorar a configuração de PFC's compostos por tiras piezelétricas, os quais são embebidos em laminados compósitos, para avaliar o seu desempenho como sensor dos modos de flutter. As variações na configuração do sensor consistem em alterações nos ângulos das camadas do laminado compósito, e também, na posição relativa desse sensor no elemento estrutural a qual foi instalado. Antes de avaliar o desempenho das configurações consideradas, obtem-se a velocidade de flutter do modelo bem como os modos envolvidos no mecanismo de acoplamento. Ao se identificar os modos, é elaborada uma métrica de desempenho das configurações testadas, a qual se baseia na maximização da potência de sinal elétrico do PFC. O modelo considerado é uma placa plana representando uma asa, a qual será instrumentada com apenas um sensor PFC.

Para que seja possível toda essa análise, um modelo dinâmico-estrutural da placa é elaborado em ABAQUS e solucionado via método dos elementos finitos. Outro modelo aerodinâmico, construído em FORTRAN usando VLM, é utilizado para se obter o carregamento aerodinâmico. As propriedades elásticas e o carregamento aerodinâmico, obtidos nesses modelos, são então acoplados na equação de movimento da placa, a qual é resolvida a cada incremento de tempo. A resposta no domínio do tempo e da freqüência é obtida para se associar a métrica de desempenho, a qual determina qual configuração de sensor tem maior capacidade de identificar os modos de flutter. 


\subsection{ORGANIZAÇÃO DO TRABALHO}

Esse trabalho é dividido em cinco capítulos cuja sequência é descrita aqui de forma resumida. O primeiro capítulo exibe uma contextulização da proposta de trabalho, descrita no resumo, e também uma discussão dos conceitos envolvidos para a construção do modelo e da metodologia de análise.

No capítulo 2 o modelo dinâmico-estrutural é descrito conforme requerido pelas equações de movimento aeroelástica. As considerações do modelo em MEF são abordadas, bem como a metodologia usada para obtenção dos parâmetros modais. O material piezelétrico é definido conforme suas equações constitutivas, permitindo agregar sua participação no modelo descrito.

No capítulo 3 é realizada uma descrição do modelo aerodinâmico, partindo de suas simplificações até suas complexidades ligadas às necessidades do problema aeroelástico. Também é definida a relação que os resultados aerodinâmicos e a equação de movimento do sistema.

No Capítulo 4, a análise aeroelástica é realizada com o modelo construído. Uma metodologia para essa análise é criada e os resultados obtidos são referentes aos casos especificados nesse capítulo, com o objetivo de avaliar o desempenho do sensor piezelétrico proposto. Para essa avaliação é definida uma métrica e uma discussão sobre os resultados.

No Capítulo 5 são discutidas as conclusões finais sobre o desempenho do sensor, bem como a eficiência do método utilizado. No final desse capítulo, sugestões de trabalhos futuros são feitas de acordo com o desenvolvimento da proposta. 


\section{MODELO DINÂMICO-ESTRUTURAL}

\subsection{INTRODUÇÃO}

A descrição do modelo dinâmico-estrutural envolve a definição dos materiais utilizados, e da construção do modelo representativo. As relações constitutivas do material piezelétrico, bem como as condições de contorno do sensor são descritas de forma destacada, para que se esclareça a forma como o sinal piezelétrico é obtido. Além da caracterização do sensor, é exibida a organizaçãoda da análise para a obtenção dos parâmetros modais exigidos pelas equações de movimento.

Os modos de vibrar e as frequências naturais são obtidos e comparados com dois métodos de implementação em elementos finitos, com o intuito de validação do modelo.

\subsection{EQUAÇÕES DE MOVIMENTO}

Para se definir o modelo dinâmico-estrutural da asa, que será representada por uma placa, adota-se a simplificação da linearidade estrutural e de seu amortecimento desprezado. A placa deverá ser discretizada em múltiplos graus de liberdade, o que exige uma representação matricial da massa e rigidez da placa. Seguindo essas considerações chega-se na equação de movimento.

$[M]\{\ddot{x}(t)\}+[K]\{x(t)\}=\{L(x, \dot{x}, t)\}$

A equação de movimento (2.1) está escrita em função do deslocamento global da estrutura, $x(t)$, e a matriz de massa e rigidez são representadas por $[\mathrm{M}] \mathrm{e}[\mathrm{K}]$ respectivamente. Então, os parâmetros do lado esquerdo da equação definem a dinâmica estrutural da asa, enquanto que o lado direito da equação representa o carregamento 
aerodinâmico $\{L(x, \dot{x}, t)\}$, que é definido no próximo capítulo de acordo com o modelo aerodinâmico adotado.

Além das matrizes de massa e rigidez da estrutura, as características dinâmicoestruturais da placa também podem ser representadas pelos modos e frequiências naturais. Para obter esses parâmetros, parte-se da solução de vibração livre (INMAN, 2008):

$[M]\{\ddot{x}(t)\}+[K]\{x(t)\}=0$

Então, utilizando uma solução harmônica simples, é obtido:

$\{x(t)\}=\{\phi\} e^{i \omega t}$

Substituindo a solução harmônica (2.3) na equação (2.2), obtêm-se a seguinte equação matricial:

$\left([K]-\omega^{2}[M]\right)\{\phi\}=\{0\}$

Para resolver a equação (2.4), aplica-se o determinante para se obter a solução diferente da trivial. Tem-se o problema de auto-valor e auto-vetor:

$\operatorname{det}\left([K]-\omega^{2}[M]\right)=0$

Os auto-valores são representados pelas freqüências naturais $\omega$, enquanto que os auto-vetores são representados por $\{\phi\}$, correspondendo a forma modal.

A solução da equação matricial (2.5) gera o polinômio característico, cujas raízes representam o quadrado das frequiências naturais do sistema. $\mathrm{O}$ número de freqüências naturais depende da discretização modal, e quando essas freqüências são substituídas na equação (2.3), são obtidos os modos de vibrar correspondentes da estrutura.

A determinação dos auto-vetores exige um processo de normalização devido ao sistema homogêneo da equação (2.4) possuir infinitas soluções. A normalização consiste em assumir o maior valor como sendo igual a 1 (INMAN, 2008). Então é possível construir a matriz modal, que agrupa todos os modos de vibrar considerados para representar a estrutura. 


$$
[\Phi]=\left[\begin{array}{lllll}
\{\phi\}_{1} & \{\phi\}_{2} & \{\phi\}_{3} & \cdots & \{\phi\}_{N}
\end{array}\right]
$$

Considerando a linearidade do modelo estrutural, garante-se que as matrizes de massa e de rigidez são simétricas, o que permite usar as propriedades de ortogonalidade em relação a essas matrizes. Essa propriedade permite o desacoplamento das $\mathrm{N}$ equações homogêneas conforme os $\mathrm{N}$ graus de liberdade considerados. Dessa forma, é possível considerar:

$$
\{x(t)\}=[\Phi]\{\eta(t)\}=\sum_{r=1}^{N}\{\phi\}_{r} \eta_{r}(t)
$$

A equação (2.7) demonstra o desacoplamento que resulta em $\mathrm{N}$ equações independentes, as quais representam o movimento em cada modo $r$ particular, sendo $\eta(t)$ a coordenada modal. No entanto, a resposta da estrutura é composta pela somatória das contribuições de cada modo.

Aplicando a equação (2.7) na equação de movimento (2.1) tem-se:

$$
[M] \llbracket \Phi][\ddot{\eta}(t)\}+[K \rrbracket \Phi]\{\eta(t)\}=\{L(x, \dot{x}, t)\}
$$

Retomando a idéia da propriedade de ortogonalidade, pode-se dizer que, para dois modos de vibrar distintos $\{\phi\}_{r}$ e $\{\phi\}_{s}$, as seguintes equações são validas em relação as matrizes de massa e rigidez (MEIROVITCH, 1986):

$$
\begin{aligned}
& \{\phi\}_{r}^{T}[M]\{\phi\}_{s}=0 \\
& \{\phi\}_{r}^{T}[K]\{\phi\}_{s}=0
\end{aligned}
$$

Então, ao se multiplicar pela esquerda, os termos da equação (2.8), pela matriz modal transposta, tem-se:

$$
[\Phi]^{T}[M][\Phi]\{\ddot{\eta}(t)\}+[\Phi]^{T}[K \llbracket \Phi]\{\eta(t)\}=[\Phi]^{T}\{L(x, \dot{x}, t)\}
$$


Sejam,

$[\bar{M}]=[\Phi]^{T}[M \rrbracket \Phi]$ e $[\bar{K}]=[\Phi]^{T}[K \llbracket \Phi]$

então:

$[\bar{M}][\ddot{\eta}(t)\}+[\bar{K}]\{\eta(t)\}=[\Phi]^{T}\{L(x, \dot{x}, t)\}$

As equações (2.9) e (2.10) só são validas se as matrizes de massa e rigidez forem simétricas. Então, se essas matrizes forem normalizadas, garantimos que essas matrizes são ortonormais.

$$
[\Phi]^{T}[M][\Phi]=[1] \quad[\Phi]^{T}[K \rrbracket \Phi]=\left[\omega^{2}\right]
$$

Com a garantia da ortonormalidade descrita pela equação (2.13), pode-se definir a equação de movimento do sistema:

$$
\{\ddot{\eta}(t)\}+\left[\omega^{2}\right]\{\eta(t)\}=[\Phi]^{T}\{L(x, \dot{x}, t)\}
$$

A matriz modal e as freqüências naturais podem representar a dinâmica estrutural da placa. Esses dados podem ser obtidos pelo método dos elementos finitos, que é capaz de calcular o deslocamento de cada nó que compõem a discretização da placa. O MEF associado a uma análise modal também pode fornecer as frequiências naturais da placa em questão. Com esses dados somados ao carregamento aerodinâmico, pode-se resolver a equação de movimento (2.14) que descreve os fenômenos de aeroelasticidade dinâmica da asa. 


\subsection{CARACTERIZAÇÃO DO MATERIAL PIEZELÉTRICO}

As características do material piezelétrico refletem nas equações constitutivas do modelo estrutural. A elasticidade das fibras piezelétricas são consideradas ortotrópicas e transversalmente isotrópicas, representando a relação tensão deformação da seguinte forma:

$$
\left[\begin{array}{c}
\sigma_{1} \\
\sigma_{2} \\
\sigma_{3} \\
\tau_{4} \\
\tau_{5} \\
\tau_{6}
\end{array}\right]=\left[\begin{array}{cccccc}
C_{11} & C_{12} & C_{13} & 0 & 0 & 0 \\
C_{12} & C_{22} & C_{23} & 0 & 0 & 0 \\
C_{13} & C_{23} & C_{33} & 0 & 0 & 0 \\
0 & 0 & 0 & C_{44} & 0 & 0 \\
0 & 0 & 0 & 0 & C_{55} & 0 \\
0 & 0 & 0 & 0 & 0 & C_{66}
\end{array}\right]\left[\begin{array}{c}
\varepsilon_{1} \\
\varepsilon_{2} \\
\varepsilon_{3} \\
\gamma_{4} \\
\gamma_{5} \\
\gamma_{6}
\end{array}\right]
$$

No entanto essa matriz é modificada quando se insere o efeito de acoplamento eletromecânico e o efeito dielétrico. O efeito eletromecânico pode acontecer com a fibra piezelétrica funcionando como atuador ou como sensor. Na função de atuador, a fibra é submetida ao efeito de um campo elétrico, que consequentemente resulta em uma deformação da fibra. Esse efeito é conhecido como efeito inverso. No entanto, quando se aplica uma tensão mecânica no material piezelétrico, resultando em um fluxo elétrico, tem-se o efeito direto, no qual o material funciona como sensor. O efeito dielétrico é resultado da propriedade do material conduzir elétrons e poder desenvolver um fluxo elétrico quando submetido a um campo elétrico.

Esses efeitos não ocorrem isoladamente, mas em conjunto com o comportamento elástico do material. A seguinte equação revela essa característica:

$$
\left\{\begin{array}{l}
S \\
D
\end{array}\right\}=\left[\begin{array}{ll}
S & d \\
d & \varepsilon
\end{array}\right]\left\{\begin{array}{l}
T \\
E
\end{array}\right\}
$$

onde $S$ é a deformação mecânica, $D$ o fluxo elétrico, $T$ a tensão mecânica, $E$ o campo elétrico, $d$ o coeficiente de acoplamento eletromecânico, $\varepsilon$ a constante dielétrica do material e $s$ a flexibilidade (inverso da rigidez) do material. A flexibilidade $s$ é representada pelo inverso da matriz 6x6 na equação (2.16), carregando isoladamente a informação elástica do material piezelétrico. 
O sistema de equações (2.16) é a relação constitutiva, de forma simplificada, do material piezelétrico. Percebemos que a parte superior do sistema, ilustra o efeito de atuador, no qual a deformação pode ser o resultado de uma tensão mecânica ou de um campo elétrico, ou de ambos. Já na parte inferior do sistema (2.16), tem-se a definição do efeito direto de sensor, em que um fluxo de carga elétrica é resultado de uma possível tensão mecânica aplicada, ou de um campo elétrico, ou de ambos ao mesmo tempo.

Existem diversas configurações de sensores/atuadores piezelétricos, sendo que esse trabalho consiste no uso do MFC. Esse arranjo, caracterizado pelo formato quadrado das seções da fibra PZT, é imerso dentro de uma matriz polimérica e revestido com eletrodos em suas faces superior e inferior. A configuração do eletrodo é que determina o sentido da polarização e o modo de atuação do piezo. Os modos mais comuns são o $d 31$ e o $d 33$ conforme mostrado abaixo:

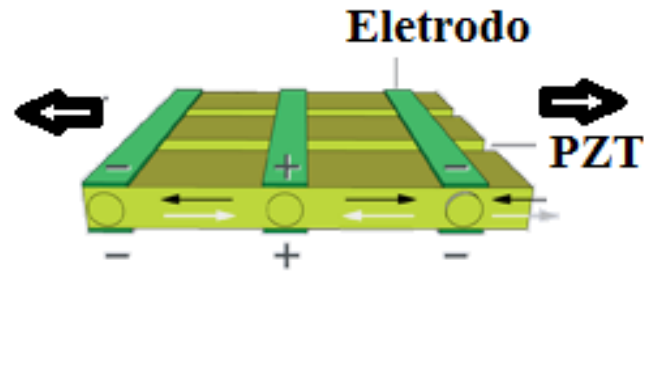

a) modo de atuação d33.

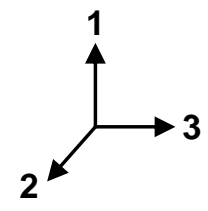

b) modo de atuação d31

FIGURA 2.1 - Modos de atuação dos PZT's (Smart Material Corporation, 2012) •

No modo $d 33$, presente na figura (2.1a), os eletrodos se distribuem entre positivos e negativos, tanto na superfície inferior quanto na superior, o que é comumente chamado de disposição de eletrodos interdigitais. O sentido da deformação é no sentido 3 , devido ao campo elétrico aplicado no sentido 3 também. Já no modo $d 31$, presente na figura (2.1b), a deformação ocorre no sentido 3 devido a um campo aplicado no sentido 1. Essa relação ocorre porque os eletrodos não são do tipo interdigitais, pois mantêm a polaridade positiva em uma face e negativa em outra. 


\subsection{DESCRIÇÃO DO MODELO ESTRUTURAL}

O modelo estrutural adotado para representar uma asa segue a simplificação de um modelo de placa. Essa consideração foi adotada devido a possibilidade de se representar o modelo dinâmico estrutural com flexões e torções, conforme esperado pelo mecanismo modal de flutter. Essa consideração de placa, também permite que o modelo seja comparado com outros modelos validados usando a teoria de Kirchhoff. Foi escolhido o software ABAQUS ${ }^{\mathrm{TM}}$ para a construção do modelo, devido a possibilidade de se representar materiais compósitos e piezelétricos, permitindo o estudo da configuração e posicionamento dos sensores.

O sensor foi caracterizado como um tipo de MFC que possui 17 barras de PZT, as quais possuem $0,38 \mathrm{~mm}$ de espessura. No entanto, essas barras são aderidas em um laminado de fibra de vidro, com resina epoxy, representado por duas camadas, cada qual com $0,5 \mathrm{~mm}$ e um ângulo particular das fibras. A figura (2.2) ilustra a configuração do sensor adotado, o qual possui $25 \mathrm{~mm}$ de largura, por $66,7 \mathrm{~mm}$ de comprimento.

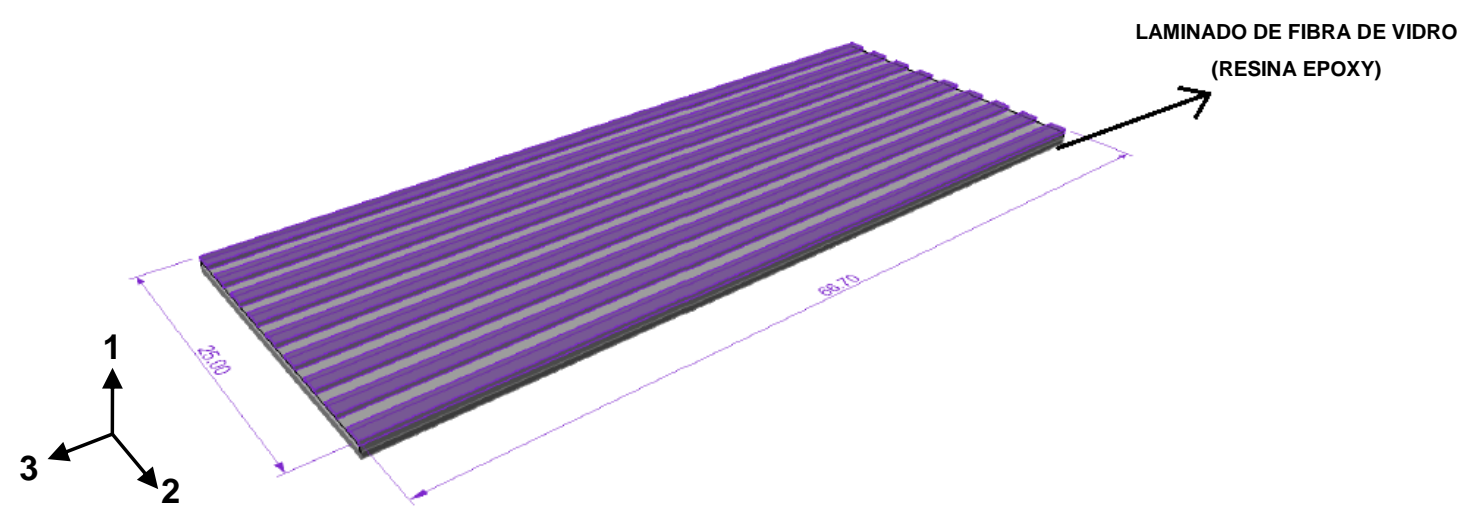

FIGURA 2.2 - Configuração do sensor.

Apesar da modelagem usar a definição de MFC, define-se o sensor estudado como PFC devido à utilização de materiais compósitos junto às fibras piezelétricas.

A asa é representada por uma placa de alumínio isotrópico com as dimensões de 200 x 800 x 2mm, com o sensor posicionado de acordo com os arranjos testados. Foi usado o alumínio AL2024 T3 (HANDBOOK METALLIC MATERIALS AND ELEMENTS FOR AEROSPACE VEHICLE STRUCTURES, 2003) considerado um módulo de elasticidade de $69 \mathrm{GPa}$ e coeficiente de Poisson de 0,33. 
O material piezelétrico das barras usa uma relação constitutiva usando a equação (2.17), representada por um material ortotrópico e transversalmente isotrópico no comportamento elástico, dieletricamente ortotrópico e com acoplamento eletromecânico anisotrópico. As direções das propriedades das barras piezelétricas, seguem a orientação da figura (2.2).

$$
\left\{\begin{array}{l}
T_{11} \\
T_{22} \\
T_{33} \\
T_{12} \\
T_{13} \\
T_{23} \\
D_{1} \\
D_{2} \\
D_{3}
\end{array}\right\}=\left[\begin{array}{ccccccccc}
C_{11} & C_{12} & C_{13} & 0 & 0 & 0 & 0 & 0 & -e_{13} \\
C_{12} & C_{11} & C_{13} & 0 & 0 & 0 & 0 & 0 & -e_{13} \\
C_{13} & C_{13} & C_{33} & 0 & 0 & 0 & 0 & 0 & -e_{33} \\
0 & 0 & 0 & C_{66} & 0 & 0 & 0 & 0 & 0 \\
0 & 0 & 0 & 0 & C_{44} & 0 & 0 & -e_{15} & 0 \\
0 & 0 & 0 & 0 & 0 & C_{44} & -e_{15} & 0 & 0 \\
0 & 0 & 0 & 0 & 0 & e_{15} & \varepsilon_{11} & 0 & 0 \\
0 & 0 & 0 & 0 & e_{15} & 0 & 0 & \varepsilon_{11} & 0 \\
e_{13} & e_{13} & e_{33} & 0 & 0 & 0 & 0 & 0 & \varepsilon_{33}
\end{array}\right]\left\{\begin{array}{l}
S_{11} \\
S_{22} \\
S_{33} \\
S_{12} \\
S_{13} \\
S_{23} \\
E_{1} \\
E_{2} \\
E_{3}
\end{array}\right\}
$$

A forma do acoplamento eletromecânico bem como as propriedades piezelétricas foram obtidos de Smart Material Corporation (2012), e seguem na tabela (1):

Tabela 1 - Propriedades das barras piezelétricas.

\begin{tabular}{|c|c|c|}
\hline Propriedades barras piezelétricas & Valor & Unidades \\
\hline$C_{11}$ & 127,20 & $\mathrm{GPa}$ \\
\hline$C_{12}$ & 80,212 & $\mathrm{GPa}$ \\
\hline$C_{13}$ & 84,670 & $\mathrm{GPa}$ \\
\hline$C_{33}$ & 117,44 & $\mathrm{GPa}$ \\
\hline$C_{44}$ & 22,989 & $\mathrm{GPa}$ \\
\hline$C_{66}$ & 23,474 & $\mathrm{GPa}$ \\
\hline$e_{13}$ & $-11,338$ & $C / m^{2}$ \\
\hline$e_{15}$ & 17,034 & $C / m^{2}$ \\
\hline$e_{33}$ & 22,145 & $C / m^{2}$ \\
\hline$\varepsilon_{11}$ & $27,71 \mathrm{e}-9$ & $F / m$ \\
\hline$\varepsilon_{33}$ & $33,64 \mathrm{e}-9$ & $F / m$ \\
\hline
\end{tabular}


O laminado de fibra de vidro foi considerado como ortotrópico e transversalmente isotrópico, com as seguintes propriedades (DANIEL; ISHAI, 1994):

Tabela 2 - Propriedades da fibra de vidro.

\begin{tabular}{|c|c|c|}
\hline $\begin{array}{c}\text { Propriedades laminado de } \\
\text { fibra de vidro }\end{array}$ & Valor & Unidade \\
\hline$E_{11}$ & 25 & $\mathrm{GPa}$ \\
\hline$E_{22}$ & 5 & $\mathrm{GPa}$ \\
\hline$E_{33}$ & 5 & $\mathrm{GPa}$ \\
\hline$G_{12}$ & 4 & $\mathrm{GPa}$ \\
\hline$G_{13}$ & 4 & $\mathrm{GPa}$ \\
\hline$G_{23}$ & 4 & $\mathrm{GPa}$ \\
\hline$v_{12}$ & 0,1 & - \\
\hline$v_{13}$ & 0,1 & - \\
\hline$v_{23}$ & 0,1 & - \\
\hline
\end{tabular}

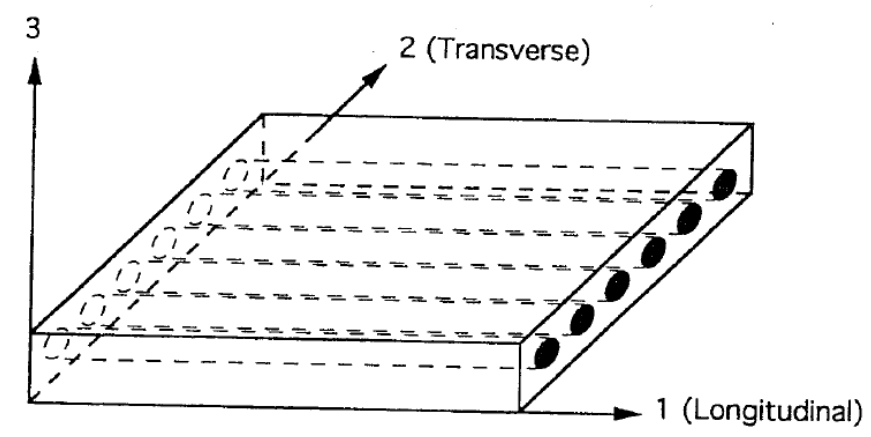

FIGURA 2.3 - Direções das propriedades do laminado (DANIEL; ISHAI, 1994).

Para cada material foi utilizado um tipo de elemento. Para as fibras PZT, foi utilizado o elemento sólido piezelétrico C3D8E, que possui 8 nós por elemento, sendo que cada nó possui 4 graus de liberdade: translação nos três eixos e o grau de liberdade elétrico. O método de interpolação usado nos elementos não prejudica os resultados de tensão elétrica do sensor, uma vez que só serão considerados resultados nodais, e não em localizações entre os nós.

O refinamento de malha foi maior no foco da análise, correspondendo ao sensor. No entanto houve um refinamento adequado com a geometria das fibras PZT e no laminado de fibra de vidro. Na placa de alumínio o conceito de malha foi de redução do número de elementos, pois, no caso de uma placa é possível conseguir bons resultados com uma malha menos refinada e que traz um custo computacional menor. Como, essas duas geometrias que 
compõem o sensor PFC, possuem um refinamento diferente do refinamento pretendido na placa de alumínio, foi necessário criar uma região de transição que aumenta o tamanho dos elementos partindo da região de contato com sensor para a periferia da placa, conforme a figura (2.4).

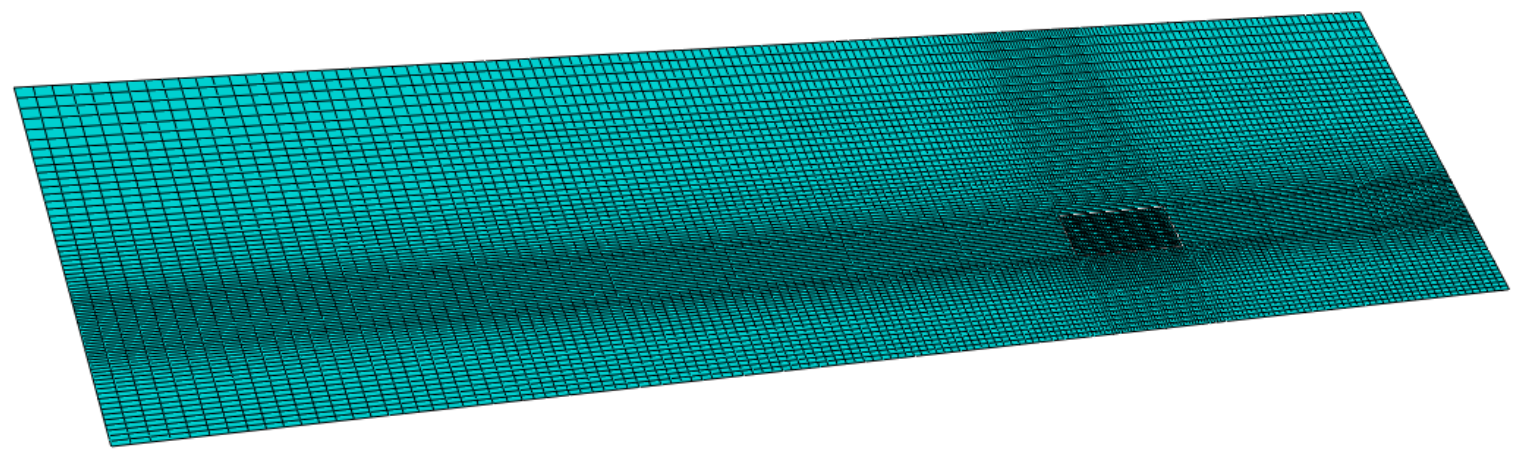

FIGURA 2.4 - Malha e região de transição.

No caso do laminado de fibra de vidro e da placa de alumínio, foram usados elementos de casca. Para a placa de alumínio foi usado o elemento S4R, que contém 4 nós, cada qual com 6 graus de liberdade: translação e rotação nas três direções. No entanto, esse elemento possui uma função de interpolação linear, pois, devido a dimensão da placa e seu grande número de elementos, é interessante usar um método com menor custo computacional. Como a espessura da placa é muito menor que as dimensões da placa, buscou-se pela utilização de um elemento que usa-se a formulação da teoria de placa de Kirchhoff, como é o caso do S4R.

O laminado usado entre as fibras PZT e as placas exige uma atenção maior na análise, pois é esperado que a influência do ângulo das camadas seja significativa na eficiência do sensor. Por esse motivo, utiliza-se o elemento S8R para esse laminado, que, em comparação com elemento usado na placa, ele possui uma função de interpolação de ordem quadrática, o que melhora a precisão da resposta. Ao utilizar esse tipo de função, o número de nós vai para 8 em cada elemento. Os graus de liberdade e a formulação de placa adotadas para esse elemento são as mesmas que aquelas adotadas para o S4R.

Um fator importante e decisivo para a modelagem é a relação que a malha estrutural deve possuir com a malha aerodinâmica. $\mathrm{O}$ carregamento a ser calculado iterativamente pelo modelo aerodinâmico, utiliza o método de malha de vórtices, que exige uma discretização 
dividindo a asa em painéis. Como o processo iterativo recebe os deslocamentos obtidos nos nós da malha estrutural e impõe esses deslocamentos nos pontos da malha aerodinâmica, é importante que exista uma relação simples entre essas malhas, o que reduz o tempo do processo. Para evitar usar algoritmos de interpolação de coordenadas, forçou-se usar na malha estrutural, nós que possuem a mesma coordenada que a malha aerodinâmica. Os deslocamentos desses nós serão obtidos para montagem da matriz modal da estrutura. A figura (2.5) ilustra essa condição pré-imposta na malha estrutural, além de esquematizar algumas condições de contorno.

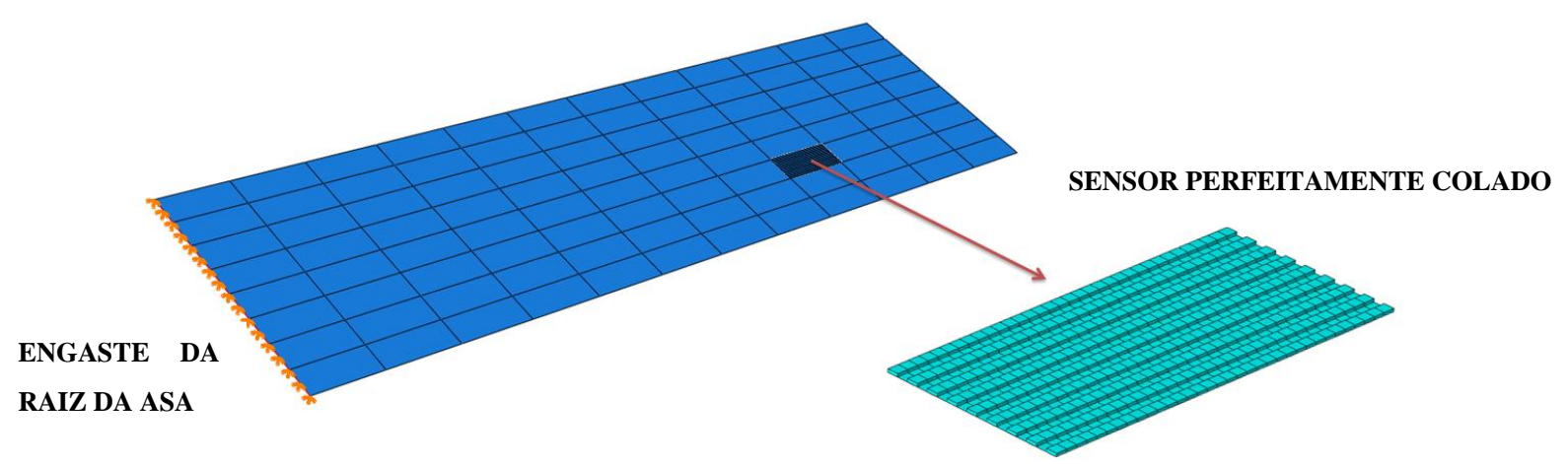

FIGURA 2.5 - Malha estrutural pré-definida.

A figura (2.5) ilustra a malha aerodinâmica, composta por 116 painéis, dentro da malha estrutural. As arestas consideradas na malha da placa, obrigam o algoritmo de malha criar um nó nas intersecções e então, é possível fazer um controle de malha estrutural dentro desses painéis, conforme a necessidade da estratégia de malha.

As condições de contorno aplicadas na análise são de fundamental importância para os resultados, principalmente, a condição de contorno elétrica aplicada ao conjunto do PFC.
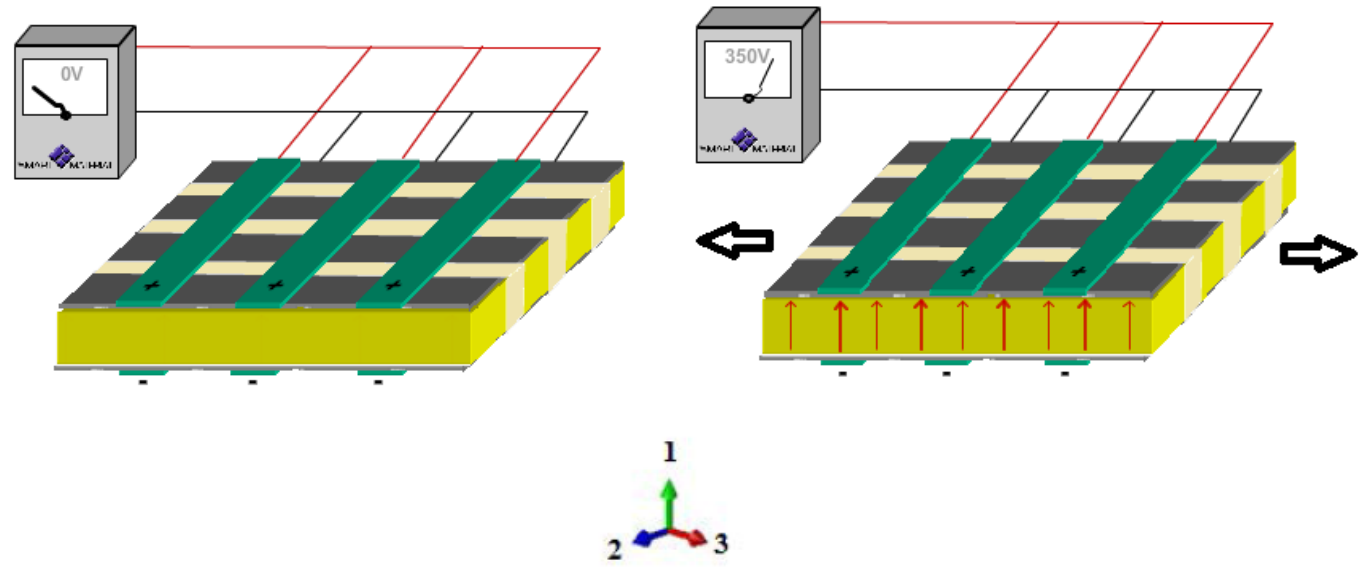

FIGURA 2.6 - MFC atuando no sentido d31. 


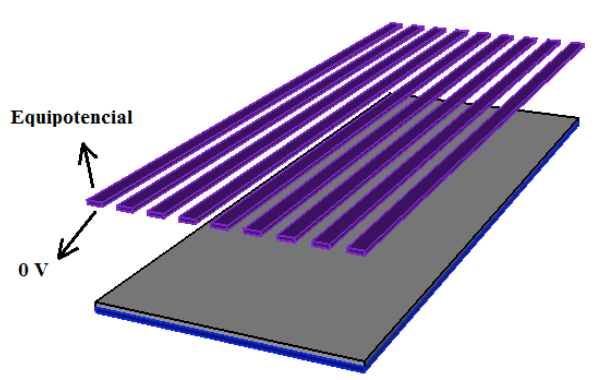

FIGURA 2.7 - Aplicação das condições de contorno.

A figura (2.7) mostra a aplicação da condição de potencial nulo na superfície inferior das fibras PZT, enquanto que, a face superior apresenta a condição equipotencial, o que reflete a realidade de um sensor PFC com uma diferença de potencial elétrico entre um eletrodo contínuo do tipo $d 31$. Essa condição garante um fluxo elétrico quando a placa é deformada.

Os contatos entre as fibras PZT com o laminado e o contato entre o laminado e a placa são declarados como perfeitamente colados. A placa foi engastada (fixada) na região que representa a raiz da asa, de maneira a impedir as translações e rotações nas três direções. Então, foi realizada uma análise modal que revela os modos de vibrar e as frequiências naturais.

Com a modelagem definida, os termos da equação (2.14), como $\left[\omega^{2}\right]$ e $[\Phi]^{T}$, sofrem a influência do material piezelétrico, que possui um efeito eletromecânico acoplado, o que acrescenta o grau de liberdade elétrico. Dessa forma, a equação de movimento adequada para representar o sistema, partindo do sistema de coordenadas global, seria o conjunto de equações (2.18):

$\left\{\begin{array}{l}\left.\left.[M]] \ddot{x}(t)\}+\left[K_{x x}\right]\right\} x(t)\right\}+\left\lfloor K_{x \varphi}\right\rfloor\{\varphi(t)\}=\{L(x, \dot{x}, t)\} \\ \left.\left[K_{\varphi x}\right]\right]\{x(t)\}+\left[K_{\varphi \varphi}\right] \varphi=\{Q(t)\}\end{array}\right.$

onde a matriz $K_{x x}$ é a matriz de rigidez elástica do sistema, $K_{x \varphi}$ e $K_{\varphi x}$ as matizes do efeito acoplado piezelétrico e $K_{\varphi \varphi}$ a matriz dielétrica. O termo $Q(t)$ representa o fluxo de cargas do sistema. 
A equação (2.18) é representada pela equação (2.14) de maneira a incluir todos esses efeitos propostos pelo surgimento dos novos termos, no entanto, antes de descrever essa equivalência, é importante se definir o sistema que precisa ser representado pelos efeitos da equação (2.18). Essa definição está diretamente ligada com os graus de liberdade que cada tipo de elemento, usado no modelo de elementos finitos, pode fornecer. Pode-se perceber que, o único elemento que possui o grau de liberdade elétrico, é o elemento C3D8E, que é usado apenas na modelagem das barras piezoelétricas. Sendo assim, a equação (2.18) representa somente essas barras piezelétricas. Dessa forma, para que esse efeito seja incluído nos termos $\left[\omega^{2}\right]$ e $[\Phi]^{T}$ da equação (2.14), que está escrita em relação ao sistema de coordenadas modais, deve-se utilizar as equações constitutivas adequadas para a caracterização do material piezelétrico, as quais são inseridas na análise modal via MEF, conforme definido na equação (2.17). Os resultados da análise sofrem a ação da rigidez piezelétrica nas frequências naturais, e da adição do graus de liberdade elétrico na matriz modal.

Outro fator importante é a maneira da utilização da matriz modal na análise como um todo. Quando se analisa as amplitudes modais nos domínios do tempo e frequência, pode-se desconsiderar a coluna referente ao grau de liberdade elétrico, da matriz modal, e resolver a equação (2.14) normalmente, pois a matriz modal, mesmo sem essa coluna, já possui a influência da rigidez piezelétrica nas demais colunas, que são ligadas aos deslocamentos dos nós da estrutura. Então, como todos os demais elementos possuem os graus de liberdade de deslocamento, pode-se considerar a equação (2.14) para representar o modelo inteiro, e então definir a geometria deformada da estrutura a qual será usada pelo solver aeroelástico, na definição do carregamento aerodinâmico.

Em relação ao sinal elétrico $Q(t)$, pode-se usar uma forma mais simples de análise, comparando com a resolução da segunda equação (2.18), devido ao propósito do trabalho. Como o objetivo principal do sensor é a detecção do sinal elétrico ligado a um determinado modo alvo, o que se procura é uma comparação da potência de sinal entre as configurações do sensor, e não a resposta temporal desse sinal. Essa particularidade permite que, com a obtenção do valor da tensão elétrica, em uma determinada configuração de sensor, obtido na análise modal, para cada modo e em qualquer nó pertencente a um elemento piezelétrico, seja possível comparar esse valor com os valores obtidos em outras configurações de sensor para o mesmo modo. Isso é possível porque o sinal elétrico do sensor, para uma dada entrada, é proporcional ao valor obtido de tensão elétrica, na análise modal via MEF. Sendo assim, 
como o valor de tensão elétrica, obtido em qualquer nó do elemento piezelétrico, é o mesmo devido a condição de contorno equipotencial, pode-se escolher um determinado nó pertencente às barras piezelétricas, calcular o valor da tensão obtida e assim usá-lo de comparação entre as configurações, o que será feito no capítulo 4.

\subsection{VALIDAÇÃO DO MODELO ESTRUTURAL}

A primeira verificação do modelo foi obtida em uma comparação entre a análise modal em ABAQUS e uma rotina em MATLAB com um modelo de placa. Essa rotina consiste na implementação da teoria de placa de Kirchhoff criada por Gruppiioni e Marques (2008), para elementos finitos através do principio variacional eletromecânico. O modelo utiliza um elemento de placa com 4 nós, sendo que cada nó possui 7 graus de liberdade: três graus de deslocamento nos três eixos, três graus de rotação nos três eixos e mais um grau de liberdade elétrico.

O modelo de Gruppioni se demonstra adequado para a comparação devido ao fato do modelo MEF do ABAQUS possuir considerações muito similares, uma vez que o elemento S4R utilizado na placa, também possui 6 graus de liberdade mecânicos e também é formulado de acordo com a teoria de Kirchhoff. Além disso, o modelo foi validado experimentalmente conforme a leitura da referência citada.

Inicialmente, a validação tem por objetivo a comparação entre os modos e frequiências naturais obtidos da placa, uma vez que, os efeitos do sensor, nesses parâmetros são muito pequenos. Portanto, os efeitos do piezelétrico foram desconsiderados em uma primeira abordagem. Em uma segunda etapa de validações, uma configuração específica de sensor foi comparada entre o método ABAQUS e o software de Gruppiioni e Marques (2008), considerando o efeito piezelétrico.

As tabelas (3), (4) e (5) realizam uma comparação do efeito do sensor nas freqüências naturais, para três posições arbitrárias de instalação, e três configurações arbitrárias de laminado compósito. Também é feita uma comparação com o caso sem sensor. 
Tabela 3 - Efeito do sensor nas frequências naturais - posição arbitrária 1 (ABAQUS).

\begin{tabular}{|l|r|r|r|r|}
\hline Posição 1 & \multicolumn{4}{|c|}{ Frequência[Hz] } \\
\hline Laminado & \multicolumn{1}{|c|}{$[0 / 45]$} & \multicolumn{1}{|c|}{$[0 / 90]$} & {$[-45 / 45]$} & Sem sensor \\
\hline Modo 1 & 2,6591 & 2,6592 & 2,6582 & 2,5762 \\
\hline Modo 2 & 16,609 & 16,609 & 16,607 & 16,382 \\
\hline Modo 3 & 21,138 & 21,135 & 21,14 & 20,727 \\
\hline Modo 4 & 46,588 & 46,588 & 46,587 & 47,512 \\
\hline Modo 5 & 65,318 & 65,312 & 65,325 & 64,525 \\
\hline
\end{tabular}

Tabela 4 - Efeito do sensor nas frequências naturais - posição arbitrária 2 (ABAQUS).

\begin{tabular}{|l|r|r|r|r|}
\hline Posição 2 & \multicolumn{4}{|c|}{ Frequência[Hz] } \\
\hline Laminado & \multicolumn{1}{|c|}{$[0 / 45]$} & \multicolumn{1}{|c|}{$[0 / 90]$} & {$[-45 / 45]$} & \multicolumn{1}{l|}{ Sem sensor } \\
\hline Modo 1 & 2,6425 & 2,6425 & 2,6425 & 2,5762 \\
\hline Modo 2 & 16,596 & 16,597 & 16,594 & 16,382 \\
\hline Modo 3 & 21,081 & 21,08 & 21,08 & 20,727 \\
\hline Modo 4 & 46,462 & 46,462 & 46,447 & 47,512 \\
\hline Modo 5 & 65,327 & 65,318 & 65,337 & 64,525 \\
\hline
\end{tabular}

Tabela 5 - Efeito do sensor nas frequências naturais - posição arbitrária 3 (ABAQUS).

\begin{tabular}{|l|r|r|r|r|}
\hline Posição 3 & \multicolumn{4}{|c|}{ Frequência[Hz] } \\
\hline Laminado & \multicolumn{1}{|c|}{$[0 / 45]$} & \multicolumn{1}{|c|}{$[0 / 90]$} & {$[-45 / 45]$} & \multicolumn{1}{l|}{ Sem sensor } \\
\hline Modo 1 & 2,6584 & 2,6585 & 2,6575 & 2,5762 \\
\hline Modo 2 & 16,584 & 16,584 & 16,584 & 16,382 \\
\hline Modo 3 & 21,111 & 21,108 & 21,114 & 20,727 \\
\hline Modo 4 & 46,399 & 46,4 & 46,394 & 47,512 \\
\hline Modo 5 & 64,799 & 64,797 & 64,804 & 64,525 \\
\hline
\end{tabular}

Ainda nessa comparação, pode-se observar que os modos também foram praticamente idênticos.

Em ambas as etapas de validação, foram considerados os cinco primeiros modos do sistema, pois essa simplificação foi adotada para o modelo aeroelástico, de maneira a simplificar a construção da matriz modal.

Então, na etapa inicial da validação, em que os efeitos peizelétricos foram desconsiderados, a malha utilizada em ambos os modelos foi a mesma a ser utilizada na malha aerodinâmica, o que cria um modelo bastante simplificado e de rápida verificação. 

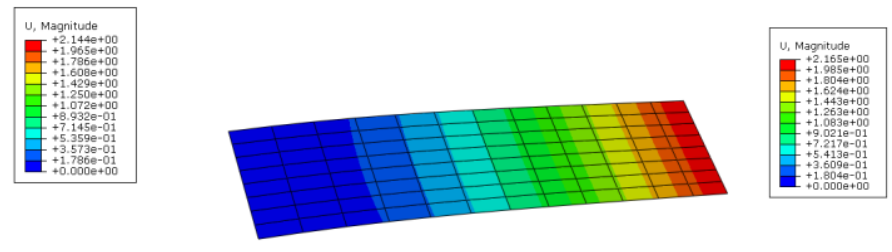

a) Primeiro modo: Flexão

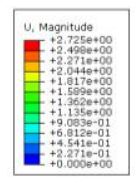

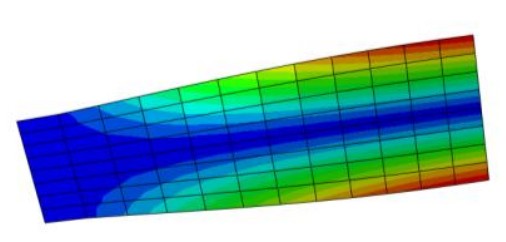

c) Terceiro modo: Torção

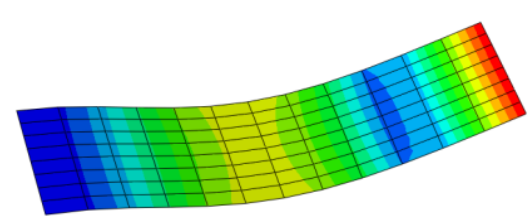

b) Segundo modo: Flexão

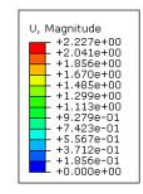

d) Quarto modo: Flexão
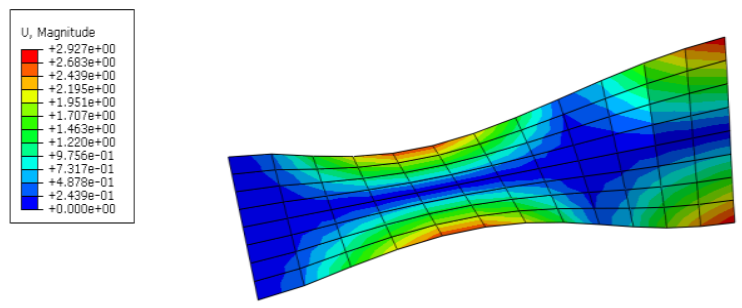

e) Quinto modo: Flexo-torção

FIGURA 2.8 - Modos de vibrar da placa em análise ABAQUS.
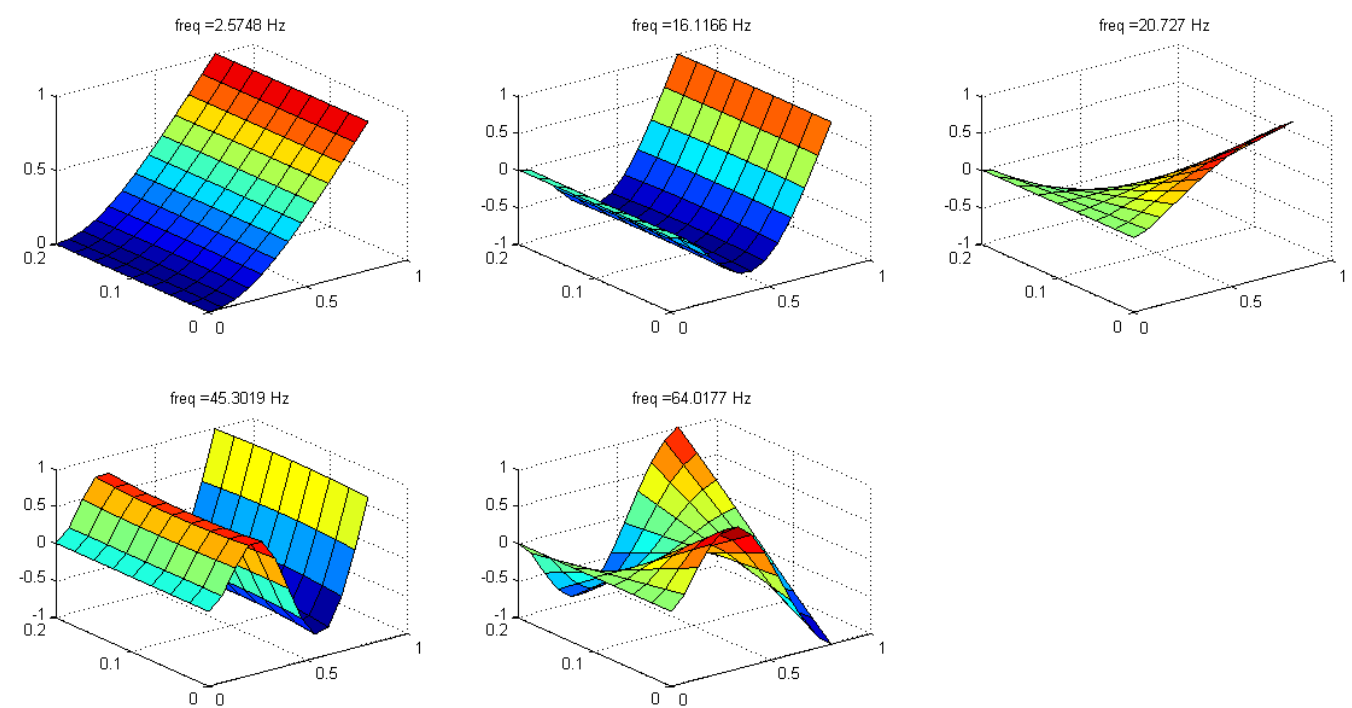

FIGURA 2.9 - Modos de vibrar da placa em análise (GRUPPIONI; MARQUES, 2008). 
Tabela 6 - Comparação entre as freqüiências naturais.

\begin{tabular}{|l|c|c|}
\hline Modo & Freqüências (Hz)ABAQUS & $\begin{array}{l}\text { Freqüências(Hz) (GRUPPIONI; } \\
\text { MARQUES, 2008) }\end{array}$ \\
\hline 1 & 2.5762 & 2.5748 \\
\hline 2 & 16.382 & 16.1166 \\
\hline 3 & 20.727 & 20.727 \\
\hline 4 & 47.512 & 45.3019 \\
\hline 5 & 64.525 & 64.0177 \\
\hline
\end{tabular}

As figuras (2.8) e (2.9), demonstram que os modos de vibrar da placa foram idênticos e que as freqüências naturais apresentam valores muito aproximados entre os métodos comparados. A rigidez estrutural da placa é o parâmetro mais significativo nos deslocamentos nodais a serem obtidos para a montagem da matriz modal. No entanto, com essa comparação, a confiabilidade do modelo ABAQUS aumenta para a obtenção da matriz modal.

$\mathrm{Na}$ segunda etapa de validação, a idéia seria comparar o modelo do ABAQUS com a literatura, em relação ao efeito que as barras piezelétricas acarretariam nas frequiências naturais e modos. É importante comentar que o programa em MATLAB de Gruppiioni e Marques (2008) não permite a caracterização do material compósito. Por esse motivo, o modelo de comparação para essa segunda etapa, seria apenas a placa metálica com as barras piezelétricas instaladas em uma posição arbitrária (posição 3). Esse tipo de modelagem é possível em ambos os métodos via MEF utilizados, sendo que as 17 barras de PZT foram consideradas também.

Sendo assim, pode-se perceber, através da tabela (7), que a diferença entre as freqüências naturais foram muito pequenas em relação aos dois métodos comparados, o que torna a modelagem do ABAQUS também válida em relação à utilização dos elementos sólidos piezelétricos. Além do efeito nas freqüências, os modos também se demonstraram praticamente idênticos. 
Tabela 7 - Comparação entre o modelo ABAQUS e o modelo da literatura - posição arbitrária 3 (considerando barras piezelétricas).

\begin{tabular}{|l|r|r|}
\hline Posição 3 & \multicolumn{2}{|c|}{ Frequências [Hz] } \\
\hline Modelo & $\begin{array}{l}\text { Modelo com efeito } \\
\text { piezelético - } \\
\text { ABAQUS }\end{array}$ & $\begin{array}{l}\text { Modelo com efeito } \\
\text { piezelético - (GRUPPIONI; } \\
\text { MARQUES, 2008) }\end{array}$ \\
\hline Modo 1 & 2,6567 & 2,6543 \\
\hline Modo 2 & 16,597 & 16,392 \\
\hline Modo 3 & 21,117 & 21,110 \\
\hline Modo 4 & 46,546 & 44,878 \\
\hline Modo 5 & 65,088 & 64,571 \\
\hline
\end{tabular}




\section{MODELO AERODINÂMICO}

\subsection{INTRODUÇÃO}

Esse capítulo desenvolve uma descrição do modelo aerodinâmico e sua relação com as equações de movimento do sistema, que descrevem o comportamento aeroelástico do modelo. Parte-se de um modelo de escoamento simplificado, com características bidimensionais, irrotacional e de regime permanente. Seguindo a sequência, as considerações para asa finita são incluídas, bem como os métodos de cálculo a serem utilizados. Por fim, a condição de escoamento não-estacionário é definida, caracterizando as condições de esteira e sistemas de coordenadas, além das condições de contorno específicas.

A relação com o as equações de movimento do sistema é descrita para se entender a relação do carregamento aerodinâmico com o modelo aeroelástico.

\subsection{MODELO INICIAL DE ESCOAMENTO}

A análise aeroeslástica realizada em cada incremento de tempo considera a atualização da estrutura, que foi deformada em um instante anterior, e que será carregada novamente em um instante futuro. Isso exige que o modelo aerodinâmico realize o cálculo da sustentação em cada instante de tempo. Para atingir esse objetivo pode-se considerar um modelo aerodinâmico incompressível, potencial, não-estacionário e de asa finita, uma vez que essa asa é representada por uma placa. No entanto, parte-se de um modelo mais simples, o qual considera o escoamento incompressível, potencial, estacionário e bidimensional.

As considerações de partida definem o escoamento como sendo sem atrito, uma vez que, na condição de fluxo potencial, não há indução de rotação, portanto os efeitos viscosos são desconsiderados. Com essas premissas, é possível aplicar a equação de Euler ao longo de uma linha de corrente e consequentemente, utilizar a equação de Bernoulli: 
$\frac{p_{1}}{\rho}+\frac{V_{1}^{2}}{2}=\frac{p_{2}}{\rho}+\frac{V_{2}^{2}}{2}=$ constante

sendo que os pontos 1 e 2 se localizam na linha de corrente considerada.

A equação de Bernoulli pode ser escrita como a diferença de pressão em função das velocidades entre os pontos:

$$
\frac{\Delta p}{\rho}=\frac{p_{2}-p_{1}}{\rho}=\frac{V_{2}^{2}-V_{1}^{2}}{2} .
$$

Como a integral do campo de pressões ao longo do contorno do aerofólio define a sustentação neste, a equação (3.2) revela uma dependência do carregamento aerodinâmico em relação à determinação do campo de velocidades. Esse campo pode ser obtido utilizando funções de campo que satisfazem a condição de irrotacionalidade e a equação da continuidade (FOX; MCDONALD, 1998).

A condição de irrotacionalidade para um caso bidimensional é representada,

$$
\frac{\partial v}{\partial x}-\frac{\partial u}{\partial y}=0
$$

Consequentemente, a função que atende essa mesma condição é definida como a função de corrente $\psi$, definida pela relação entre as direções da velocidade em $x$ e $y$, que são $u$ e $v$ respectivamente.

$$
\begin{aligned}
& u=\frac{\partial \psi}{\partial y} \\
& v=-\frac{\partial \psi}{\partial x}
\end{aligned}
$$

Atendendo também a equação da continuidade, temos a definição da função potencial $\phi$, que, analogamente às funções de corrente, seguem às seguintes condições: 


$$
\begin{aligned}
& \frac{\partial u}{\partial x}+\frac{\partial v}{\partial y}=0, \\
& u=-\frac{\partial \phi}{\partial x} \\
& v=-\frac{\partial \phi}{\partial y} .
\end{aligned}
$$

As equações (3.4) e (3.6) definem a relação direta entre a velocidade de um campo bidimensional e as funções potenciais e de corrente. Essas funções definem as características geométricas do escoamento. Essas equações também podem ser usadas para definir as equações de Laplace, que, no escoamento bidimensional são:

$$
\frac{\partial^{2} \psi}{\partial x^{2}}+\frac{\partial^{2} \psi}{\partial y^{2}}=0, \quad \frac{\partial^{2} \phi}{\partial x^{2}}+\frac{\partial^{2} \phi}{\partial y^{2}}=0
$$

Existem cinco soluções básicas para as equações de Laplace, as quais definem o escoamento e são nomeadas como escoamento uniforme, escoamento de fonte, escomento de sumidouro, vórtice irrotacional e dipolo.

No sentido físico, a combinação desses escoamentos pode ser realizada com o objetivo de criar tipos de escoamentos mais coplexos, conforme desejado para representar o fluxo ao redor do corpo em estudo. Matematicamente, essa sobreposição das funções de corrente e potencial pode ser feita, uma vez que a equação de Laplace é linear e permite que as funções resposta sejam uma combinação linear entre as cinco respostas básicas.

A versatilidade de representar novos escoamentos utilizando os básicos permite modelar o escoamento em geometrias mais complexas, como os aerofólios, que são de difícil representação. Existem métodos que utilizam a representação de perfis aerodinâmicos em um cilindro equivalente, conhecido como método da transformada de Kutta-Joukowski (ABBOTT; DOENHOFF, 1949). Entretanto, como esses métodos apresentam dificuldades para serem adaptados a modelos de asas finitas, optou-se por usar outros métodos. 


\subsection{REPRESENTAÇÃO GEOMÉTRICA DO AEROFÓLIO}

O modelo até então desenvolvido, é baseado em um escoamento incompressível, irrotacional, bidimensional e estacionário, pelo qual a geometria do aerofólio é respresentada por uma combinação linear das soluções da equação de Laplace. A sustentação é calculada através do campo de pressões que é dependente do campo de velocidades, obtido pela equação de Bernoulli. Esse modelo precisa ser adaptado para o caso de uma asa finita e um regime não-estacionário.

\subsubsection{Considerações de asa fintia}

O modelo de asa finita leva em consideração o efeito da ponta de asa. Esse efeito gera uma diferença no campo de velocidades, e consequentemente no cálculo da sustentação do aerofólio. O efeito de ponta de asa ocorre quando o escoamento do intradorso e extradorso enfrentam pressões diferentes, e então, na região em que não há restrição ao encontro desses escoamentos (na ponta da asa), é gerada uma vorticidade. Essa vorticidade causa o desvio do escoamento no bordo de fuga, e esse desvio é gerado para baixo, carcterizando o efeito de downwash. A diferença causada no valor calculado da sustentação é insignificante para pequenos ângulos de ataque. No entanto, o efeito no arrasto é mais significativo.

A aplicação matemática de vorticidade pode ser considerada no cálculo da sustentação através do teorema de Kutta-Joukowski, que sugere a seguinte relação:

$\vec{L}=\rho \vec{V}_{\infty} \times \vec{\Gamma}$

Nessa equação, usa-se o conceito de circulação, que é uma função de vorticidade. No entanto, para se calcular a velocidade induzida por um segmento de vórtice do escoamento, usa-se a equação de Biot-Savart:

$$
d \vec{V}=\frac{\Gamma}{4 \pi} \frac{d \vec{l} \times \vec{r}}{|\vec{r}|^{3}}
$$




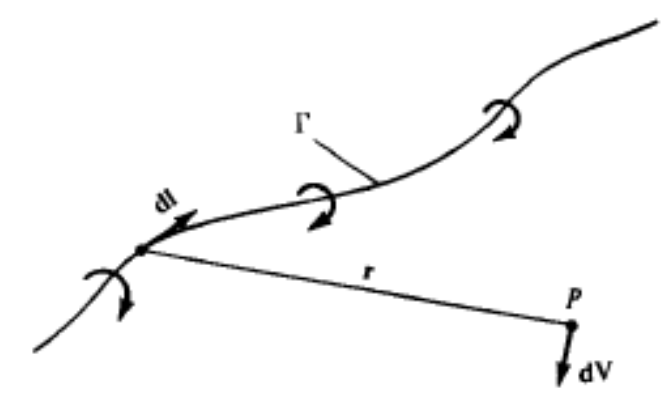

FIGURA 3.1 - Lei de Biot-Savart (ANDERSON, 1991).

A equação de Biot-Savart também pode ser aplicada a segmentos retos de vórtices, o que exige reescrever a equação (3.9) conforme sugerido por Katz e Plotkin (1991).

$$
\vec{V}=\frac{\Gamma}{4 \pi} \frac{\vec{r}_{1} \times \vec{r}_{2}}{\left|\vec{r}_{1} \times \vec{r}_{2}\right|^{2}}\left(\vec{r}_{1}-\vec{r}_{2}\right)\left(\frac{\vec{r}_{1}}{\left|\vec{r}_{1}\right|}-\frac{\vec{r}_{2}}{\left|\vec{r}_{2}\right|}\right)
$$

A representação da definição de Katz e Plotkin (1991) é ilustrada na figura (3.2).

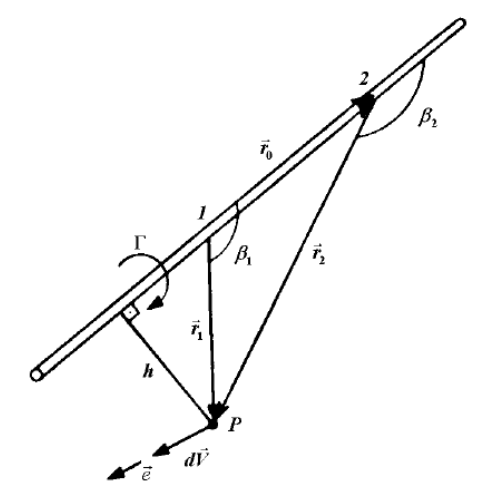

FIGURA 3.2 - Lei de Biot-Savart para segmentos retos (KATZ; PLOTKIN, 1991).

Com o conceito de que a vorticidade induz velocidade em um determinado ponto, é possível de se obter o campo de velocidades para qualquer tipo de geometria de asa, ao se distribuir vorticidades em determinadas divisões de área da asa. Por essa razão, é muito importante a especificação do segmento de vórtice a ser usado, para que esse gere uma boa aproximação do comportamento do escoamento. 
O físico alemão Hermann Helmholtz criou três teoremas a serem respeitados para a implementação dos segmentos de vórtices (HOUGHTON; CARPENTER, 2003):

$1^{\circ} \mathrm{A}$ intensidade de um segmento de vórtice deve ser constante ao longo do seu comprimento. $2^{\circ}$ Um segmento de vórtice não pode terminar em um fluído, devendo se estender até o infinito ou formar uma trajetória fechada.

$3^{\circ}$ Um segmento de vórtice não se destrói com o tempo e sua intensidade se conserva.

A aplicação clássica de segmentos de vórtices em aerodinâmica é encontrada na teoria da linha de sustentação de Prandtl, o qual utiliza linhas de vórtices espalhadas pela envergadura da asa, em formato de vórtices ferradura, os quais atendem os teoremas de Helmholtz, e oferecem bons resultados. Uma sofisticação dessa aplicação é encontrada na utilização de anéis de vórtices em superfícies, porém, essa aplicação exige uma discretização em painéis, caracterizando malhas de vórtices. No entanto, associado a essa idéia, é necessário desenvolver uma metodologia de discretização dessa malha de vórtices, que pode ser atendida pela aplicação do método dos painéis.

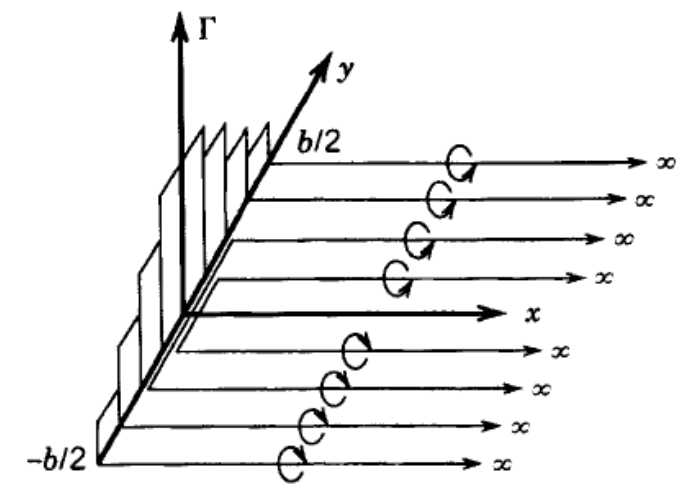

FIGURA 3.3 - Teoria da linha de sustentação de Prandtl (KUETHE; CHOW, 1998).

\subsubsection{Método de malha de vórtices}

Esse método conhecido como método dos anéis de vórtice, do inglês: Vortex Lattice Method (VLM). O VLM é resultado da associação entre o Método dos Painéis com o Método de Vórtices, como proposto por Lewis (1981). Uma revisão histórica sobre o método pode ser obtida em Hess (1990).

No método VLM, a superfície da asa é dividida em áreas, chamadas de painéis, que são de mesma área e igualmente espaçados. Essa divisão facilita a criação de uma malha 
aerodinâmica, ao se definir apenas o número de divisões ao longo da envergadura $j$, e o número de divisões ao longo da corda $i$, conforme a figura (3.4).
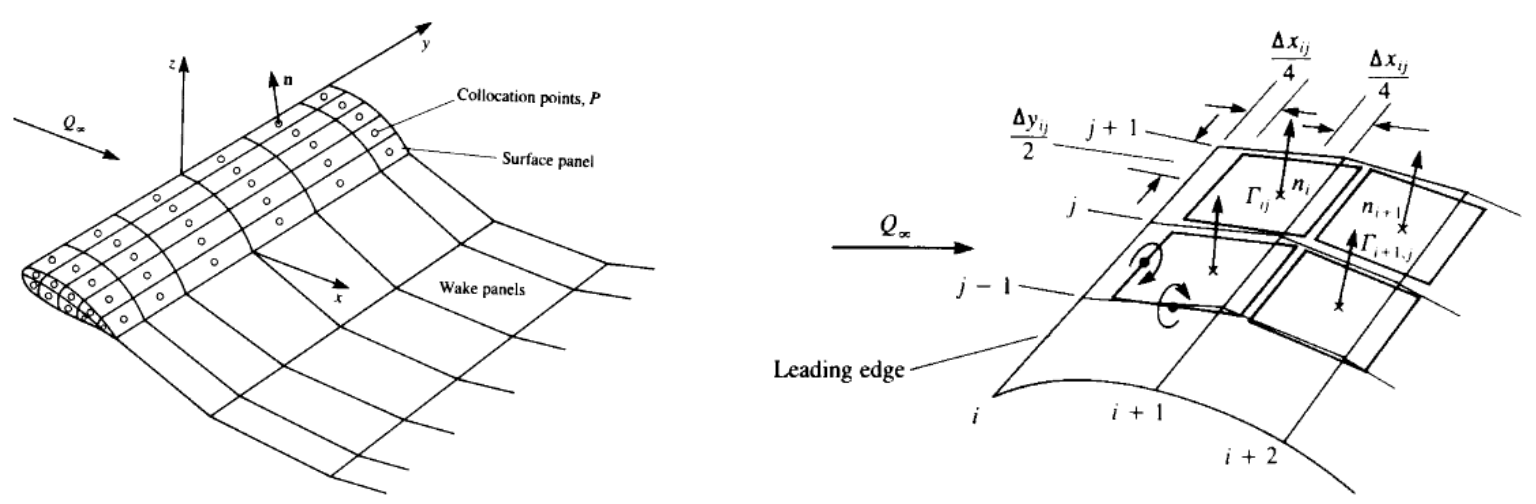

\section{FIGURA 3.4 - Descrição da malha aerodinâmica pelo método VLM (KATZ; PLOTKIN, 1991).}

Os anéis de vórtices, conforme ilustra a figura (3.4), são distribuídos ao longo dos painéis, sendo que a porção dianteira do anel passa pela linha de $1 / 4$ de corda do painel e o ponto de controle, onde se aplica a condição de contorno, fica localizado no centro do anel, que corresponde a linha de $3 / 4$ de corda do painel. O sentido da circulação $\vec{\Gamma}$, definida pela regra da mão direita. Esse anel é composto de quatro arestas, cada uma representando um segmento reto de vórtice, sendo que, a velocidade que cada um destes segmentos induz num painel pode ser calculada pela equação (3.10). Contudo, considerando os diversos anéis de vórtices, cada qual em um painel da asa, é necessário se calcular a velocidade induzida em um determinado painel devido a cada um desses anéis, e também, a influência do próprio painel nele mesmo.

Para que essa idéia seja matematicamente reproduzida, é necessário associá-la a condição de contorno de fluxo normal nulo. Nessa condição, a componente de velocidade normal ao escoamento considera a contribuição de cada painel, a qual é função da circulação associada. Sendo assim, a condição de contorno é dada por:

$\left[\vec{V}_{11}\left(\Gamma_{1}\right)+\vec{V}_{12}\left(\Gamma_{2}\right)+\vec{V}_{13}\left(\Gamma_{3}\right)+\cdots+\vec{V}_{1 m}\left(\Gamma_{m}\right)+\vec{V}_{\infty}\right] \vec{n}_{1}=0$

$\left(\begin{array}{cccc}a_{11} & a_{12} & \cdots & a_{1 m} \\ a_{21} & a_{22} & \cdots & a_{2 m} \\ \vdots & \vdots & \ddots & \vdots \\ a_{m 1} & a_{m 2} & \cdots & a_{m m}\end{array}\right)\left(\begin{array}{c}\Gamma_{1} \\ \Gamma_{2} \\ \vdots \\ \Gamma_{m}\end{array}\right)=-\vec{V}_{\infty}\left(\begin{array}{c}\vec{n}_{1} \\ \vec{n}_{2} \\ \vdots \\ \vec{n}_{m}\end{array}\right)$ 
Pela equação (3.11) temos a representação da velocidade induzida pela circulação de cada um dos $m$ painéis, no painel de número 1. Ao se desenvolver a equação (3.11) para toda a malha aerodinâmica, chega-se na equação (3.12), onde o lado esquerdo da equação representa a parte da velocidade normal induzida pela vorticidade da asa, e o lado direito, a parte da velocidade normal do fluxo passante na asa. Esse sistema de equações apresenta como incógnita o valor da circulação em cada painel, os quais são usados para calcular o valor da sustentação pelo teorema de Kutta-Joukowski.

É importante comentar que, dentre os quatro segmentos retos de vórtices, apenas dois podem satisfazer a condição de escoamento normal nulo, que são os segmentos paralelos a direção da corda. Portanto, apenas estes segmentos serão considerados para calcular a indução de velocidade.

Outro ponto importante é a consideração da vorticidade no bordo de fuga. Segundo o proposto pela condição de Kutta, a variação da circulação (associada à vorticidade) no bordo de fuga deve ser nula, para que a teoria concorde com a realidade experimental das linhas de corrente ao redor de um aerofólio. Para que essa condição seja respeitada no modelo de asa finita e não-estacionário, é necessário considerar o efeito da esteira do bordo de fuga, a qual deve também ser discretizada em painéis. Com isso, para incremento de tempo, pode-se aplicar a condição de que a circulação do bordo de fuga da asa será igual a circulação da região da esteira próxima ao bordo de fuga. Com isso, a variação de circulação do bordo de fuga se anula ao longo da envergadura, respeitando a condição de Kutta.

Em relação à esteira, também é importante caracterizar sua direção inicial, o que não é possível com a teoria de downwash, no entanto é possível considerar dados experimentais para tal (KATZ; PLOTKIN, 1991).

\subsection{MODELO AERODINÂMICO FINAL: NÃO - ESTACIONÁRIO}

Nos itens anteriores foi possível criar condições para a consideração de escoamento tridimensional, restando agora, criar as considerações de aerodinâmica não-estacionária. Com isso, o modelo finalmente atinge suas características finais, de escoamento incompressível, potencial, tridimensional e não-estacionário. 
Antes de definir a condição de fluxo não-estacionário, é importante definir a condição de contorno que determina a circulação na asa. A equação que representa essa condição é a consideração de fluxo normal nulo:

$\vec{V}_{n}=\vec{V}_{\infty} \cdot \vec{n}+\vec{w}=0$

Na equação (3.13), $\vec{V}_{\infty}$ é a velocidade do escoamento, $\vec{n}$ o vetor normal à área do painel da asa, e $\vec{w}$ é a velocidade que os vórtices dos painéis induziram na asa. Então, essa equação fica definida por:

$\vec{w}=-\vec{V}_{\infty} \cdot \vec{n}$.

A velocidade induzida pelas vorticidades dos painéis na asa é definida pela equação (3.12), e, a velocidade do escoamento é definida como a velocidade induzida pela esteira, também calculada pela equação (3.12), somada com a velocidade do movimento relativo da asa, a qual exige a definição de um sistema de coordenadas. Essa definição cria condições de se introduzir as deformações da estrutura (dados obtidos pela equação de movimento) para cada instante de tempo, e devido ao carregamento aerodinâmico.

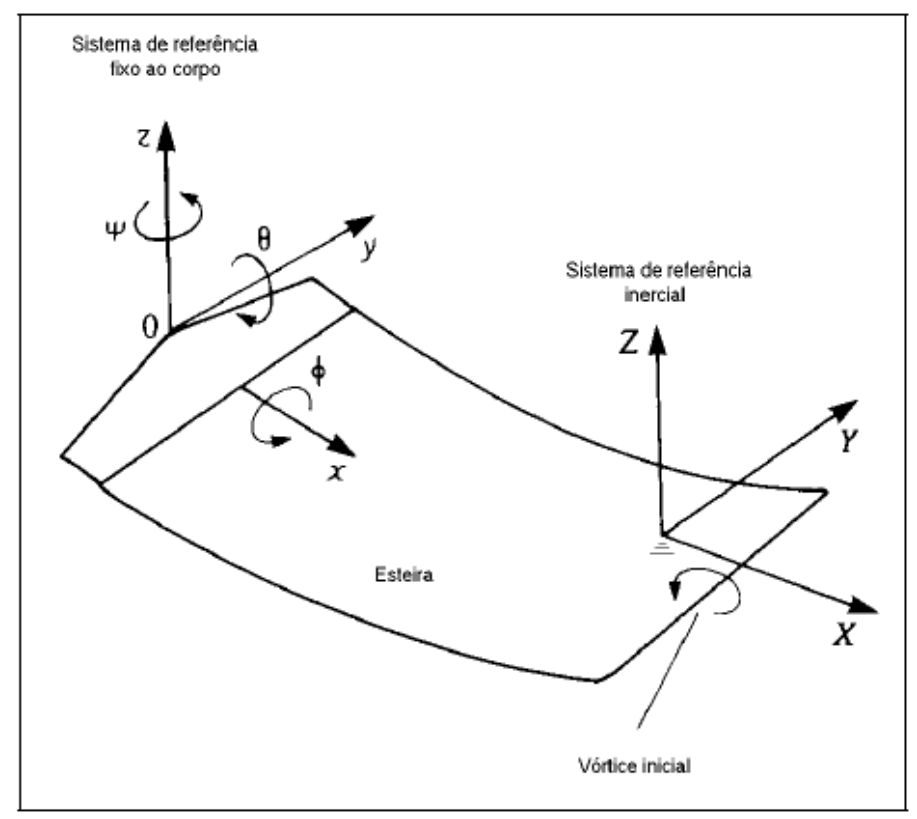

FIGURA 3.5 - Sistema de coordenadas da velocidade relativa da asa (KATZ; PLOTKIN, 1991) 
Então, o sistema $X, Y, Z$ é o sistema global, considerado inercial. Já o sistema $x, y, z$ é o sistema fixo na asa. A velocidade da asa em relação ao referencial inercial é descrita por:

$$
\vec{v}=-\left[\vec{V}_{0}+\vec{v}_{r e l}+\vec{\Omega} \times \vec{R}_{0}\right]
$$

onde $\vec{v}$ é a velocidade da asa, $\vec{V}_{0}$ é a velocidade de translação do sistema local em relação ao sistema global, $\vec{v}_{r e l}$ é a velocidade relativa da asa em relação ao sistema local (x,y,z) e $\vec{\Omega}$ a velocidade angular desse mesmo sistema de coordenadas.

Com essa criação de sistema de coordenadas local e global, é possível caracterizar os efeitos de esteira e também, os efeitos de deformação da asa ao longo do tempo, o que deixa de caracterizar a asa como um corpo rígido e permite a inserção do efeito aeroelástico. Os dados usados para calcular a velocidade relativa da asa, $\vec{v}_{r e l}$, serão fornecidos pela resposta da equação de movimento, a qual exibe a amplitude dos nós da malha elástica e aerodinâmica devido ao carregamento aerodinâmico, em cada instante de tempo.

Para se calcular a velocidade induzida pela esteira é necessário utilizar a condição de Kutta para cada instante de tempo. Nas figuras (3.6) e (3.7) podemos observar essa condição sendo aplicada para cada instante de tempo, a qual, além de permitir a representação mais real da esteira, também facilita a obtenção da circulação na esteira.

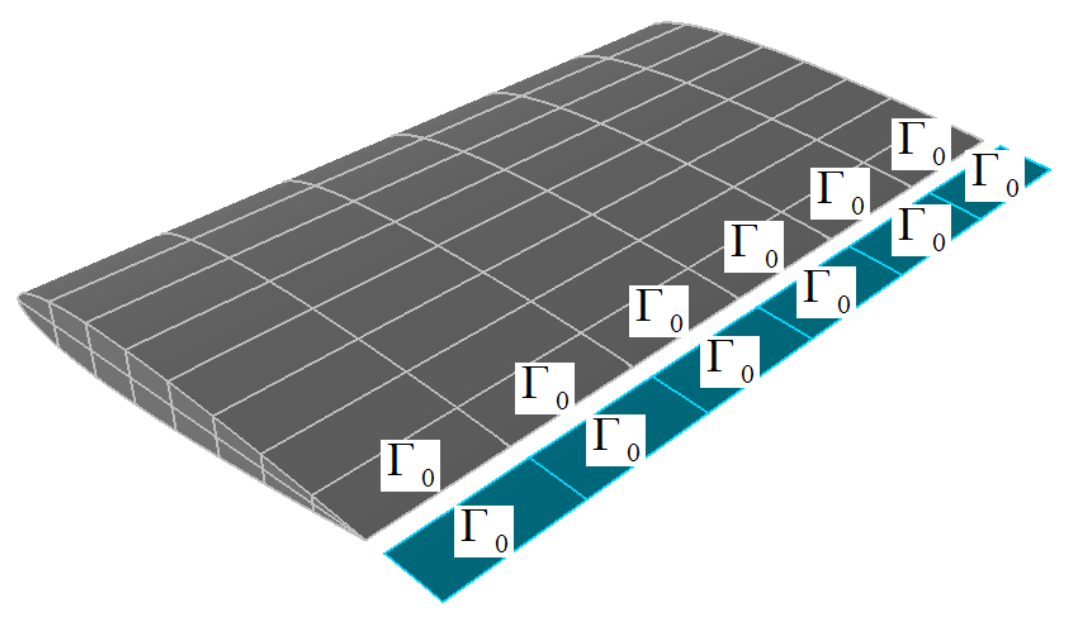

FIGURA 3.6 - Condição de Kutta aplicada no instante inicial. 


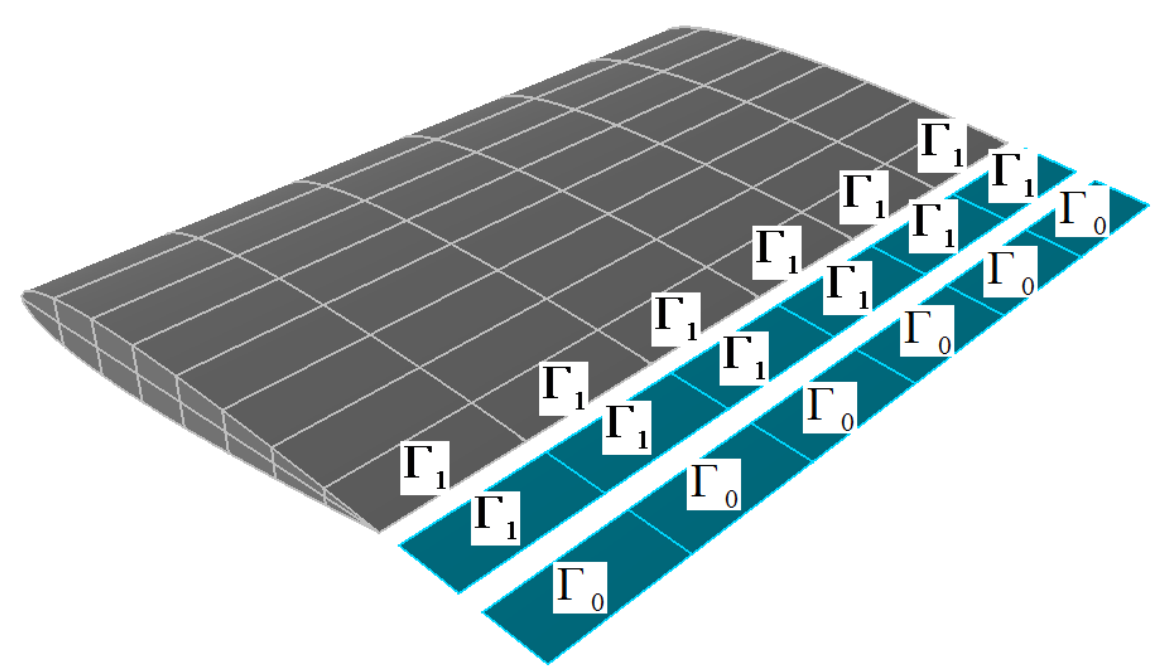

FIGURA 3.7 - Condição de Kutta aplicada no instante seguinte ao inicial.

Então é possível concluir que, para cada passo de tempo, a esteira vai sendo ampliada e os valores de circulação da esteira, próximos aos painéis do bordo de fuga da asa, são iguais às circulações correspondentes nos painéis do bordo de fuga da asa. Sendo assim, a velocidade da esteira pode ser definida pelos valores da circulação determinados nos passos anteriores.

$$
\vec{v}_{k}=\left(\begin{array}{llll}
a_{m 1} & a_{m 2} & \cdots & a_{m m}
\end{array}\right)\left(\begin{array}{c}
\Gamma_{1} \\
\Gamma_{2} \\
\vdots \\
\Gamma_{m}
\end{array}\right)
$$

Conforme a equação (3.16), $\vec{v}_{k}$ é a velocidade da esteira e $m$ é o número de painéis ao longo da envergadura.

Então, definida a velocidade da esteira, a velocidade relativa da asa e a velocidade induzida pelas vorticidades da asa, a equação (3.14) pode ser detalhada como:

$$
\left.\left(\begin{array}{cccc}
a_{11} & a_{11} & \cdots & a_{11} \\
a_{11} & a_{11} & \cdots & a_{11} \\
\vdots & \vdots & \ddots & \vdots \\
a_{11} & a_{11} & \cdots & a_{11}
\end{array}\right)\left(\begin{array}{c}
\Gamma_{1} \\
\Gamma_{2} \\
\vdots \\
\Gamma_{m}
\end{array}\right)=\left\{-\vec{V}_{0}+\vec{v}_{r e l}+\vec{\Omega} \times \vec{R}_{0}\right]+\left[\vec{v}_{k}\right]\right\} \cdot \vec{n}
$$


Essa equação caracteriza um sistema linear de equações, cujas incógnitas são os valores das circulações em cada painel. Como o modelo é não-estacionário, a equação (3.17) é resolvida para cada passo de tempo, e então, antes de seguir para resolver o próximo passo, os valores de circulação são utilizados para se calcular a diferença de pressão entre os painéis do extradorso e intradorso. A equação de Bernoulli para o caso não-estacionário, associada com o teorema de Kutta-Joukowski é deduzida por Katz e Plotkin (1991), conforme a equação (3.18).

$$
\frac{\Delta p}{\rho}=\frac{V_{\infty} \Gamma \cos (\alpha)}{S_{p}}+\frac{\partial \Gamma}{\partial t}
$$

Nessa equação, temos que $\Delta p$ é a diferença de pressão entre extradorso e intradorso, $\rho$ é a densidade do escoamento, $V_{\infty}$ a velocidade do escoamento, $\alpha$ o ângulo de ataque, $S_{p}$ a área do painel e $\Gamma$ a circulação do painel.

Com o valor da diferença de pressão em cada painel, e com sua respectiva área de asa, o produto dessas grandezas resulta na sustentação do painel. No entanto, como esses cálculos são realizados para cada passo de tempo, o diagrama que resume o funcionamento da rotina que calcula o modelo aerodinâmico segue na figura (3.8). 


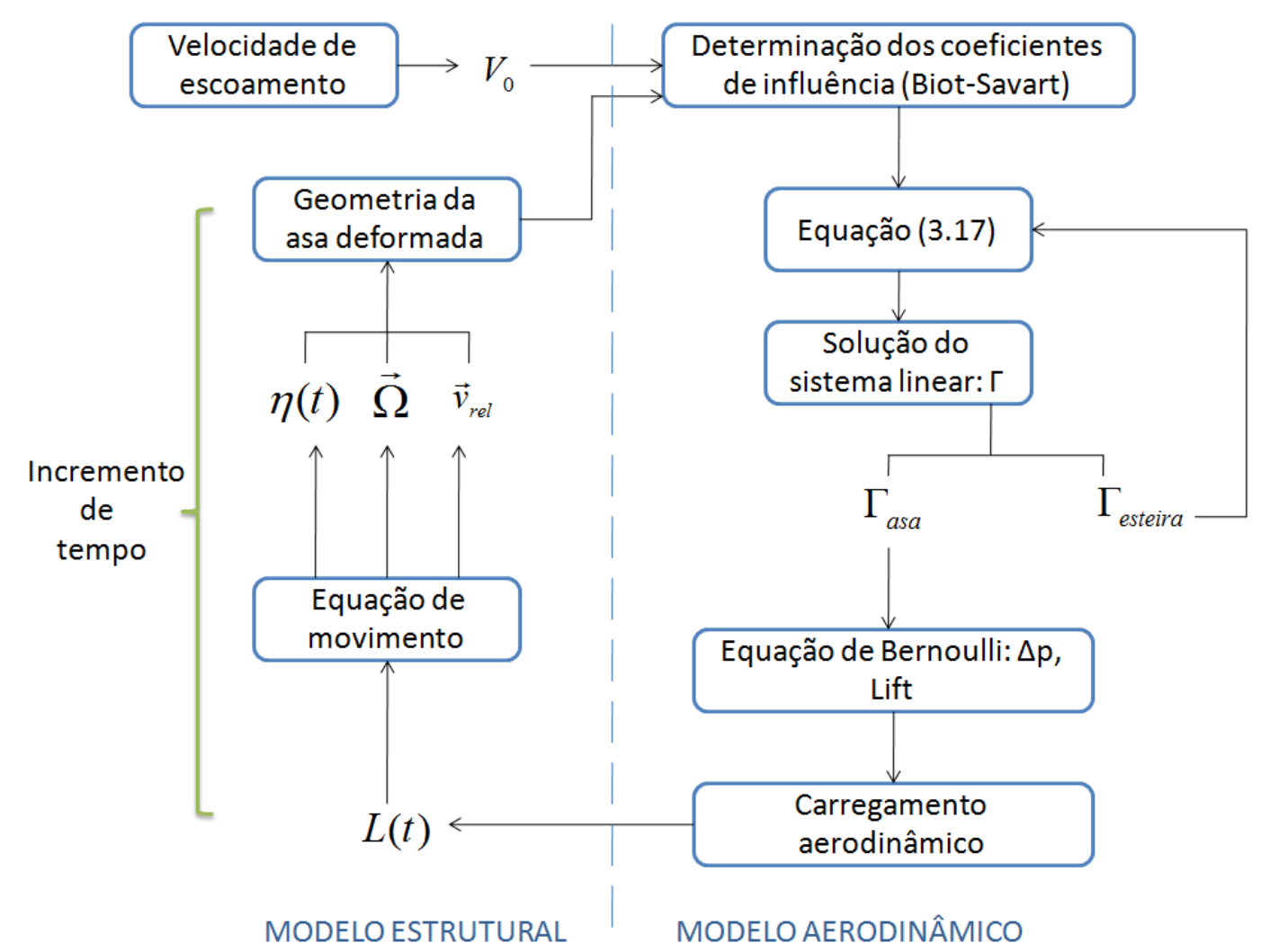

FIGURA 3.8 - Interação do modelo aerodinâmico com o modelo estrutural. 


\section{ANÁLISE AEROELÁSTICA E RESULTADOS}

\subsection{INTRODUÇÃO}

Nesse capítulo foi definida a metodologia de análise de flutter e do desempenho do sensor piezelétrico. Inicialmente foi ilustrado o procedimento de intercâmbio de informações entre os modelos estruturais e aerodinâmicos, que é fundamental para a resolução da equação de movimento do sistema. A escolha dos parâmetros a serem avaliados foi definida, sendo estes: o ângulo das camadas do laminado de fibra de vidro, a posição do sensor em relação à placa e as velocidades de escoamento.

A métrica de acoplamento modal também foi descrita, para que seja possível relacionar a análise de flutter com o desempenho do sensor proposto. Dessa forma, foram obtidos os resultados, definindo as respostas da placa para cada velocidade de escoamento, o mecanismo modal de acordo com a métrica e a potência de sinal do sensor nos modos de flutter. Com os resultados obtidos, foi possível realizar a discussão sobre o efeito dos parâmetros do sensor na detecção do flutter.

\subsection{CONSIDERAÇÕES INICIAIS}

A análise aeroelástica se concentra na resolução da equação de movimento (definida no capítulo 2), a qual exigiu uma elaboração do modelo dinâmico-estrutural e do modelo aerodinâmico para obtenção do carregamento. Com esses dois modelos definidos, é possível simular a resposta no domínio do tempo e no domínio da freqüência para cada velocidade de fluxo considerada.

Seguindo essa possibilidade, é possível determinar a velocidade de flutter, bem como os modos envolvidos no surgimento do mesmo. Essa determinação é feita utilizando a resposta dos cinco primeiros modos aeroelásticos no domínio da freqüência e sua confirmação física na resposta temporal desses modos. Após encontrar a velocidade de flutter, outra 
análise é criada no sentido de melhor visualização do mecanismo de acoplamento modal, a qual exige a definição de uma métrica de acoplamento que se baseia na resposta modal da abordagem inicial. Ao se determinar os modos envolvidos, é possível avaliar o desempenho do PFC na eficiência como sensor do flutter. Essa avaliação é feita baseada na potência de sinal obtida em cada posição considerada na análise geral. A figura (4.1) ilustra, de maneira simplificada, a organização da análise de flutter associada com a resolução da equação de movimento.

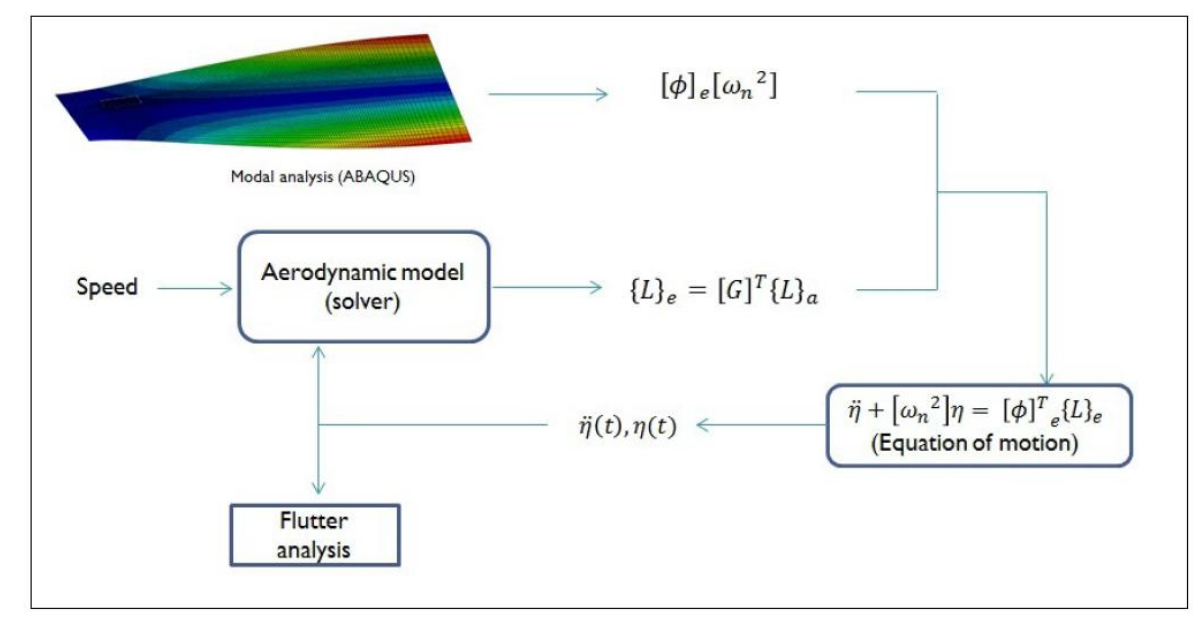

FIGURA 4.1 - Organização de análise de flutter.

A figura (4.1) mostra a transferência dos dados do modelo MEF para o modelo aerodinâmico e vice-versa. Nesse procedimento, é usada uma matriz de mudança de base $G$, pois ambos os modelos podem possuir sistemas de coordenadas diferentes já que são trabalhados em domínios diferentes. Essa troca de informações, que usa métodos numéricos de interpolação, deve ser feita com determinada precisão, pois pode afetar a obtenção da matriz modal, comprometendo os resultados da análise como um todo. Uma avaliação do desempenho dos métodos numéricos mais usados nessa tarefa pode ser encontrada em Smith, Hodges e Cesnik (2000). No entanto, para que, esse fator de precisão não comprometa os resultados, nesse trabalho, os sistemas de coordenadas nos modelos aerodinâmico e estrutural coincidem. Além disso, os nós da malha aerodinâmica possuem as mesmas coordenadas que os nós da malha estrutural, os quais são utilizados para transmitir deslocamento. Essas simplificações foram abordadas de forma mais detalhada no segundo capítulo. 
Os parâmetros a serem variados na configuração do sensor são a posição e o ângulo das camadas do laminado de fibra de vidro e resina epoxy. Foram simuladas algumas possibilidades de configuração de um único sensor aderido à asa, sem avaliar o desmepenho de arranjos de sensores.

Foram escolhidas três posições possíveis de instalação do sensor, de acordo com a figura (4.2), e em cada posição foram simuladas três possibilidades de laminado, sendo esses formados pelo empilhamento de camadas unidirecionais (fibra e resina), com a angulação dessas camadas em graus: [0/90], [0/45] e [-45/45].

\section{$\sqrt{\text { Escoamento }}$}

Raiz da asa
\begin{tabular}{|c|c|c|c|c|c|c|c|c|c|c|c|}
\hline & & Pos 3 & & & & & & & & & \\
\hline & & & & & & & & & & & \\
\hline & Pos1 & & & & & & & & & & \\
\hline & & & & & & & & & & & \\
\hline & & & & & & & & Pos 2 & & & \\
\hline & & & & & & & & & & & \\
\hline
\end{tabular}

FIGURA 4.2 - Posições do sensor na placa.

Considerando três posições que utilizam três possibilidades de laminado para cada uma, tem-se um total de nove modelos geométricos de asa com sensor. No entanto, foram avaliadas sete condições de escoamento, cada qual em uma velocidade, sendo estas: 05, 10, $15,25,28,30$ e $32 \mathrm{~m} / \mathrm{s}$.

As posições do sensor foram escolhidas de acordo com os modos da placa obtidos na seção (2.4). De acordo com as posições onde a placa apresenta as maiores deformações no sentido de atuação da fibra piezelétrica, e atendendo aos cinco modos considerados, foram escolhidas as três posições de instalação do sensor. Nessas posições é possível obter uma potência de sinal maior, uma vez que esta é proporcional à deformação do piezelétrico.

Para determinar a região da placa que apresentaria maiores deformações, quando o modo alvo é excitado, fez-se, utilizando o MEF, o cálculo do campo de deformações na condição de excitação de cada um dos modos, o que é possível ainda na análise modal realizada. Então, como a deformação das barras piezelétricas está na direção da longarina da 
asa (devido ao modo de atuação $d 31$ ), o campo de deformações obtido foi também nessa direção, como mostra a figura (4.3).
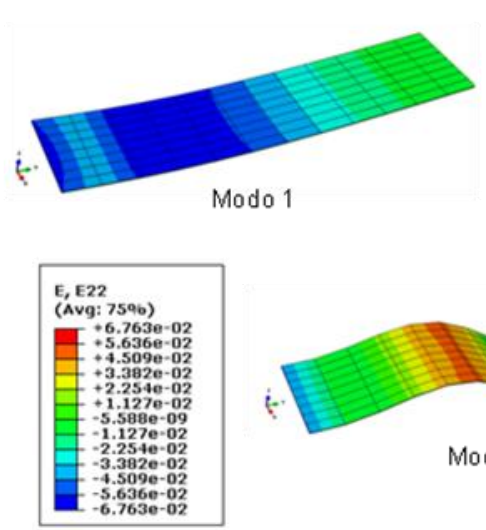

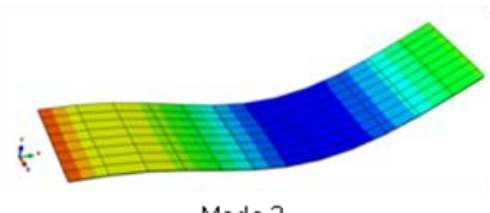

Modo 2

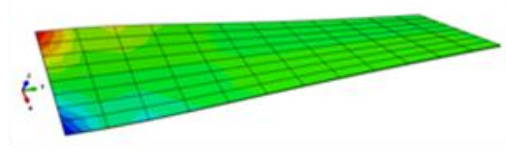

Modo 3
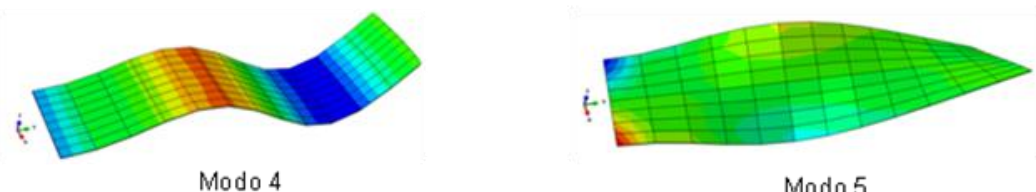

FIGURA 4.3 - Posições do sensor avaliadas.

Então, como o mecanismo de flutter esperado envolve os modos de flexão acoplando com o de torção, as posições escolhidas para se atender o segundo e o terceiro modo, foram aquelas em que apresentam as maiores deformações nesses modos. Essas posições se concentram próximas a raiz da asa (no caso no modo 2), e também próximo a ponta da asa (no caso do modo 3). Por esse motivo, as posições 01 e 03 se localizam próximas a raiz, enquanto que a posição 02 se localiza próxima à ponta da asa. É importante lembrar que a região exatamente na raiz da asa não pode ser considerada para posicionar o sensor, uma vez que essa região possui uma condição de contorno que pode prejudicar o funcionamento do sensor.

As configurações de laminado foram escolhidas usando-se os laminados $0^{\circ}, 90^{\circ}$ e $45^{\circ}$ porque cada uma dessas angulações oferece uma característica em especial. Na camada de $0^{\circ}$ o modulo de elasticidade é máximo, pois está alinhado com as fibras. $\mathrm{Na}$ camada de $90^{\circ}$, o laminado apresenta o módulo mínimo e no laminado de $45^{\circ}$ a resitência ao cisalhamento é máxima. Podem-se observar essas características pela figura (4.4), em que as constantes de engenharia da camada são comparadas com as propriedades do laminado de acordo com a angulação do mesmo. 


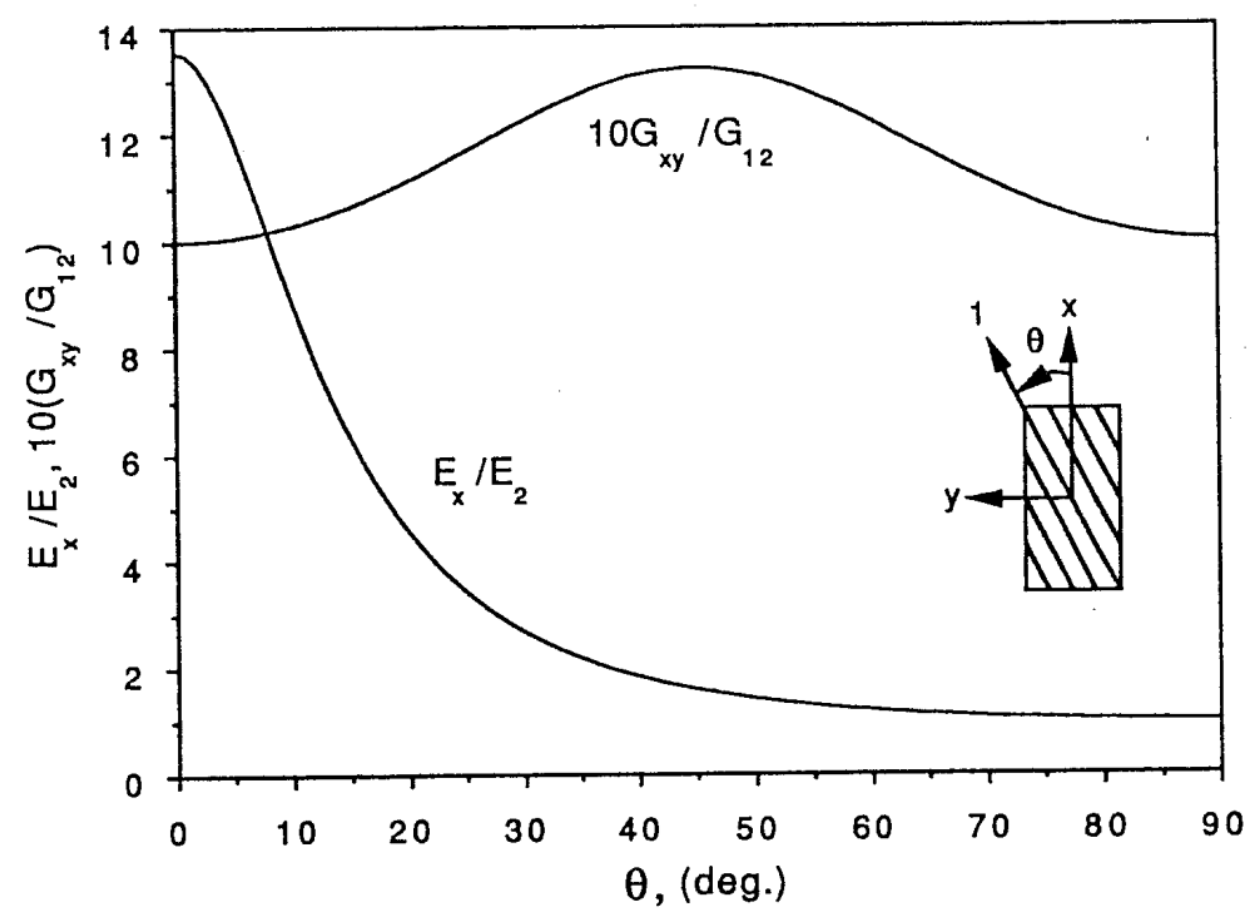

FIGURA 4.4 - Variações das propriedades do laminado de acordo com a angulação das fibras (DANIEL; ISHAI, 1994).

As velocidades foram escolhidas de acordo com a primeira análise simulada de flutter (para a placa), em que se variou a velocidade do escoamento de 0 a $50 \mathrm{~m} / \mathrm{s}$, em intervalos de $10 \mathrm{~m} / \mathrm{s}$ igualmente espaçados. Foi esperado que, dentro dessa faixa de velocidade, o flutter aconteceria. Analisando as respostas das simulações, no domínio da freqüência e do tempo, observou-se que o flutter ocorreu perto de $30 \mathrm{~m} / \mathrm{s}$. Por esse motivo a faixa de velocidades foi truncada de 0 a $32 \mathrm{~m} / \mathrm{s}$, e análises de escoamento na vizinhança de $30 \mathrm{~m} / \mathrm{s}$ foram consideradas, chegando às sete velocidades adotadas para uma melhor visualização do fenômeno através das respostas modais.

\subsection{OBTENÇÃO DA RESPOSTA MODAL}

A rotina em Fortran desenvolvida por Benini (2002) foi utilizada nesse trabalho para obter a resposta aeroelástica da asa. Essa rotina resolve a equação de movimento do sistema 
em cada instante de tempo, cujos passos são ilustrados pela figura (4.5), a qual resume a idéia das figuras (3.8) e (4.1) de maneira generalizada.

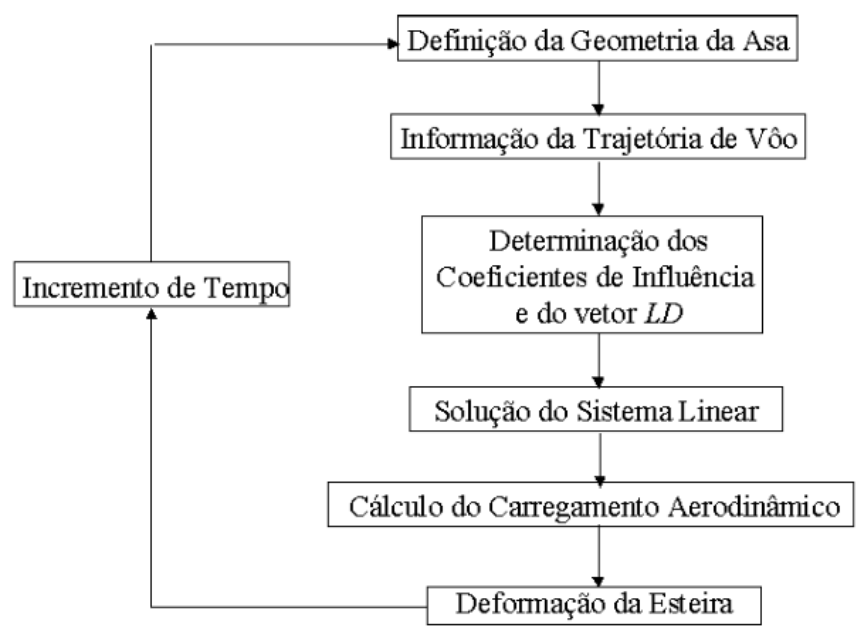

\section{FIGURA 4.5 - Resolução da equação de movimento aeroelástica (BENINI, 2002).}

Para obtenção do carregamento aerodinâmico em cada instante de tempo, inicialmente a geometria é definida de acordo com a discretização da malha aerodinâmica da asa (VLM). A forma atualizada dessa geometria é definida de acordo com os deslocamentos, que são obtidos no modelo dinâmico estrutural da asa. Com esses deslocamentos, a matriz de coeficiente de influencias é obtida e o sistema de equações resultante é resolvido para obtenção da circulação, e consequentemente a distribuição da sustentação na asa. Com esse carregamento, a equação de movimento do sistema é resolvida, e assim, os deslocamentos do instante de tempo seguinte são obtidos, ao passo que, a resposta modal do instante em questão é obtida. Com os deslocamentos do passo seguinte, é possível determinar a nova distribuição da malha aerodinâmica atualizada, para que tudo se repita para o passo seguinte.

A resposta no domínio do tempo é obtida para cada um dos cinco modos, ao se completarem o número de passos em que a análise foi calculada. A resposta de freqüência é obtida utilizando a transformada rápida de Fourrier (FFT). Por isso, para cada modo, é obtida a resposta aeroelástica em ambos os domínios.

É importante se atentar ao fato de que, apesar da malha estrutural ser mais refinada do que a aerodinâmica, existem pontos com coordenadas em comum nessas malhas. Esses pontos são ilustrados pela figura (4.6) e definem exatamente os 117 nós nos quais são 
calculados seus deslocamentos verticais e, através destes, definida a matrix modal descrita no capítulo 2.

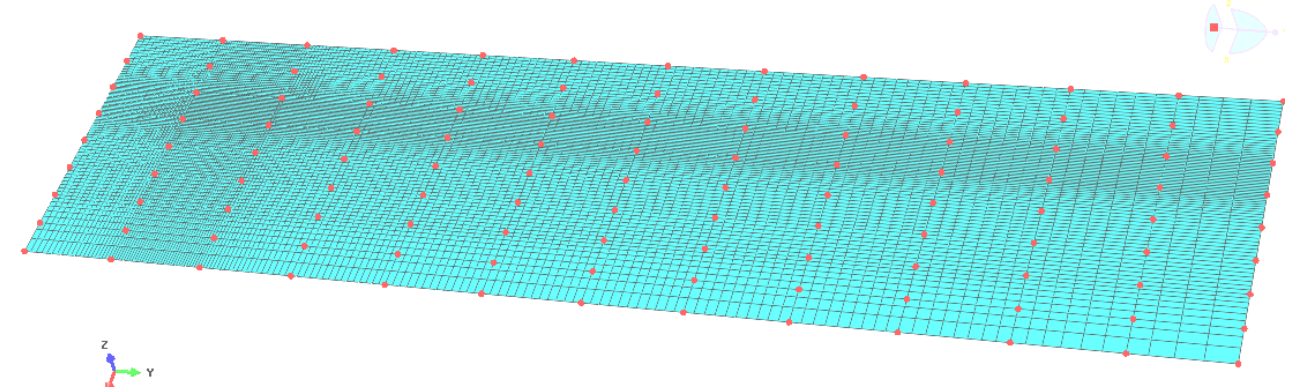

FIGURA 4.6 - Nós selecionados para obtenção da matriz modal.

Os nós que compreendem a região de instalação do $\mathrm{PFC}$, não pertencem à placa, e sim ao topo das fibras PZT, na região dos quatro vértices que delimitam o PFC. Nesses nós, além dos deslocamentos verticais, também é obtido o valor das voltagens, uma vez que, o elemento utilizado nessa região possui o grau de liberdade elétrico.

O resultado calculado pela rotina em FORTRAN é ilustrado pela figura (4.7), como de exemplo, de acordo com uma simulação feita para o laminado $\left[-45 / 45^{\circ}\right]$ na posição número 1 e para a velocidade de $30 \mathrm{~m} / \mathrm{s}$.
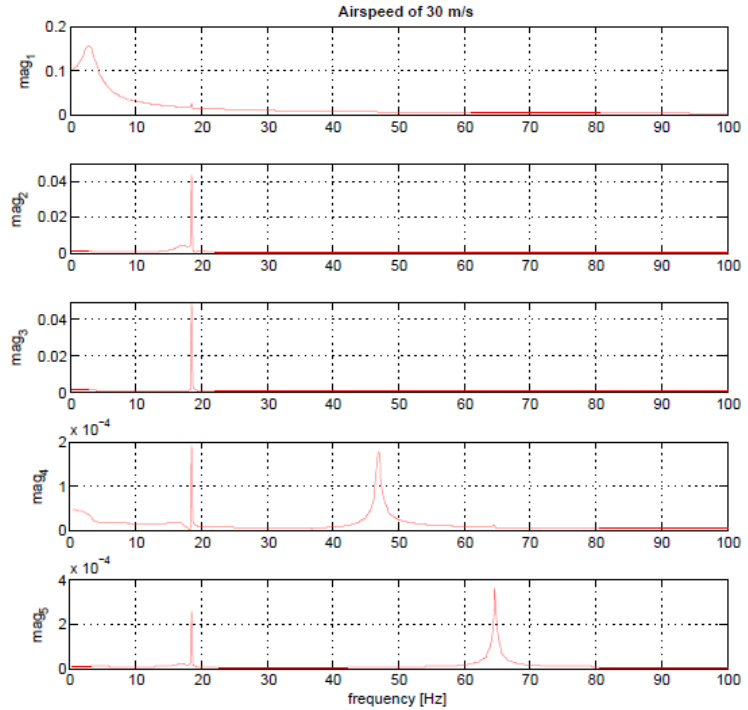
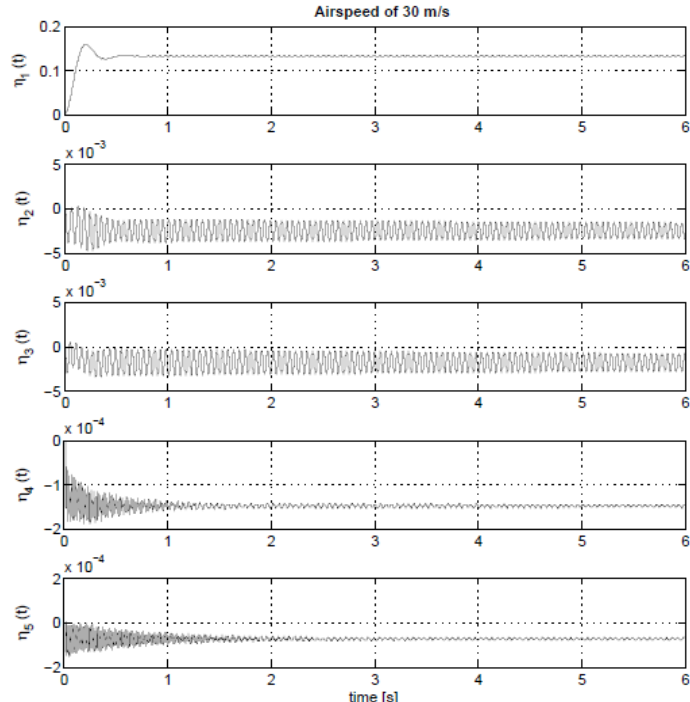

FIGURA 4.7 - Exemplo de resposta aeroelástica nos domínios da freqüência e do tempo. 


\subsection{MÉTRICA DE ACOPLAMENTO MODAL}

Através da resposta em frequiência obtida, é possível se determinar quais modos se acoplam e em qual velocidade isso ocorre. Porém, para se obter uma visualização mais detalhada desse acoplamento, é necessário elaborar uma métrica de correlação entre os modos. A métrica desenvolvida se baseia na multiplicação entre a resposta aeroelástica, em cada modo, por uma função que descreve a resposta sem interferência de outros modos. Essa função é obtida da resposta modal no domínio da frequiência com escoamento nulo, considerando apenas a dinâmica estrutural da placa, e é definida da seguinte forma (PREUMONT et al., 2003):

$g_{i}(\omega)=\frac{2 \xi_{i} \omega_{i}^{2}}{\omega_{i}^{2}-\omega^{2}+2 j \xi_{i} \omega_{i} \omega}$

Em que $\xi_{i}$ é o amortecimento estrutural do iésimo modo, $\omega_{i}$ a frequiência natural do iésimo modo, $\omega$ o domínio da frequiência e $g_{i}(\omega)$ a amplitude do modo em função da frequiência. Preumont et al. (2003) utilizou a equação (4.1) na função de filtro modal, o que é similar ao utilizado nesse trabalho.

A representação de cada um dos cinco modos é ilustrada pela figura (4.8).

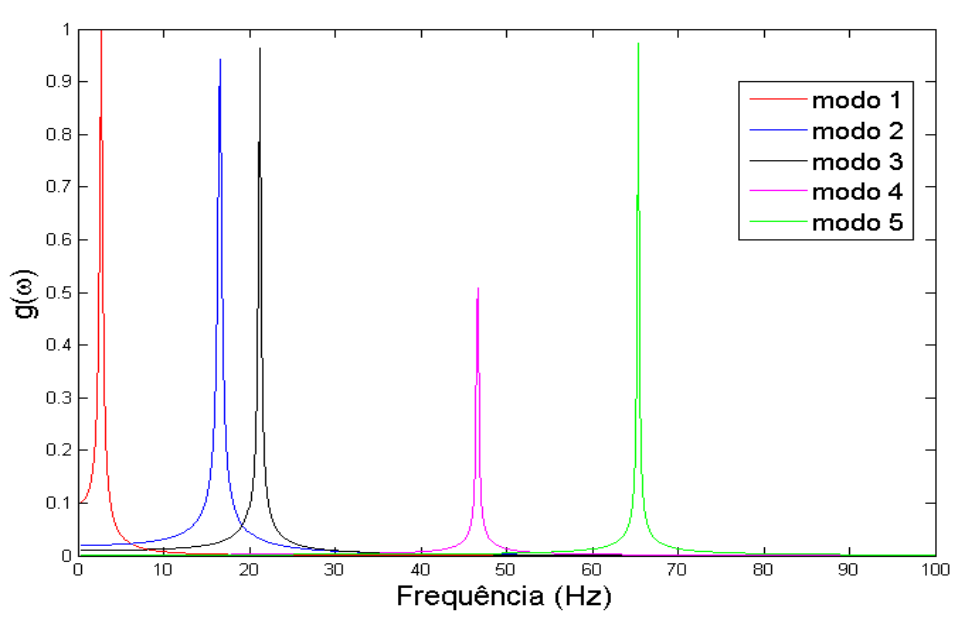

FIGURA 4.8 - Modos representados no domínio da frequência pela equação (4.1), na condição de escoamento nulo. 
Então, foi criada uma matriz que armazena todas as possíveis combinações de contaminações modais, para os cinco primeiros modos considerados.

$$
\left[\begin{array}{lllll}
{\left[\eta_{1} \cdot g(\omega)_{1}\right]} & {\left[\eta_{1} \cdot g(\omega)_{2}\right]} & {\left[\eta_{1} \cdot g(\omega)_{3}\right]} & {\left[\eta_{1} \cdot g(\omega)_{4}\right]} & {\left[\eta_{1} \cdot g(\omega)_{5}\right]} \\
{\left[\eta_{2} \cdot g(\omega)_{1}\right]} & {\left[\eta_{2} \cdot g(\omega)_{2}\right]} & {\left[\eta_{2} \cdot g(\omega)_{3}\right]} & {\left[\eta_{2} \cdot g(\omega)_{4}\right]} & {\left[\eta_{2} \cdot g(\omega)_{5}\right]} \\
{\left[\eta_{3} \cdot g(\omega)_{1}\right]} & {\left[\eta_{3} \cdot g(\omega)_{2}\right]} & {\left[\eta_{3} \cdot g(\omega)_{3}\right]} & {\left[\eta_{3} \cdot g(\omega)_{4}\right]} & {\left[\eta_{3} \cdot g(\omega)_{5}\right]} \\
{\left[\eta_{4} \cdot g(\omega)_{1}\right]} & {\left[\eta_{4} \cdot g(\omega)_{2}\right]} & {\left[\eta_{4} \cdot g(\omega)_{3}\right]} & {\left[\eta_{4} \cdot g(\omega)_{4}\right]} & {\left[\eta_{4} \cdot g(\omega)_{5}\right]} \\
{\left[\eta_{5} \cdot g(\omega)_{1}\right]} & {\left[\eta_{5} \cdot g(\omega)_{2}\right]} & {\left[\eta_{5} \cdot g(\omega)_{3}\right]} & {\left[\eta_{5} \cdot g(\omega)_{4}\right]} & {\left[\eta_{5} \cdot g(\omega)_{5}\right]}
\end{array}\right]_{5 \times 5}
$$

$\mathrm{Na}$ equação (4.2), a resposta aeroelástica $\eta_{i}$, definida por um vetor coluna é multiplicada por $g(\omega)_{i}$ no formato de um vetor linha, e essa operação matricial de multiplicação modo a modo, além de multiplicar uma função pela outra, ponto a ponto, gera a somatória dos termos dessa multiplicação, e dessa maneira, sugere uma métrica que é representada por um único número (resultado da somatória) e que pode ser representada por um gráfico de barras. Um exemplo desse gráfico, ilustrado pela figura (4.9 b), representa a contaminação modal do iésimo modo aeroelástico na jotaésima função $g(\omega)$.
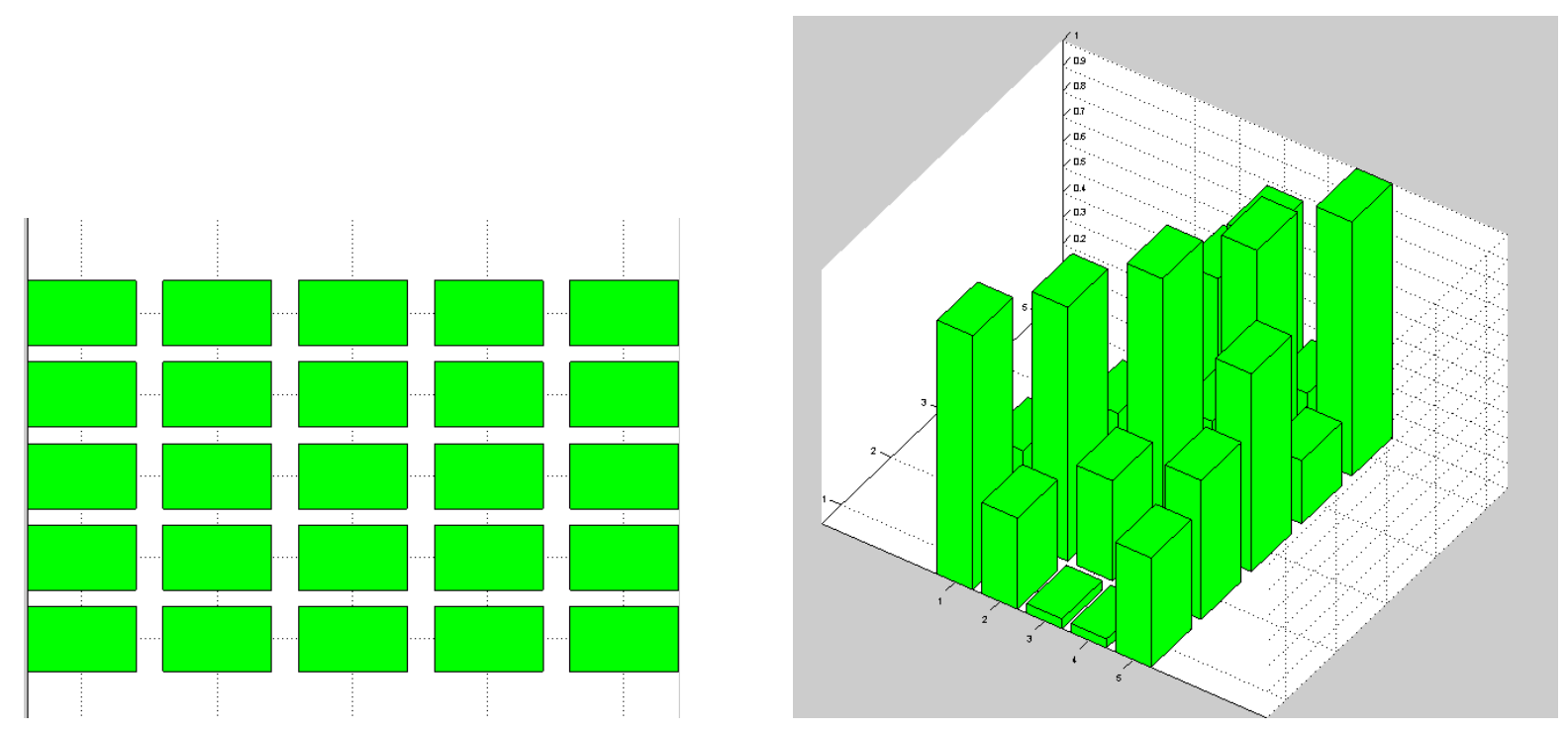

a) Regiões correspondentes a matriz (4.2).

b) Exemplo de ilustração das métricas.

FIGURA 4.9 - Ilustração da métrica adotada como avaliação do acoplamento modal, através de géfico de barras. 
Com a identificação dos modos envolvidos no mecanismo de flutter, é possível avaliar a potência do sinal piezelétrico para cada configuração testada e para cada condição de velocidade. Essa analise é realizada somente nos modos identificados como alvo, que são os responsáveis pelo acoplamento dos modos.

Li, Tang e Li (2004) sugerem que o local ótimo para se instalar os sensores em uma estrutura é onde ocorre a amplitude máxima de vibração, para um determinado modo, ou então, o local onde aparecem variações rápidas dessa amplitude de vibração.

Foi adotado um critério de avaliação de desempenho, na qual é buscada a configuração que irá gerar a maior potência de sinal já que está é proporcional às recomendações de $\mathrm{Li}$, Tang e Li (2004). No entanto, a amplitude que atende as necessidades de análise proposta nesse trabalho, é a amplitude de deformação das barras piezelétricas.

\subsection{DETERMINAÇÃO DA VELOCIDADE DE FLUTTER}

O primeiro passo para a análise de flutter proposta é o conhecimento da faixa de velocidades em que essa instabilidade ocorre, e para isso, foi utilizado o método de verificação da resposta de cada modo no domínio de freqüência e no domínio do tempo. Conforme a seção (4.2), para cada um dos nove casos, foi realizada uma simulação aeroelástica para as velocidades de $05,10,15,25,28,30$ e $32 \mathrm{~m} / \mathrm{s}$.

Para os nove casos de posição e configuração do sensor, a faixa de velocidade da instabilidade se concentra em torno do mesmo valor, o que mostra que a influência do sensor não interfere significativamente a ponto de alterar essa velocidade. Seguindo esse indicativo, e com o objetivo de ilustrar a análise de velocidade de flutter, apenas o caso da posição 02 do laminado $\left[0 / 90^{\circ}\right]$ é mostrado como segue abaixo, entre as figuras de (4.10) a (4.25). 

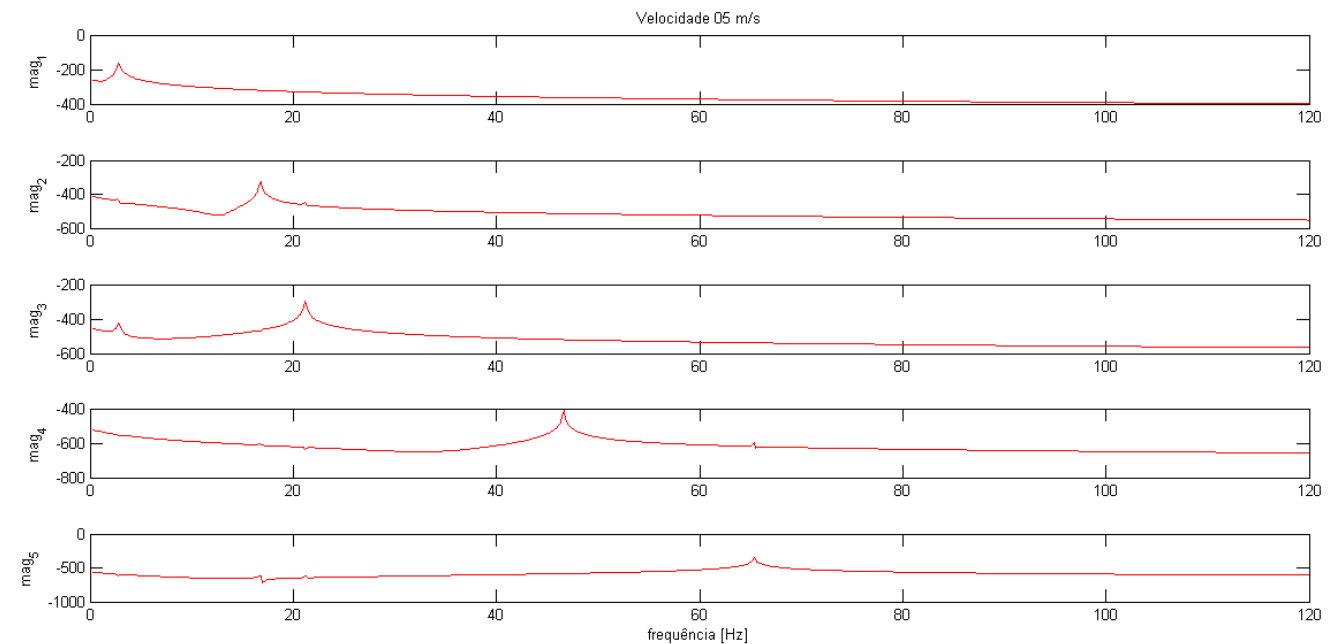

FIGURA 4.10 - Resposta dos cinco primeiros modos no domínio da frequência, para a velocidade de $5 \mathrm{~m} / \mathrm{s}$.
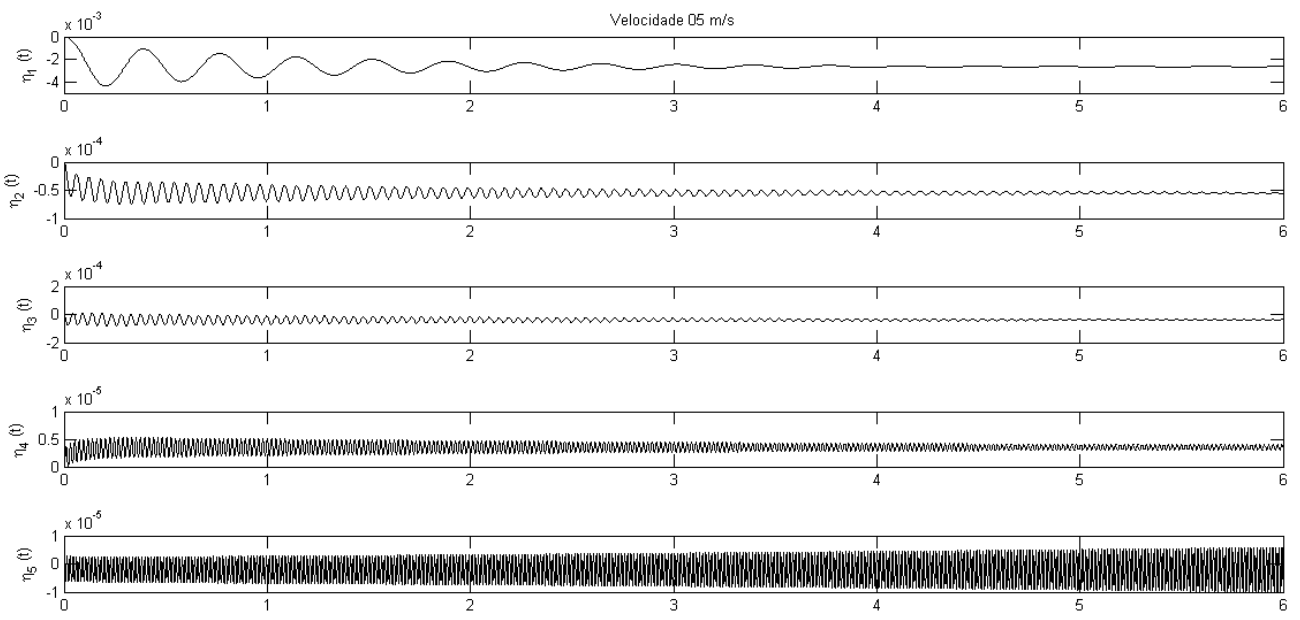

tempo [s]

FIGURA 4.11 - Resposta temporal dos cinco primeiros modos, na velocidade de $5 \mathrm{~m} / \mathrm{s}$. 

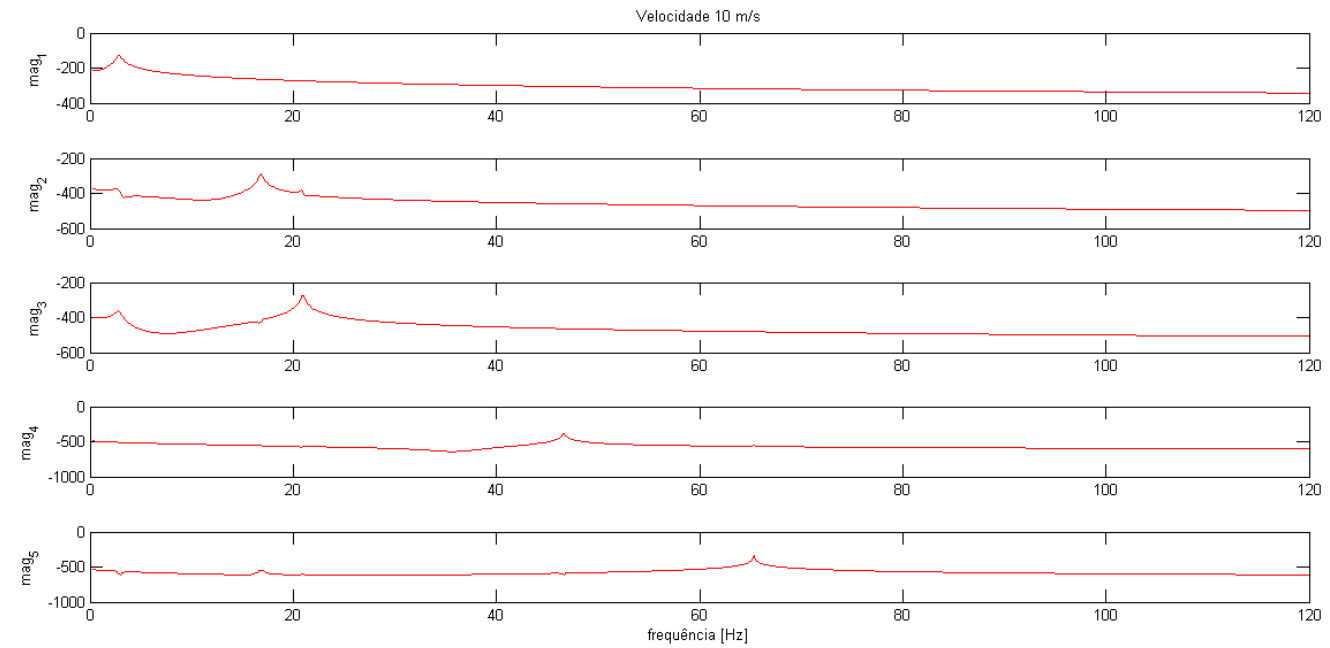

FIGURA 4.12 - Resposta dos cinco primeiros modos no domínio da frequência, para a velocidade de $10 \mathrm{~m} / \mathrm{s}$.
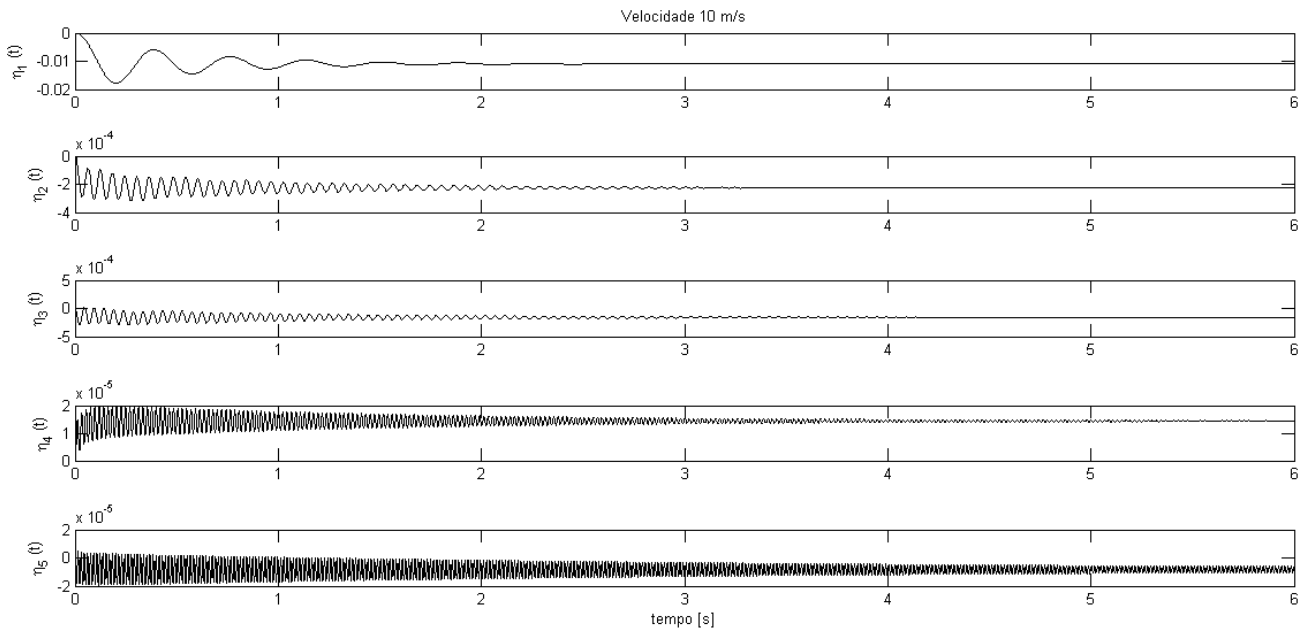

FIGURA 4.13 - Resposta temporal dos cinco primeiros modos, na velocidade de $10 \mathrm{~m} / \mathrm{s}$. 

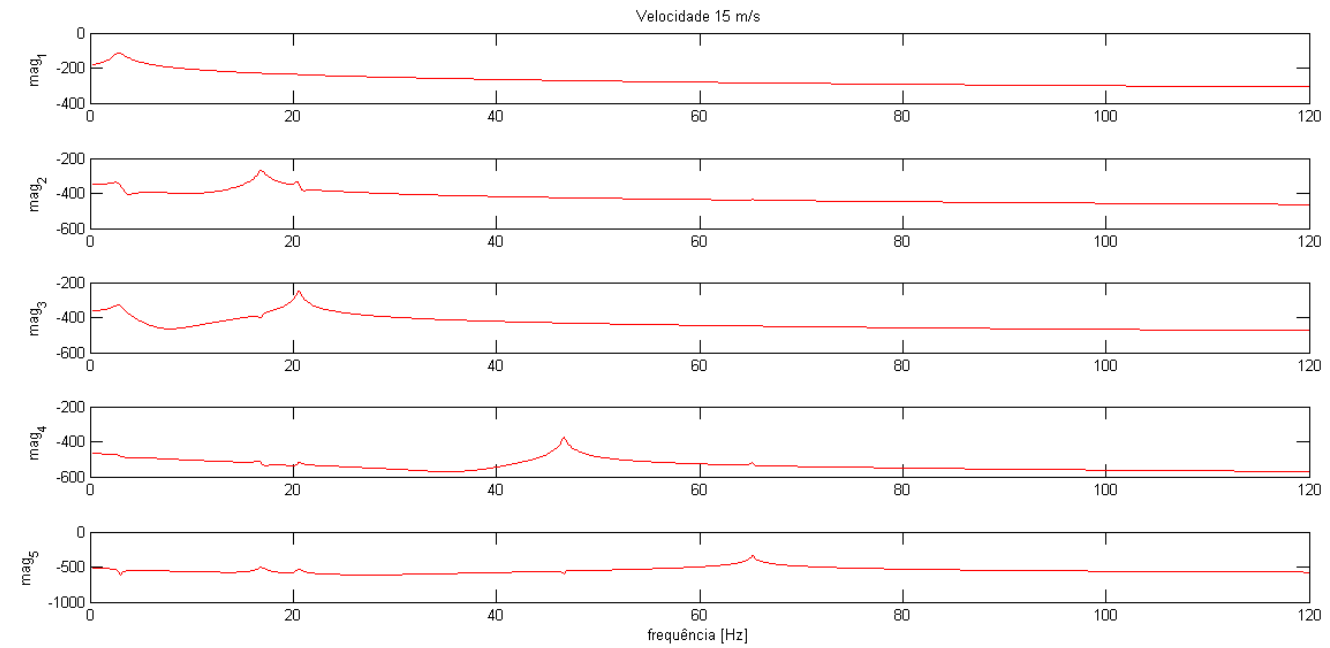

FIGURA 4.14 - Resposta dos cinco primeiros modos no domínio da frequência, para a velocidade de $15 \mathrm{~m} / \mathrm{s}$.

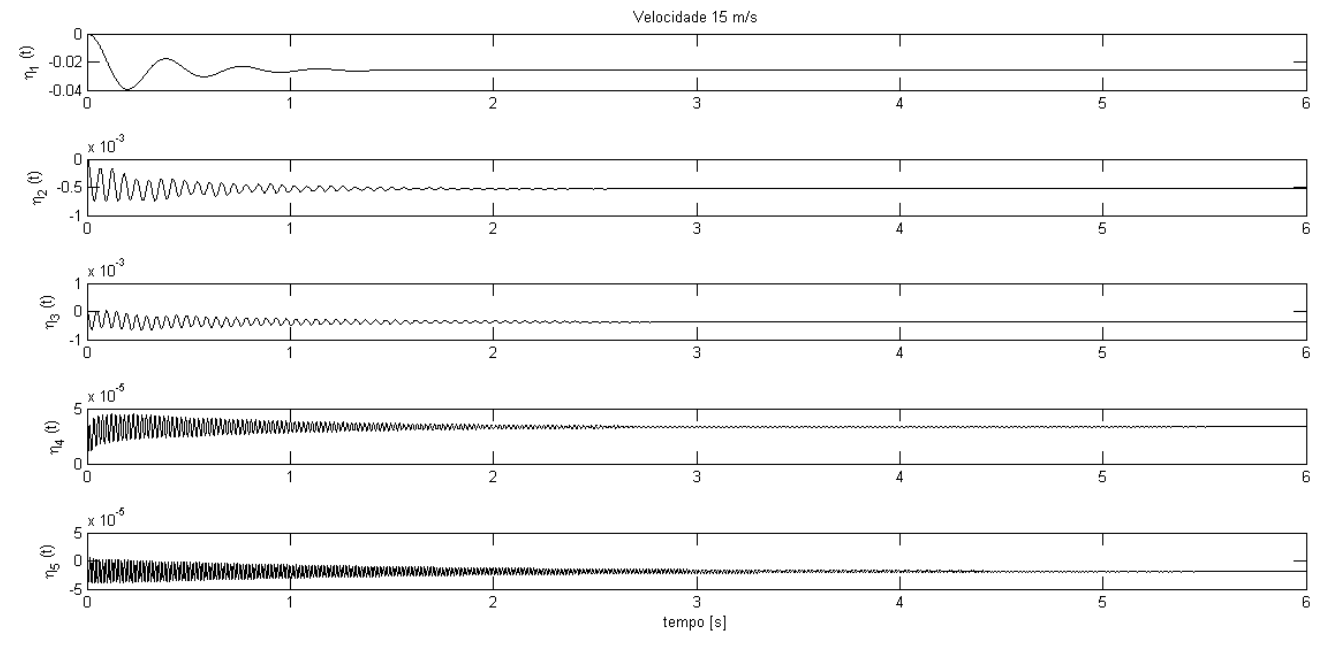

FIGURA 4.15 - Resposta temporal dos cinco primeiros modos, na velocidade de $15 \mathrm{~m} / \mathrm{s}$. 

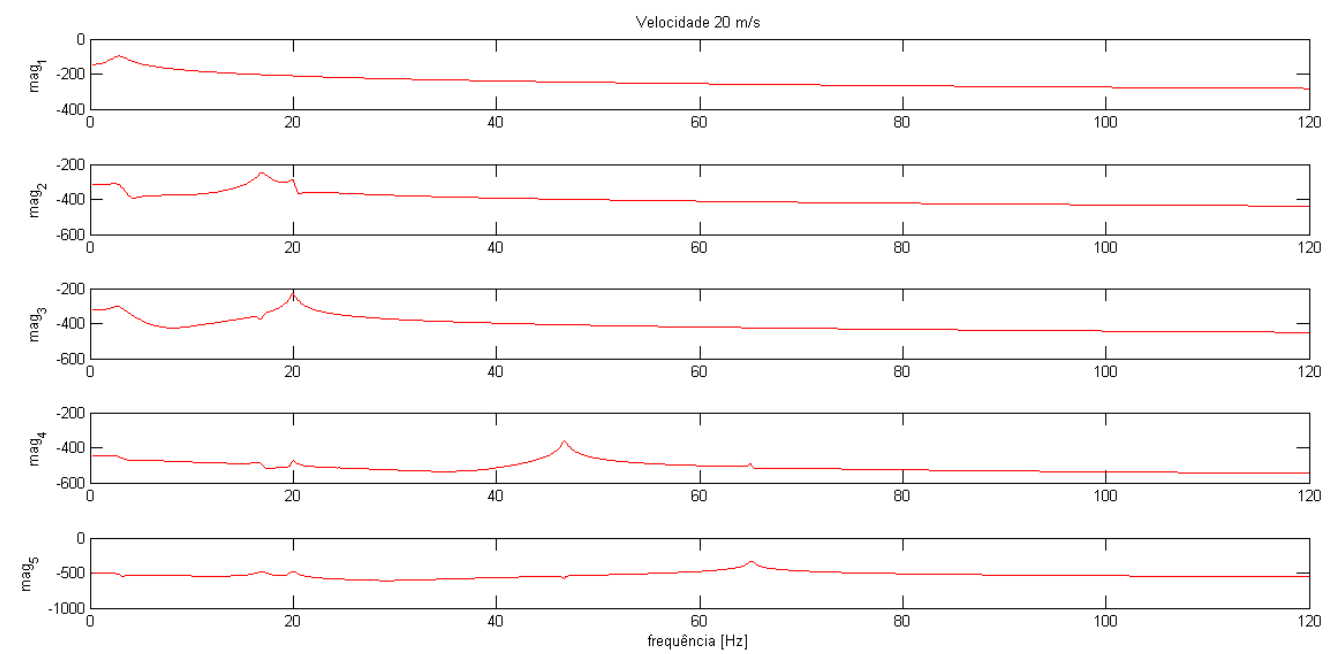

FIGURA 4.16 - Resposta dos cinco primeiros modos no domínio da frequência, para a velocidade de $20 \mathrm{~m} / \mathrm{s}$.
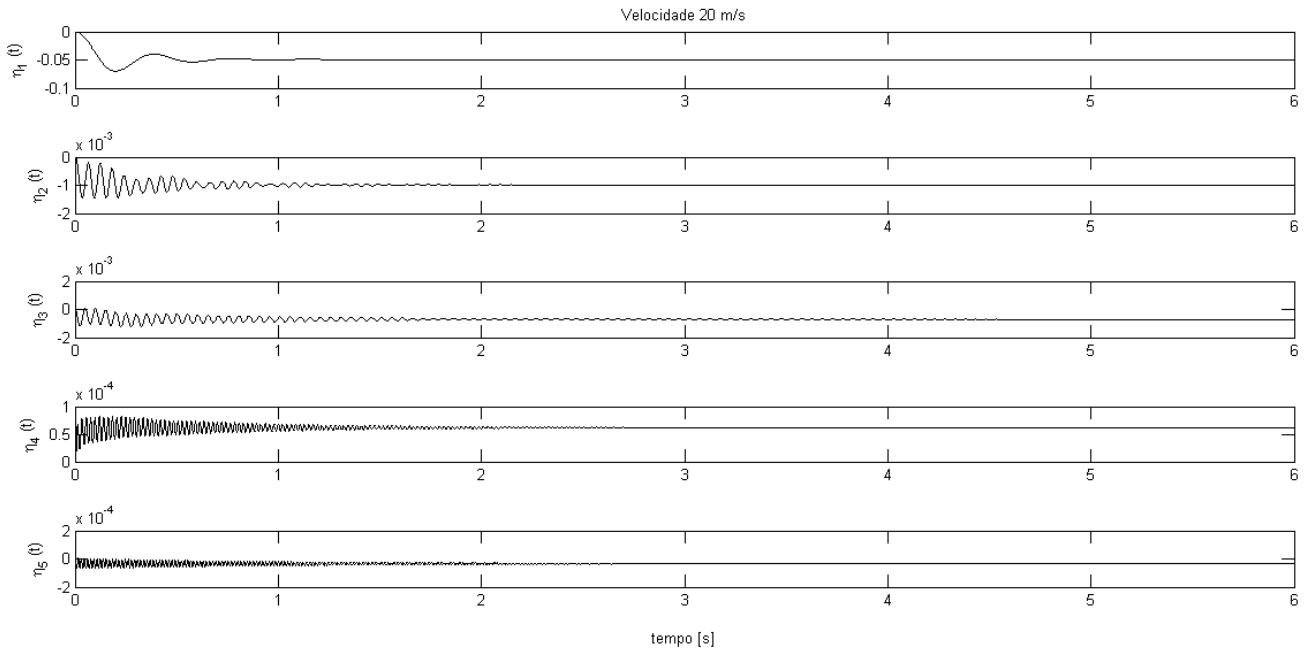

FIGURA 4.17 - Resposta temporal dos cinco primeiros modos, na velocidade de $20 \mathrm{~m} / \mathrm{s}$. 

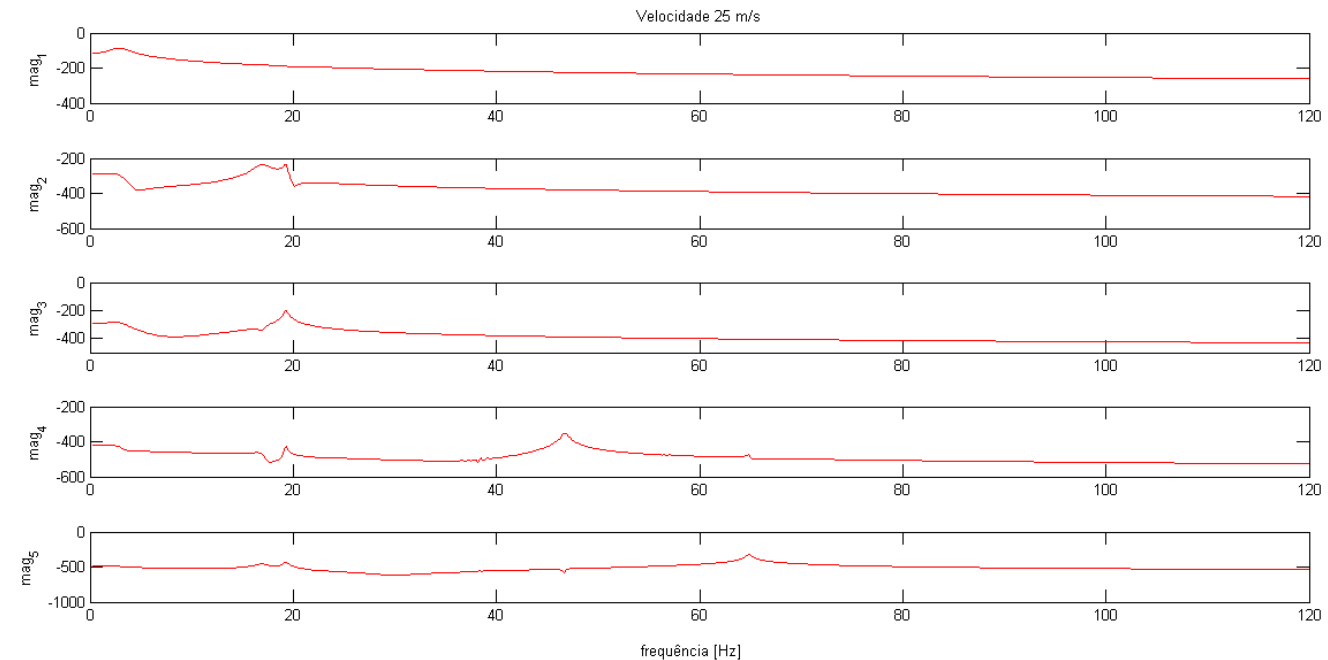

FIGURA 4.18 - Resposta dos cinco primeiros modos no domínio da frequência, para a velocidade de $25 \mathrm{~m} / \mathrm{s}$.
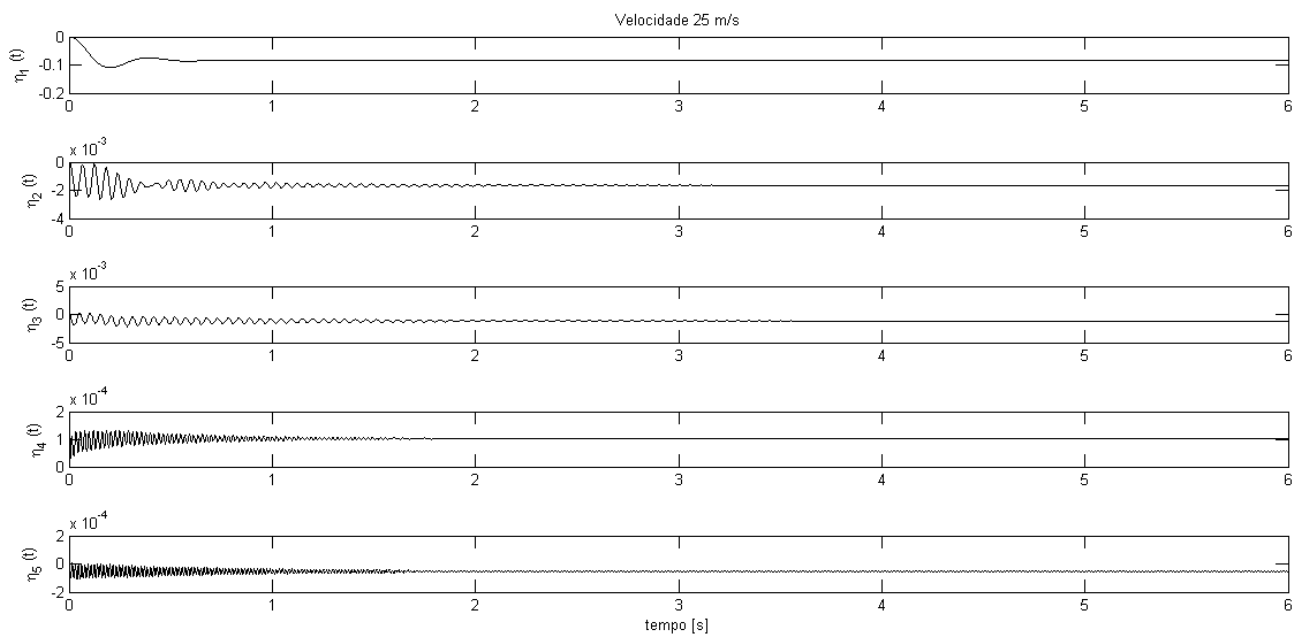

FIGURA 4.19 - Resposta temporal dos cinco primeiros modos, na velocidade de $25 \mathrm{~m} / \mathrm{s}$. 

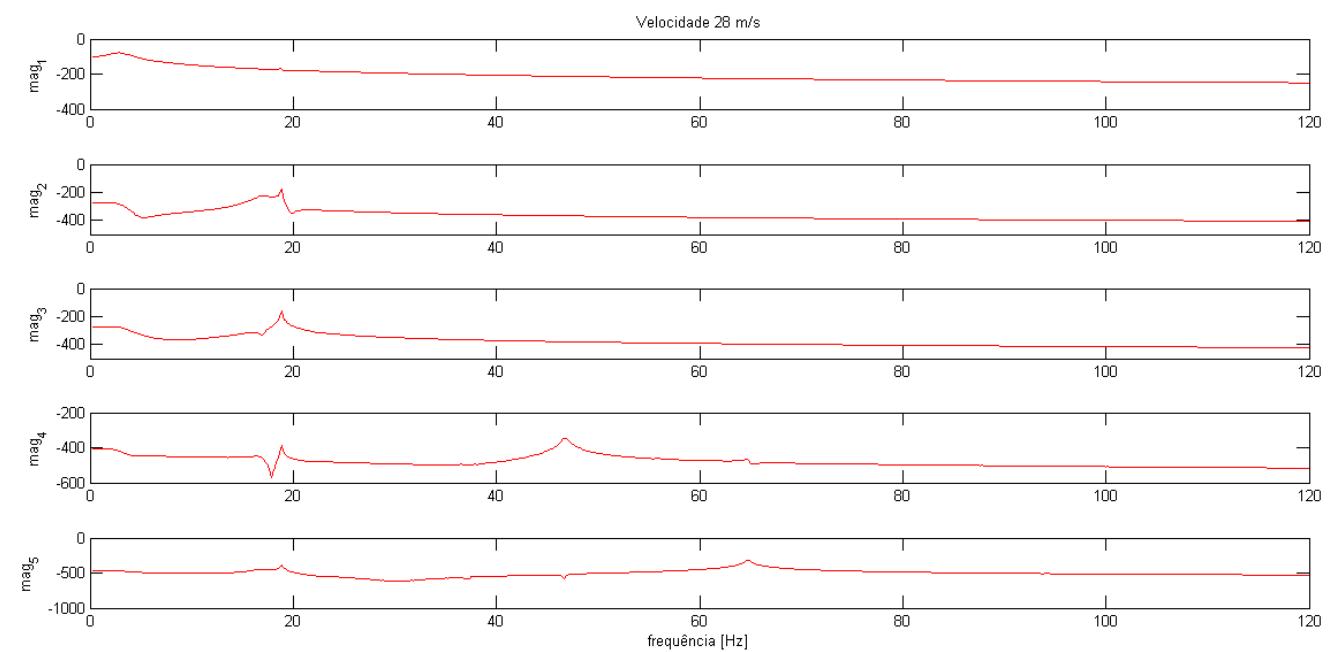

FIGURA 4.20 - Resposta dos cinco primeiros modos no domínio da frequência, para a velocidade de $28 \mathrm{~m} / \mathrm{s}$.

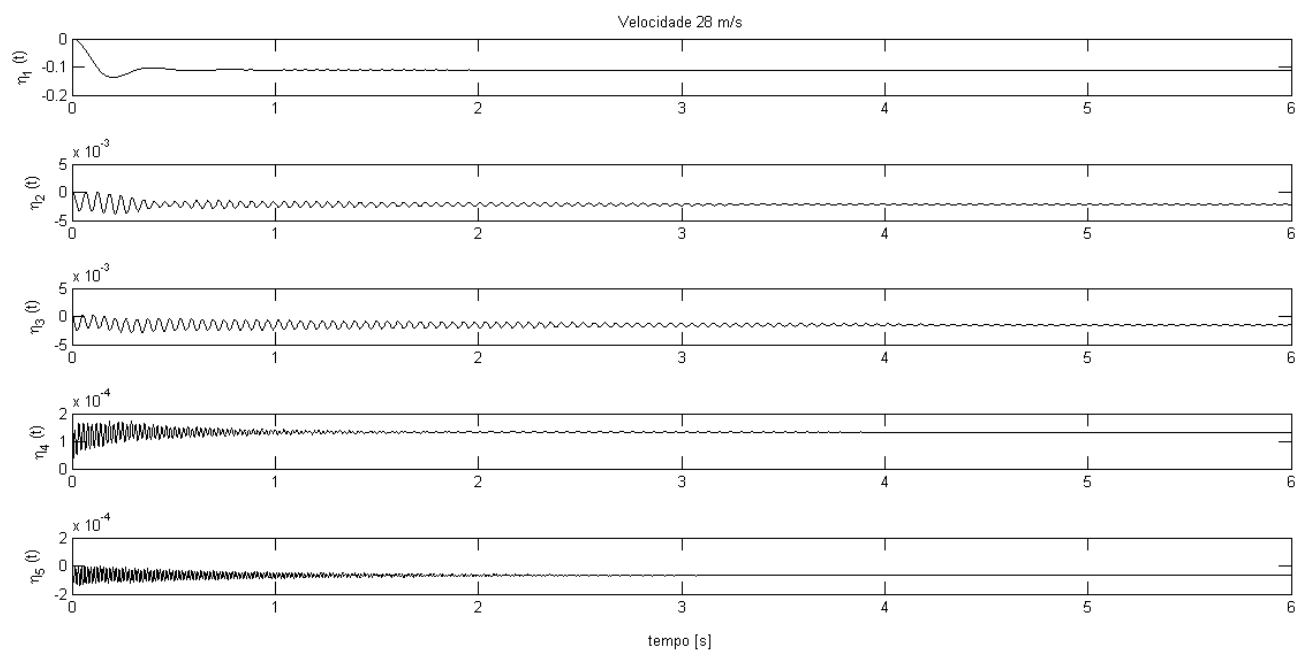

FIGURA 4.21 - Resposta temporal dos cinco primeiros modos, na velocidade de $28 \mathrm{~m} / \mathrm{s}$. 

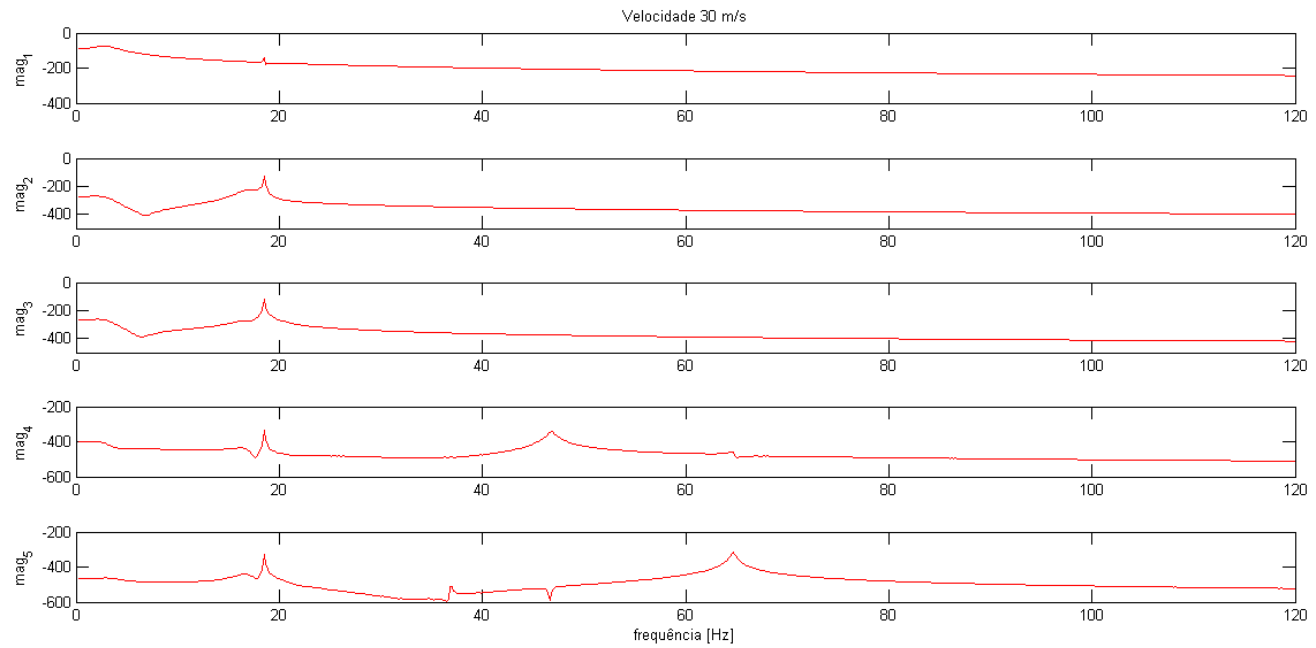

FIGURA 4.22 - Resposta dos cinco primeiros modos no domínio da frequência, para a velocidade de $30 \mathrm{~m} / \mathrm{s}$.

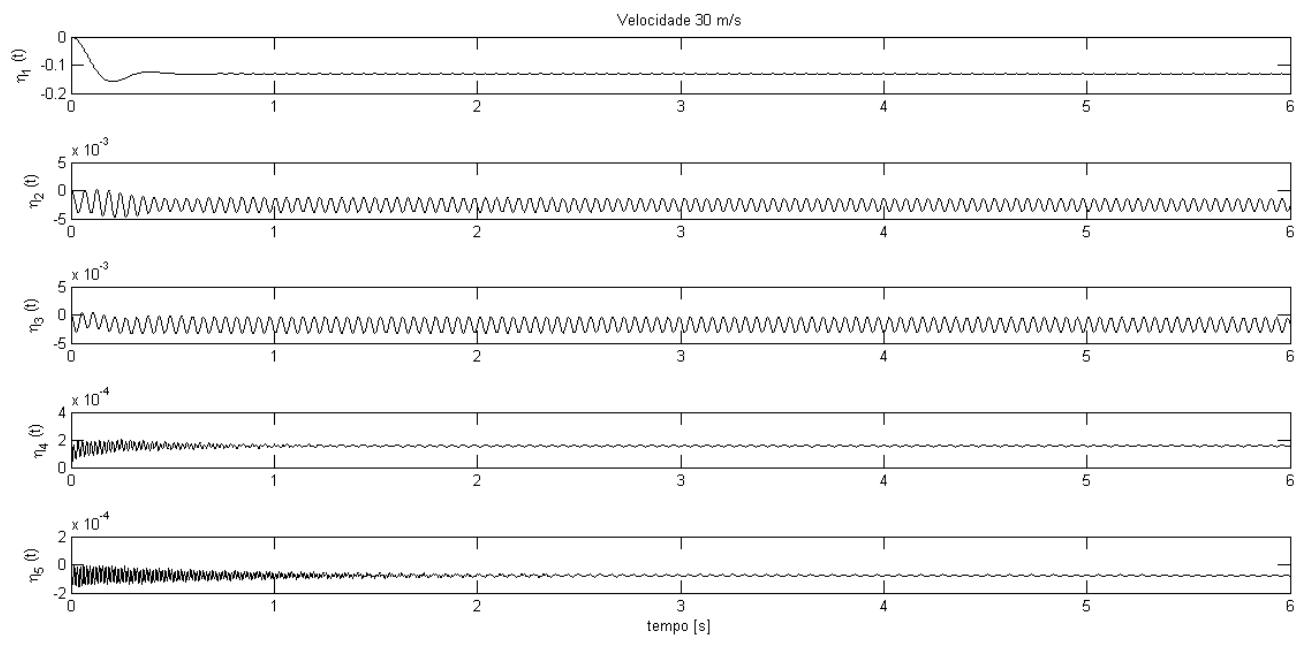

FIGURA 4.23 - Resposta temporal dos cinco primeiros modos, na velocidade de $30 \mathrm{~m} / \mathrm{s}$. 

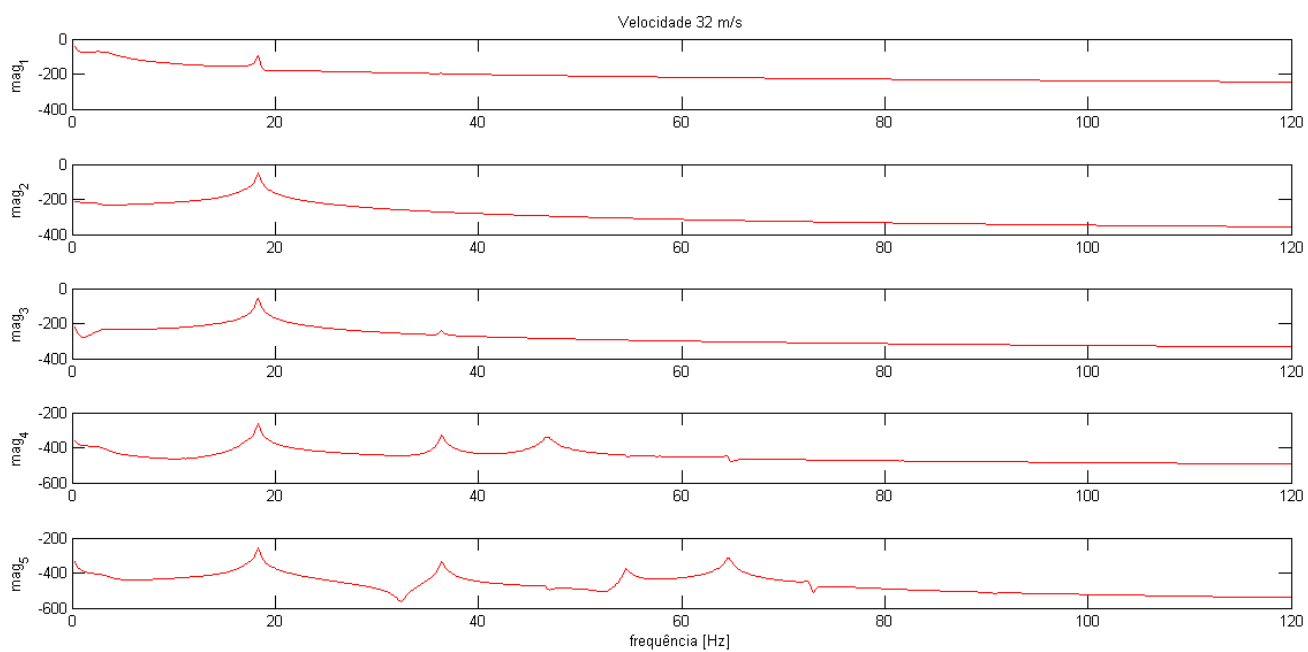

FIGURA 4.24 - Resposta dos cinco primeiros modos no domínio da frequência, para a velocidade de $32 \mathrm{~m} / \mathrm{s}$.
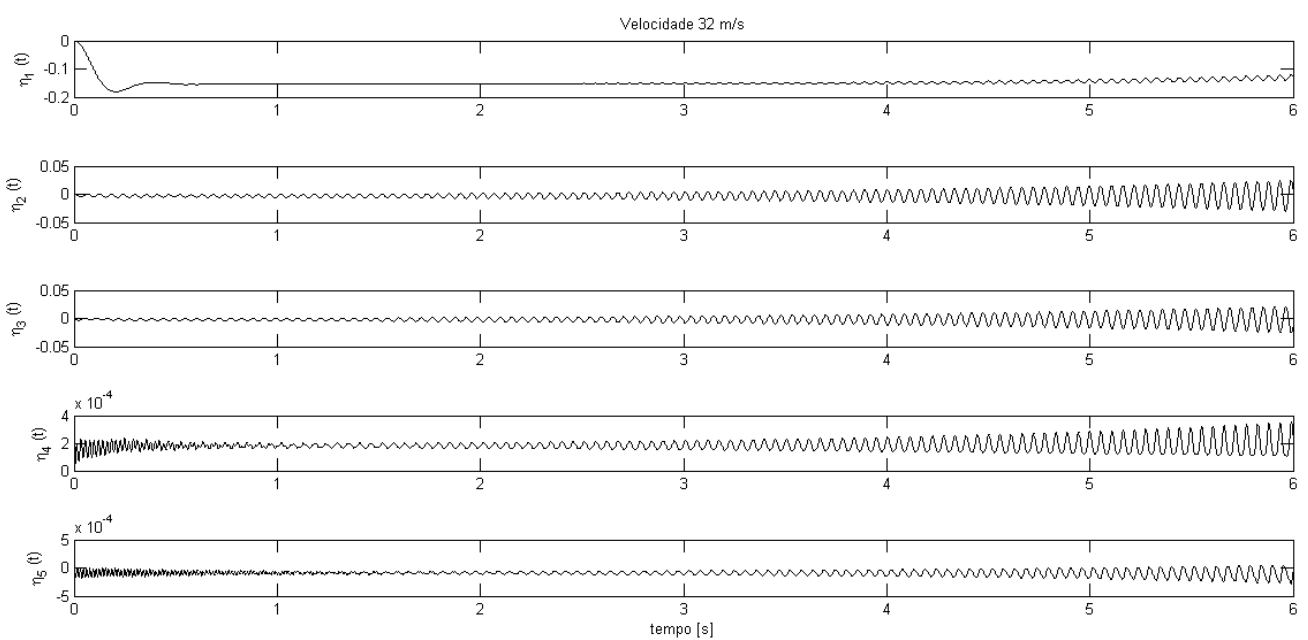

FIGURA 4.25 - Resposta temporal dos cinco primeiros modos, na velocidade de $32 \mathrm{~m} / \mathrm{s}$.

$\mathrm{Na}$ velocidade inicial, é possível verificar que existe um amortecimento nos 4 primeiros modos, com exceção do quinto modo, o que está relacionado com um erro numérico devido a ordem de grandeza relativa dos parâmetros. No entanto, no caminho do aumento de velocidade, o amortecimento começa a crescer, o que estabiliza o quinto modo (figura 4.13). Em $15 \mathrm{~m} / \mathrm{s}$, é possível perceber, pela figura (4.14), que uma leve participação do terceiro modo no segundo modo se inicia. Essa interferência é cada vez maior, e, na velocidade de $25 \mathrm{~m} / \mathrm{s}$, já é notável que o quarto e o quinto modo possuem participação do 
segundo e terceiro modo, na mesma faixa de frequência. Essa característica, somada com o aumento do amortecimento dos modos (gráficos no domínio do tempo), indica que a velocidade de flutter está próxima.

Dando continuidade, na velocidade de $30 \mathrm{~m} / \mathrm{s}$, conforme a figura (4.23), percebe-se uma queda brusca de amortecimento da resposta temporal do segundo e terceiro modo. Ao continuar o aumento de velocidade, em $32 \mathrm{~m} / \mathrm{s}$, observa-se pela figura (4.25) que a resposta temporal de quase todos os modos se torna instável, o que indica uma instabilidade pósflutter. Por esse motivo, acredita-se que a velocidade de flutter é de $30 \mathrm{~m} / \mathrm{s}$ e o mecanismo responsável para tal envolve o acoplamento do terceiro modo no segundo modo.

Para se avaliar a variável física, multiplica-se a matriz pseudo-inversa da matriz modal pela matriz formada pelos vetores linha do resultado da equação de movimento referente a cada modo. A variável física resgatada, representada pelos cinco primeiros modos é o ângulo de ataque. Sendo assim, é possível avaliar a evolução do flutter pelos gráficos que seguem das figuras (4.26) à (4.28), que mostram a reposta temporal do ângulo de ataque.

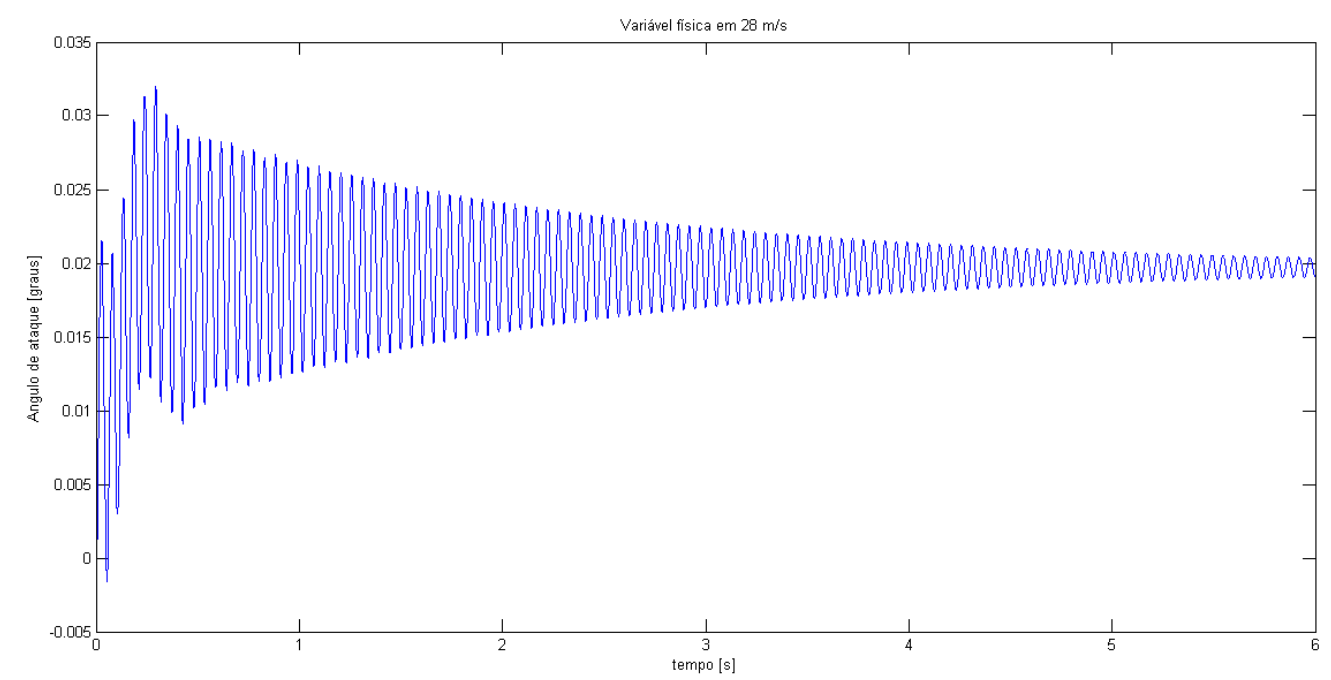

FIGURA 4.26 - Comportamento do ângulo de ataque em $28 \mathrm{~m} / \mathrm{s}$. 


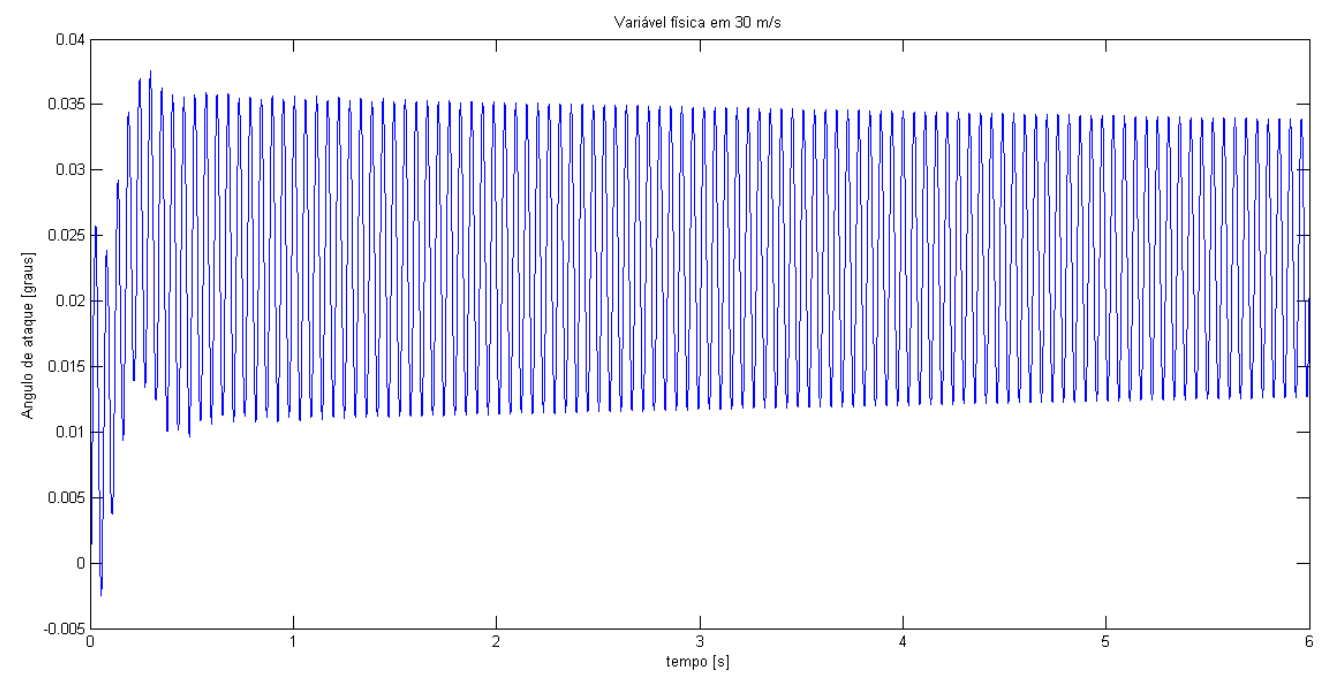

FIGURA 4.27 - Comportamento do ângulo de ataque em $30 \mathrm{~m} / \mathrm{s}$.

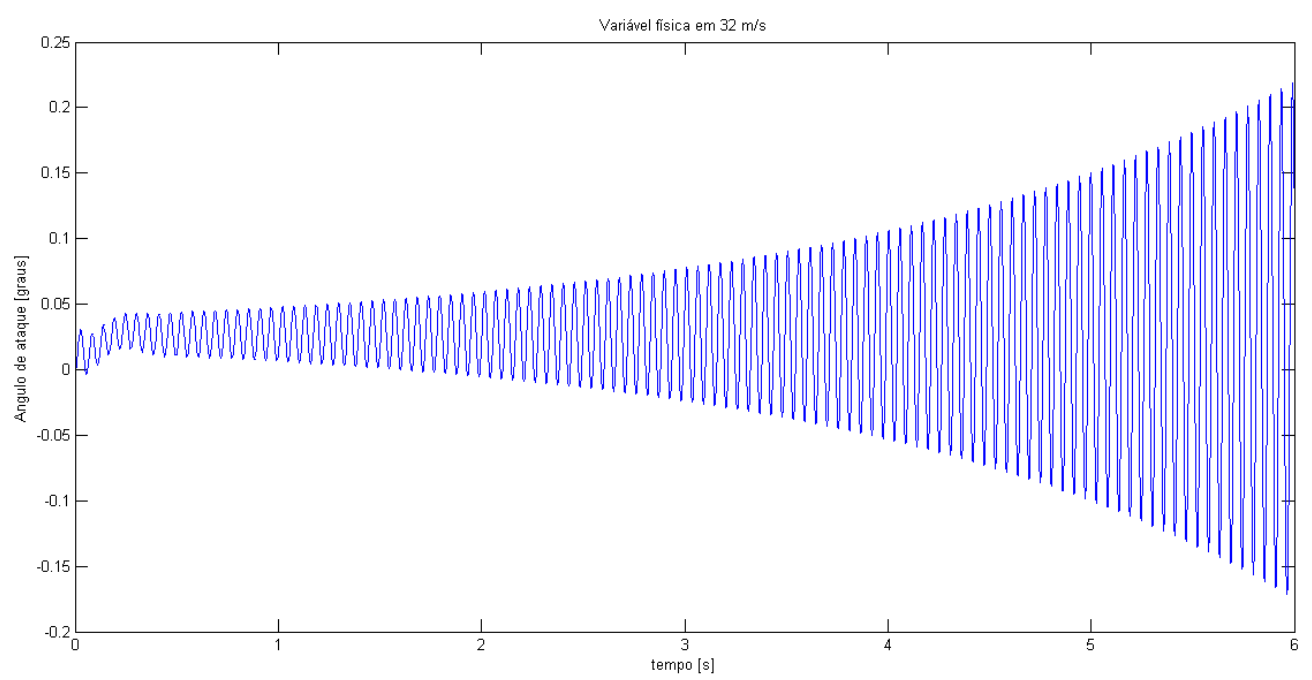

FIGURA 4.28 - Comportamento do ângulo de ataque em 32 m/s.

Para poder confirmar a hipótese levantada a respeito do acoplamento modal, é utilizado a idéia da seção (4.4), e através de um gráfico de barras, é possível visualizar a métrica de acoplamento em cada velocidade. A figura (4.29) exibe a métrica de acoplamento para o mesmo caso exemplo situado na posição 02 e laminado [0/90]. 


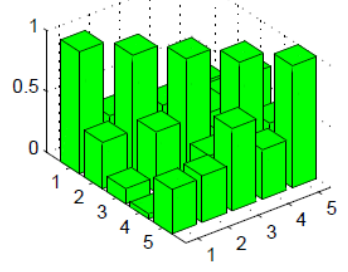

(a) $5 \frac{m}{s}$

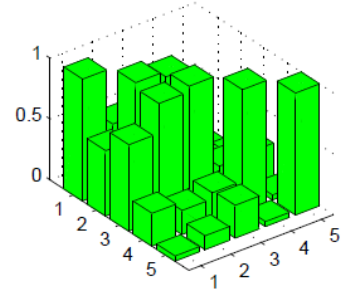

(e) $25 \frac{\mathrm{m}}{\mathrm{s}}$

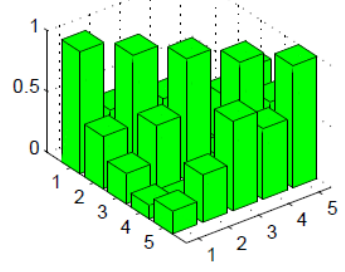

(b) $10 \frac{\mathrm{m}}{\mathrm{s}}$

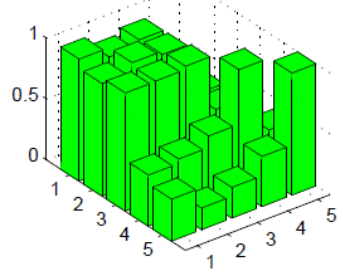

(f) $28 \frac{m}{s}$

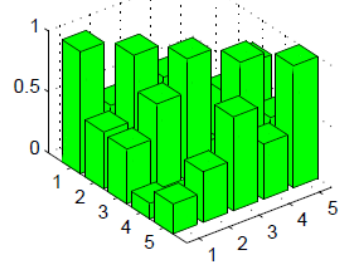

(c) $15 \frac{\mathrm{m}}{\mathrm{s}}$

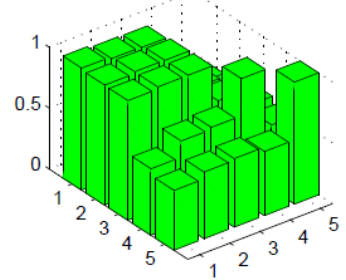

(g) $30 \frac{\mathrm{m}}{\mathrm{s}}$

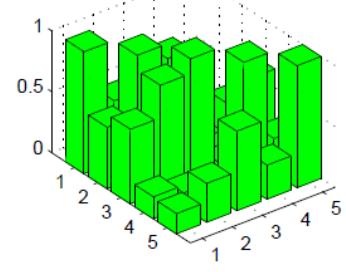

(d) $20 \frac{\mathrm{m}}{\mathrm{s}}$

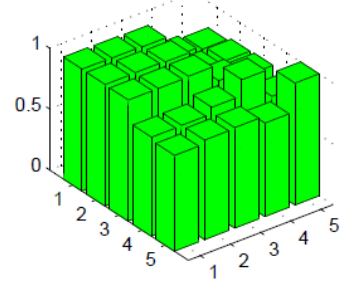

(h) $32 \frac{\mathrm{m}}{\mathrm{s}}$

FIGURA 4.29 - Métrica de acoplamento modal.

Essa figura demonstra o nítido acoplamento entre o segundo e terceiro modo apartir da velocidade de $25 \mathrm{~m} / \mathrm{s}$, velocidade na qual as métricas de acoplamento crescem em comparação com as velocidades anteriores. A figura (4.29) também exibe o acoplamento dos demais modos em velocidades superiores.

Confirmada a hipótese dos modos alvos de flutter serem o segundo e o terceiro, é possível avaliar o desempenho do sensor para a leitura desses modos. No entanto, antes de fazer essa avaliação, foi realizado uma análise de sensibilidade do sensor às variações de configuração do PFC. Para isso é importante retomar as considerações da seção (2.4), em que o sinal de voltagem é obtido das extremidades das barras piezelétricas e é caracterizado por quatro pontos. Nesses pontos, o valor de voltagem é o mesmo para uma mesma configuração, devido a condição de equipotencial aplicada às barras piezelétricas. Então, o sinal de voltagem é lido em qualquer um desses pontos, e é possível visualizá-lo através de uma representação no dimínio da frequência depois de aplicar uma transformada rápida de Fourier (FFT) na resposta temporal desse sinal. 


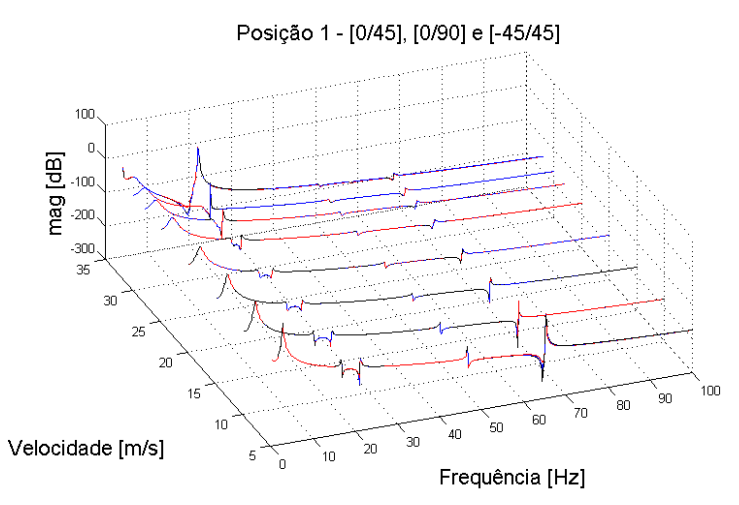

a)FFT posição 01: [0/45] linha azul, [0/90] linha vermelha e $[-45 / 45]$ linha preta.

\section{FIGURA 4.30 - FFT's do sinal elétrico do sensor.}

Através das FFT's da figura (4.30a), a qual compara os três laminados apenas na posição 01 , percebe-se que o sinal de voltagem, para todas velocidades simuladas, apresentouse muito aproximado, o que significa que a variação nos ângulos das camadas do laminado não interfere no sinal lido obtido pelo sensor. No entanto, quando se compara uma mudança de posições, como contrasta as figuras (4.30 a e b), a mudança do sinal elétrico é muito mais sensível. A falta de sensibilidade do ângulo das camadas do laminado, está ligada a dimensão relativa desse laminado na placa, bem como sua espessura. Por esse motivo, conclui-se que, para avaliar a eficiência do sensor, é importante focar a análise na comparação das diferentes posições, e então, desconsiderar a variação dos laminados.

Definido que a análise de eficiência se concentrará apenas nas variações de posição nos modos 2 e 3, é necessário comparar a potência de sinal nessas condições. As figuras (4.31) e (4.32) ilustram a comparação proposta nos dois modos e identifica a evolução da potência de sinal em unidade decibél $(\mathrm{dB})$ de acordo com todas as velocidades simuladas.

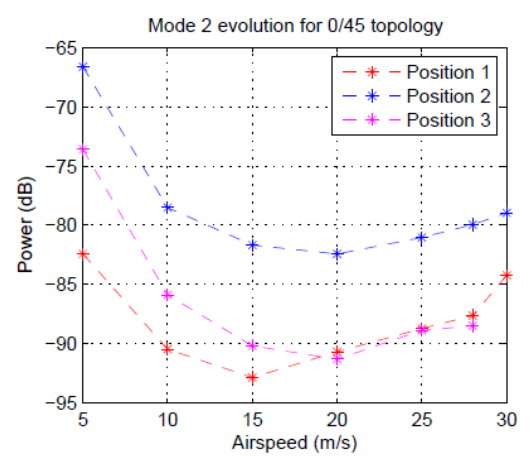

(a)

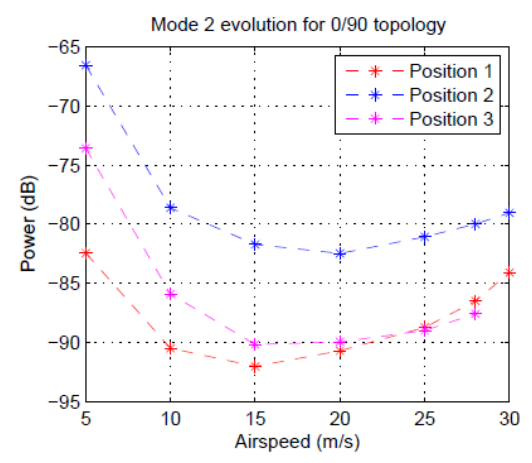

(b)

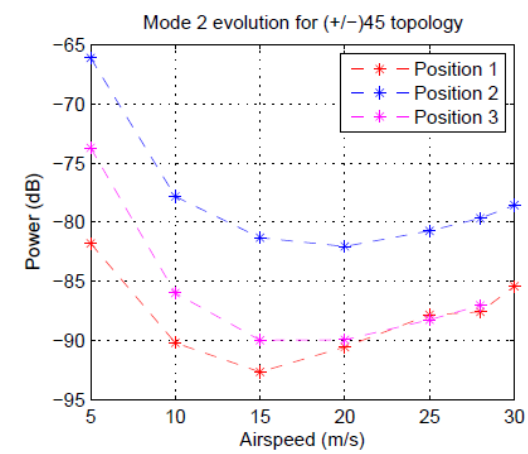

(c)

FIGURA 4.31 - Desempenho do sensor na leitura do modo 2. 


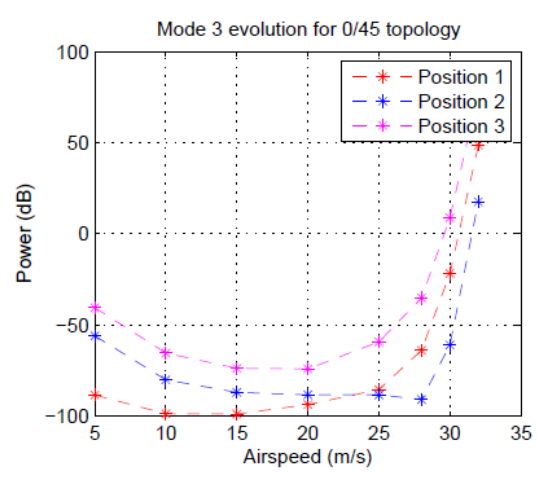

(a)

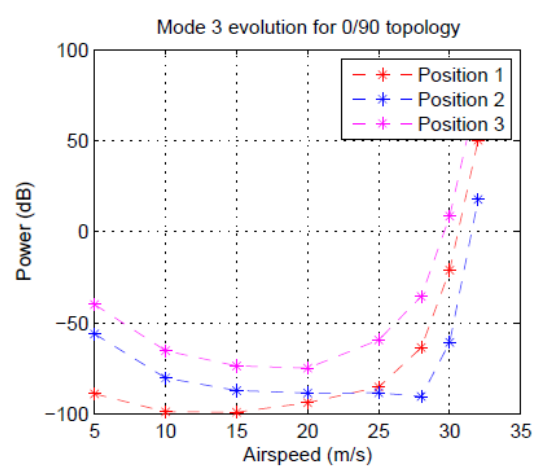

(b)

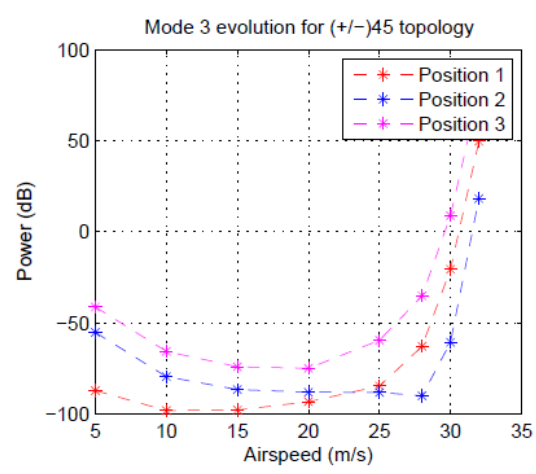

(c)

FIGURA 4.32 - Desempenho do sensor na leitura do modo 3.

Os gráficos das figuras (4.31) e (4.32) revelam o desempenho das 9 configurações de sensor analisadas, em cada um dos modos alvos. Em relação ao modo 2, a figura (4.31) demonstra que independente da configuração do laminado, e da velocidade considerada, a posição 02 é que apresenta maior potência de sinal, ao se comparar com as demais posições. Analogamente, para o modo 3, a posição que gera a maior potencia de sinal é a posição 03 , conforme a figura (4.32). Essa análise também demonstra que a posição 01 não é interessante para a obtenção dos modos alvo e pode até prejudicar a obtenção do sinal elétrico. 


\section{CONCLUSÕES}

\subsection{CONSIDERAÇÕES FINAIS}

A metodologia proposta utilizou-se da criação da um modelo dinâmico-estrutural da asa em MEF, e um modelo aerodinâmico não-estacionário, representando um escoamento incompressível e potencial. Com os parâmetros elásticos da asa e o carregamento aerodinâmico obtidos, esse acoplamento entre fluido e estrutura é consolidado na equação de movimento, que é resolvida em incrementos de tempo. A metodologia permite obter a resposta modal da estrutura no domínio da freqüência e do tempo.

Essa metodologia, que foi utilizada para avaliar o efeito da utilização de laminados compósitos no desempenho do sensor, permite incluir o efeito piezelétrico na matriz de rigidez da estrutura, bem como, obter o sinal de tensão elétrica nos nós do sensor que possuem o grau de liberdade elétrico. Com isso, é possível analisar a potência do sinal elétrico gerado no domínio da frequiência e de tempo, permitindo também, a representação do estado físico de ângulo de ataque, através do sensor.

Os resultados consistiram, em um primeiro passo, na determinação da velocidade de flutter e visualização de seu mecanismo modal, e num segundo passo, na avaliação do desempenho do sensor de acordo com cada configuração de laminado. O empilhamento dos laminados não interferiu consideravelmente no seu desempenho, sendo que a influência da posição do sensor foi maior. No entanto, isso pode ser explicado pela utilização de um único sensor, o que limita a contribuição do material compósito na rigidez da asa. Além da utilização de um sensor, o tamanho deste é de aproximadamente $1 \%$ em relação ao tamanho da placa.

Os resultados sobre o mecanismo modal utilizando as respostas em freqüência e no domínio do tempo, em paralelo com a representação de acoplamento modal, usando o diagrama de barras, permitiram uma comparação que acabou confirmando a determinação dos modos de flutter, bem como sua velocidade. Esse método de visualização permite ser aplicado em geometrias mais complexas. 
A utilização do MEF para representar a dinâmica estrutural da asa, não restringe a representação desta por uma placa, como também, permite a importação de geometrias mais complexas, as quais podem ser desenhadas em progamas CAD. Essa versatilidade é acompanhada pela utilização do método dos painéis no modelo aerodinâmico, que também permite geometrias diferentes de uma placa simples. Além dessa flexibilidade, o fato de a aerodinâmica ser modelada separadamente da dinâmica estrutural, permite utilizar modelos aerodinâmicos mais refinados para se obter o carregamento, como o exemplo do uso de CFD a ser usado em conjunto com o modelo em elementos finitos.

De maneira geral, o método se demonstrou bastante flexível, e apresentou bons resultados para um caso simples, o que oferece aplicação desse método em casos mais complexos, envolvendo até mesmo, implementação de otimização na configuração dos sensores.

\subsection{TRABALHOS FUTUROS}

Conforme sugerido pelos resultados obtidos, modelos mais complexos podem ser analisados para confirmar a versatilidade e robustez da metodologia proposta. Então, é possível sugerir as seguintes modificações para trabalhos futuros:

- A utilização de um maior número de modos para representar a resposta da estrutura, o que resulta em uma verificação mais detalhada do mecanismo modal.

- $\quad$ A utilização de geometrias mais complexas de estrutura, a começar por uma asa com nervuras e longarinas.

- Inclusão de efeitos de não-linearidade no modelo dinâmico-estrutural. Esse estudo pode ser feito, uma vez que os modelos são construídos separadamente e unidos por uma equação de movimento. Além disso, esse estudo é importante, uma vez que se aproxima mais da realidade do fenômeno aeroelástico.

- $\quad$ Em relação à verificação do efeito do material compósito, pode-se utilizar um maior número de camadas no laminado, bem como uma otimização do ângulo das camadas de acordo com o modo alvo. Uma comparação entre laminados simétricos e não simétricos pode ser feita nesse sentido. 
- A otimização da posição de um único sensor, bem como suas dimensões, para se obter os modos alvo. Essa opção é interessante devido à simplicidade de utilização de um único sensor.

- O tamanho dos sensores, bem como o número destes pode ser aumentado, para representar uma influência maior do compósito no modelo estrutural. A essa modificação também é sugerido um estudo de otimização das dimensões e número dos sensores.

- Verificação da aplicação de sistemas de controle dos modos alvo.

- $\quad$ Refinamento do modelo aerodinâmico.

- $\quad$ Aplicação da metodologia proposta em métodos de ensaios em vôo para aeronaves de estruturas com material compósito. O sensor PFC se demonstrou versátil e que pode ser melhorado ao ser embebido com laminados. Além disso, a utilização de um único sensor com boa sensibilidade de sinal pode significar numa redução de peso de instrumentação de ensaio. 


\section{REFERÊNCIAS BIBLIOGRÁFICAS}

ABBOTT, I. H.; DOENHOFF, A. E. V. Theory of Wings Sections. New York: McGrawHill, 1949. p. 693

ABREU, G. L. C. .; RIBEIRO, J. F.; STEFFEN, V. Finite Element Modeling of a Plate with Localized Piezoelectric Sensors and Actuators. v. XXVI, n. 2, p. 117-128, 2004.

ALLIK, H.; HUGHES, T. J. R. FINITE ELEMENT METHOD FOR PIEZOELECTRIC VIBRATION. International Journal for Numerical Methods in Engineering, v. 2, n. December 1968, p. 151-157, 1970.

ANDERSON, J. D. /UNIVERSITY OF M. Fundamentals of Aerodynamics. 3rd. ed. New York: McGraw-Hill, 1991.p. 876

ATTARAN, A. et al. Structural optimization of an aeroelastically tailored composite flat plate made of woven fiberglass/epoxy. Aerospace Science and Technology, v. 15, n. 5, p. 393401, jul. 2011.

BENINI, G. R. Modelo numérico para simulação da resposta aeroelástica de asas fixas. [S.1.] Universidade de São Paulo, 2002.

BISPlinGHOFF, R. L.; ASHLEY, H.; HALFMAN, R. L. Aeroelasticity. [S.l.] AddisonWesley Publishing Company, 1955.

BRAVO-CASTILLERO, J. et al. Closed-form expressions for the effective coefficients of a fiber-reinforced composite with transversely isotropic constituents - II. Piezoelectric and square symmetry. Mechanics of Materials, v. 33, p. 237-248, 2001.

CORPORATION, S. M. MFC P1 and F1 (d33 effect) standard inventory sizes/MFC P2 and P3 (d31 effect), standard inventory sizes. Disponível em: <http://www.smartmaterial.com/MFC-product-main.html>. 
DANIEL, I. M.; ISHAI, O. Engineering Mechanics of Composite Materials. 1. ed. New York: Oxford University Press, 1994. p. 385

DJOJODIHARDJO, R. H.; WINDALL, S. E. A Numerical Method for the Calculation of Nonlinear, Unsteady Lifting Potential Flow Problems. AIAA Journal, v. 7, p. 2001-2009, 1969.

DOWELL, E. H. et al. A Modern Course in Aeroelasticity. 3rd. ed. Dordrecth: Kluwer Academic Publishers, 1995. p. 699

DOWELL, E. H.; HALL, K. C. Modeling of Fluid-Structure Interaction. Annual Review of Fluid Mechanics, v. 33, p. 445-490, 2001.

FOX, R. W.; MCDONALD, A. T. Introduction to Fluid Mechanics. 5th. ed. [S.1.] J.Wiley, 1998. p. 762

GRUPPIONI, E. M.; MARQUES, F. D. CONTROLE AEROELÁSTICO POR LÓGICA DIFUSA DE UMA ASA FLEXÍVEL NÃO-LINEAR COM ATUADORES. [S.1.] Universidade de São Paulo, 2008.

GUO, S.; CHENG, W.; CUI, D. Aeroelastic Tailoring of Composite Wing Structures by Laminate Layup Optimization. AIAA Journal, v. 44, n. 12, p. 3146-3150, dez. 2006.

GUO, S. J.; BANNERJEE, J. R.; CHEUNG, C. W. The effect of laminate lay-up on the flutter speed of composite wings. Journal of Aerospace Engineering, v. 217, n. 3, p. 115-122, 2003.

HANDBOOK METALLIC MATERIALS AND ELEMENTS FOR. [S.1: s.n.].

HEEG, J. Analytical and Experimental Investigation of Flutter Suppression by Piezoelectric Actuation. NASA Technical Paper 3241, n. February, p. 47, 1993. 
HESS, J. L. Panel Methods in Computational Fluid Dynamics. Annual Review of Fluid Mechanics, v. 22, p. 255-274, 1990.

HODGES, D. H.; PIERCE, G. A. Introduction to Structural Dynamics and Aeroelasticity. 1st. ed. [S.1.] Press Syndicate of the University of Cambrige, 2002. p. 170

HOUGHTON, E. L.; CARPENTER, P. W. Aerodynamics for Engineering Students. 5th. ed. [S.1.] Butterworth-Heinemann, 2003. p. 590

INMAN, D. J. Engineering Vibration. 3. ed. Upper Saddle river, N.J.: Pearson Prentice Hall, 2008 .

JAFFE, H.; BERLINCOURT, D. A.; CMOLIK, C. Piezoelectric Properties of Polycrystalline Lead Titanate Zirconate Compositions. Proceedings of the IRE, v. 48, n. 2, p. 220-229, 1954.

KATZ, J.; PLOTKIN, A. Low Speed Aerodynamics. Singapure: McGraw-Hill, 1991. p. 632

KAYRAN, A. Flight flutter testing and aeroelastic stability of aircraft. Aircraft Engineering and Aerospace Technology, v. 79, n. 5, p. 494-506, 2007.

KEHOE, M. W. A Historical Overview of Flight Flutter Testing. NASA Technical Memorandum 4720, n. October, 1995.

KIM, D. H.; OH, I. K. Lamination Optimization of Composite Curved Wing for Maximum Flutter Stability Using Micro Genetic Algorithm. Key Engineering Materials, v. 324-325, p. 743-746, 2006.

KIM, T. et al. Structural design optimization of a tiltrotor aircraft composite wing to enhance whirl flutter stability. Composite Structures, v. 95, p. 283-294, jan. 2013.

KUETHE, A. M.; CHOW, C. Y. Foundations of Aerodynamics. 5th. ed. New York: John Wiley Sons, 1998. p. 572 
LAM, K. Y. et al. A finite-element model for piezoelectric composite laminates. Smart Materials and Structures, v. 6, n. 5, p. 583-591, 1 out. 1997.

LEO, D. J. ENGINEERING ANALYSIS OF SMART MATERIAL SYSTEMS. Hoboken, N.J.: John Wiley Sons, 2007.

LEWIS, R. I. Surface Vorticity Modelling of Separated Flows from Two-Dimensional Bluff Bodies of Arbitrary Shape. Journal of Mechanical Engineering Science, v. 23, p. 1-12, 1981.

LI, Z. N.; TANG, J.; LI, Q. S. Optimal sensor locations for structural vibration measurements. Applied Acoustics, v. 65, n. 8, p. 807-818, ago. 2004.

MAMAN, N.; FARHAT, C. Matching Fluid and Structure Meshes for Aeroelastic Computations: A Parallel Approach. Computers and Structures, v. 54, n. 4, p. 779-785, 1995.

MEIROVITCH, L. Elements of Vibration analysis. 2. ed. New York: McGraw-Hill, 1986. p. 548

MEVEL, L.; BASSEVILLE, M.; BENVENISTE, A. Fast In-Flight Detection of Flutter Onset: A Statistical Approach. Journal of Guidance, Control, and Dynamics, v. 28, n. 3, p. 431-438, maio. 2005.

NJUGUNA, J. Flutter prediction, suppression and control in aircraft composite wings as a design prerequisite: a survey. Structural Control and Health Monitoring, v. 14, n. 5, p. 715-758, ago. 2007.

PARTON, V. Z.; KUDRYAVTSEV, B. A. Electromagnetoelasticity: Piezoelectrics and Electrically Conductive Solids. Amsterdan, The Netehrlands: Gordon and Breach Science Publishers., 1988. 
PATIL, M. J.; HODGES, D. H.; CESNIK, C. E. S. Nonlinear Aeroelastic Analysis of Complete Aircraft in Subsonic Flow. Journal of Aircraft, v. 37, p. 753-760, 2000.

PREIDIKMAN, S.; MOOK, D. Time-Domain Simulations of Linear and Nonlinear Aeroelastic Behavior. Journal of Vibration and Control, v. 6, n. 8, p. 1135-1175, 1 jan. 2000.

PREUMONT, A. et al. Spatial filters in structural control. Journal of Sound and Vibration, v. 265 , p. 61-79, 2003.

ROBERTS, S. Dielectric and Piezoelectric Properties of Barium Titanate. Phys. Rev., v. 71, n. 12, p. 890-895, 1947.

SARTORATO, M.; MEDEIROS, R.; TITA, V. A finite element for active composite plates with piezoelectric layers and experimental validationSão Paulo: $X$ World Congress on Computational Mechanics, 2012, Sao Paulo. Proceedings of X WCCM, 2012

SCANLAN, R. H. Introduction to the Study of Aircraft Vibration and Flutter. New York, NY: Macmillan, 1951.p. 428

SCHLIPPE, B. V. The Question of Spontaneous Wing Oscillations (Determination of Critical Velocity Through Flight-Oscillation Tests). NACA TM-806, 1936.

SMITH, M. J.; HODGES, D. H.; CESNIK, C. E. S. Evaluation of Computational Algorithms Suitable for Fluid-Structure Interactions. Journal of Aircraft, v. 37, p. 282-289, 2000.

SODANO, H. A. Macro-Fiber Composites for Sensing, Actuation and Power Generation by. [S.1.] Faculty of the Virginia Polytechnic Institute, 2003.

SONG, Z.-G.; LI, F.-M. Active aeroelastic flutter analysis and vibration control of supersonic composite laminated plate. Composite Structures, v. 94, n. 2, p. 702-713, jan. 2012. 
STRGANAC, T. W.; MOOK, D. T. Numerical Model of Unsteady Subsonic Aeroelastic Behavior. AIAA Journal, v. 28, p. 903-909, 1990.

THEODORSEN, T. General Theory of Aerodynamic Instability and the Mechanism of Flutter. [S.1: s.n.].

VERBOVEN, P. et al. Modal parameter estimation and monitoring for on-line flight flutter analysis. Mechanical Systems and Signal Processing, v. 18, n. 3, p. 587-610, maio. 2004. 